\title{
A multifaceted role of progranulin in regulating amyloid-beta dynamics and responses
}

Huan $\mathrm{Du}^{1}$, Man Ying Wong ${ }^{3}$, Tingting Zhang ${ }^{1}$, Mariela Nunez Santos ${ }^{1}$, Charlene Hsu ${ }^{1}$, Junke Zhang ${ }^{2}$, Haiyuan $\mathrm{Yu}^{2}$, Wenjie $\mathrm{Luo}^{3}$ and Fenghua $\mathrm{Hu}^{1}$

${ }^{1}$ Department of Molecular Biology and Genetics, ${ }^{2}$ Department of Computational Biology, Weill Institute for Cell and Molecular Biology, Cornell University, Ithaca, NY 14853, USA

${ }^{3}$ Feil Family Brain \& Mind Research Institute, Weill Cornell Medicine, 407 E 61st St, New York, NY 10065 , USA

*Running Title: PGRN regulates A-beta dynamics and responses

${ }^{\#}$ To whom correspondence should be addressed: Fenghua Hu, 345 Weill Hall, Ithaca, NY 14853, TEL: 6072550667, FAX: 607-2555961, Email: fh87@cornell.edu 


\begin{abstract}
Haploinsufficiency of progranulin (PGRN) is a leading cause of frontotemporal lobar degeneration (FTLD). PGRN polymorphisms are associated with Alzheimer's disease (AD). PGRN is highly expressed in the microglia near $A \beta$ plaques and influences plaque dynamics and microglial activation. However, the detailed mechanisms remain elusive. Here we report that PGRN deficiency reduces human APP and A $\beta$ levels in the young male but not female mice. PGRN deficient microglia exhibit increased expression of markers associated with microglial activation, including CD68, Galectin-3, TREM2 and GPNMB, specifically near A $\beta$ plaques. In addition, PGRN loss leads to up-regulation of lysosome proteins and an increase in the nuclear localization of TFE3, a transcription factor involved in lysosome biogenesis. Cultured PGRN deficient microglia show enhanced nuclear translocation of TFE3 and inflammation in response to A $\beta$ fibril treatment. Taken together, our data revealed a sex- and age-dependent effect of PGRN on amyloid metabolism and a role of PGRN in regulating lysosomal activities and inflammation in plaque-associated microglia, which may contribute to the disease mechanism associated with PGRN polymorphisms in AD.
\end{abstract}

Keywords: Progranulin (PGRN); Frontotemporal Lobar Degeneration (FTLD); Alzheimer's disease (AD) lysosome; inflammation; Amyloid-beta $(\mathrm{A} \beta)$ plaque 


\section{Introduction}

Progranulin (PGRN), encoded by the granulin (GRN) gene in humans, has been shown to be a key player in brain aging and neurodegenerative diseases. First, PGRN haploinsufficiency resulting from mutations in the $G R N$ gene, is one of the major causes of frontotemporal lobar degeneration (FTLD) with TDP-43 positive inclusions (Baker et al., 2006; Cruts et al., 2006; Gass et al., 2006). Secondly, complete loss of PGRN in humans is known to cause neuronal ceroid lipofuscinosis (NCL) (Almeida et al., 2016; Smith et al., 2012), a group of lysosomal storage diseases. Thirdly, a recent study identified $G R N$ as one of the two main determinants of differential aging in the cerebral cortex with genome-wide significance (Rhinn and Abeliovich, 2017). Fourthly, $G R N$ is one of the five risk factors for a recently recognized disease entity, limbic-predominant age-related TDP-43 encephalopathy (LATE)(Nelson et al., 2019). Finally, PGRN polymorphisms contribute to the risk of Alzheimer's disease (AD) (Kamalainen et al., 2013; Perry et al., 2013; Sheng et al., 2014; Xu et al., 2017), and serum PGRN levels are inversely proportional to the risk of AD development (Hsiung et al., 2011).

PGRN is an evolutionarily conserved, secreted glycoprotein of $88 \mathrm{kDa}$ comprised of 7.5 granulin repeats(Bateman and Bennett, 2009; Nicholson et al., 2012). The full-length precursor can be proteolytically cleaved into several biologically active granulin peptides (granulins A, B, C, D, E, F, G), which have distinct activities in some cases (Holler et al., 2017; Tolkatchev et al., 2008). Multiple recent studies have suggested a critical role of PGRN in the lysosome. Since its genetic link to NCL was discovered (Almeida et al., 2016; Smith et al., 2012), lysosome dysfunction and lipofuscin accumulation have also been reported in PGRN knockout mice (Ahmed et al., 2010; Gotzl et al., 2018; Tanaka et al., 2014). FTLD patients with GRN mutation have also been reported to have NCL-related phenotypes (Gotzl et al., 2014; Valdez et al., 2017; Ward et al., 2017). Within the cell, PGRN is localized in the lysosome compartment (Hu et al., 2010). PGRN traffics to the lysosome via direct interactions with the trafficking receptor sortilin or the lysosome precursor protein prosaposin (Hu et al., 2010; Zhou et al., 2015; Zhou et al., 2017c). Within the lysosome, PGRN is processed to granulin peptides by cathepsins (Holler et al., 2017; Lee et al., 2017; Zhou et al., 2017b). While the functions of granulin peptides remain to be fully characterized, PGRN and granulin peptides have been shown to regulate lysosome enzyme activities, such as cathepsin D (Beel et al., 2017; Butler et al., 2019; Valdez et al., 2017; Zhou et al., 2017a) and glucocerebrosidase (Arrant et al., 2019; Valdez et al., 2019; Zhou et al., 2019).

In the brain, PGRN is mainly expressed by neurons and microglia (Kao et al., 2017). Microglia, the resident immune cells in the brain, produce and secrete especially high levels of PGRN, especially those which have become reactive following insult or trauma (Hu et al., 2010; Moisse et al., 2009; Naphade et al., 2010; Philips et al., 2010; Zhou et al., 2017c). PGRN is a well-established modulator of immune function and has been shown to regulate microglial activation, migration, phagocytosis, complement levels, and synapse pruning 
(Lui et al., 2016; Martens et al., 2012; Pickford et al., 2011; Van Damme et al., 2008; Yin et al., 2010). In Alzheimer's disease (AD) mouse models and human patients, PGRN was found to be highly expressed in the microglia surrounding A $\beta$ plaques (Minami et al., 2014) (Mendsaikhan et al., 2019; Pereson et al., 2009). Microglial specific reduction of PGRN expression has been shown to result in impaired phagocytosis, increased plaque load and exacerbated cognitive deficits in the mouse AD models, while lentivirus mediated PGRN overexpression has opposite results (Minami et al., 2014). Consistent with this result, lentivirus mediated PGRN overexpression or intrahippocampal injection of PGRN protein has been shown to reduce A $\beta$ plaques via increasing the activity of neprilysin, a key amyloid beta degrading enzyme (Van Kampen and Kay, 2017) or through inhibiting the expression of BACE-1, an enzyme involved in A $\beta$ generation (Guan et al., 2020). However, another study has found significantly reduced diffuse $A \beta$ plaque growth in hippocampus and cortex in aged PGRN deficient mice using the APPswe/PS1 $\triangle E$ 9 (APP/PS1) mouse model (Takahashi et al., 2017). Grn+/- mice have also been shown to have marginally significant reduction in plaque numbers and plaque area in female mice at 16-18 months, although limited number of mice were used in the study (Hosokawa et al., 2018). The mechanisms causing the discrepancies in these findings remains to be determined.

In addition, how PGRN regulates lysosomal function and microglia mediated inflammation is still unclear, and whether lysosome abnormalities caused by PGRN deficiency contributes to microglial phenotypes remains to be tested. Microglia-mediated inflammation (Aldana, 2019; Colonna and Butovsky, 2017; Hammond et al., 2019; Hansen et al., 2018; Hickman et al., 2018) and endo-lysosomal dysfunction (Bajaj et al., 2019; Lie and Nixon, 2019; Wang et al., 2018) are common mechanisms shared by many neurodegenerative diseases. Proper endosome-lysosome function is critical for degradation of phagocytosed materials in microglia, and thus is essential for the health of microglia (Podlesny-Drabiniok et al., 2020). In this study, we show that PGRN deficiency leads to an upregulation of lysosomal enzyme cathepsins, lysosome membrane protein CD68 and GPMNB, and cell surface receptor TREM2, as well as the $\beta$-galactoside-binding protein Galectin-3 specifically in microglia near A $\beta$ plaque. Furthermore, we demonstrate that PGRN deficiency in microglia results in lysosome abnormalities and increased inflammatory responses after A $\beta$ fibrils treatment. Taken together, our data support that PGRN regulates microglia mediated inflammation through modulating lysosomal functions.

\section{Results}

\section{PGRN is highly expressed in the microglia around A $\beta$ plaques}

To determine the role of PGRN in microglial responses to A $\beta$, we first examined PGRN localization and expression pattern in the 5XFAD mouse model, which is a rapid-onset amyloid plaque models (Oakley et al., 2006). Immunostaining showed that PGRN is mainly expressed in the IBA1 positive microglia around A $\beta$ 
plaques (stained with the 6E10 antibody) in the 5XFAD mice (Fig S1A and S1B), consistent with previous reports from two other amyloid plaque mouse models, Tg2576 and APPPS1 (Minami et al., 2014; Pereson et al., 2009). Additionally, PGRN exhibited strong colocalization with LAMP1 around A $\beta$ plaques (Fig S1C), which might represent PGRN signals from the lysosome compartment in dystrophic axons surrounding the A $\beta$ plaques as previously reported (Gowrishankar et al., 2015).

\section{PGRN deficiency affects A $\beta$ plaques deposition in 5XFAD mice in a sex and age dependent manner}

To determine the role of PGRN in AD pathogenesis, we crossed the 5XFAD mice with $\mathrm{Grn}^{-/}$mice. The 5XFAD mice have spatial memory deficits in the Y-maze test at 4-5 months of age (Fig. S2), as reported previously (Oakley et al., 2006). However, ablation of PGRN in the 5XFAD background does not seem to have a significant effect on this behavioral change, although there was a trend of alleviating the deficits in the male mice (Fig. S2).

Next, we examined whether PGRN deficiency affects A $\beta$ plaque pathology in the 5XFAD mouse model. The 5XFAD mice start to show amyloid deposition and gliosis at 2 months, especially in subiculum and deep cortical layers (Oakley et al., 2006). We examined $A \beta$ pathology by using thioflavin $S$ (ThioS) staining to detect dense core $\mathrm{A} \beta$ plaques and anti-A $\beta$ antibody (6E10) staining to quantify diffuse $\mathrm{A} \beta$ plaques in the 4.5month-old mice. Both ThioS staining and anti-A $\beta$ antibody staining revealed a significant reduction in the area, number and intensity of $\mathrm{A} \beta$ plaques in the male 5XFAD $\mathrm{Grn}^{-/-}$mice in the cortex compared to age matched male 5XFAD mice (Fig 1A and 1B). A similar trend was observed in the subiculum region but did not reach statistical significance (Fig. 1B). On the other hand, ablation of PGRN does not seem to affect A $\beta$ plaque deposition in the female 5XFAD mice (Fig. 1). To further dissect the role of PGRN in regulating A $\beta$ dynamics, we performed ELISA to measure the levels of soluble and insoluble A $\beta$ in the cortical lysates. PGRN deficiency in male mice results in a significant decrease of $A \beta 40$ and $A \beta 42$ in both soluble and insoluble fractions (Fig 2A). No effect of PGRN ablation was observed in the female mice (Fig. 2A), consistent with our staining results (Fig. $1)$.

The decrease in the $A \beta$ levels in both the soluble and insoluble fractions suggests that $A \beta$ production might be affected by PGRN loss in males. Thus, we decided to examine the levels of amyloid precursor protein (APP) in these mice. Immunoblot analysis revealed a significant reduction in the levels of human mutant APP expressed from the transgene in the 4.5-month-old male mice (Fig. 2B, 2C). No significant changes in the levels of presenilin1 (PS1), BACE1 or endogenous mouse APP have been observed in these mice (Fig. 2B, 2C). Since both APP and PS1 transgenes are driven by the mouse Thy 1 promoter in the 5XFAD mice and PGRN deficiency only affects APP levels, it suggests that PGRN affects APP levels post-transcriptionally. However, PGRN deficiency alone do not have any effect on the levels of endogenous APP, PS1 or BACE1 in mice (Fig. 
S3). These data suggests that loss of PGRN specifically affects in the metabolism of human mutant APP protein expressed from the transgene in the young male mice.

Since $A \beta$ pathology is a dynamic process and worsens with aging, we also analyzed A $\beta$ accumulation in the 10month-old 5XFAD and 5XFAD $\mathrm{Grn}^{-/-}$mice. ThioS staining and anti-A $\beta$ antibody staining showed either no significant change or a slight decrease in the area and number of $A \beta$ plaques in the both male and female 5XFAD $\mathrm{Gr}^{-/}$mice compared to age and sex matched 5XFAD mice (Fig. 3A, Fig. S4). The total intensity of $\mathrm{A} \beta$ plaques and the levels of both soluble and insoluble $\mathrm{A} \beta 40$ and $\mathrm{A} \beta 42$ are not altered in both male and female $\mathrm{Grn}^{-/-}$mice (Fig. 3A and 3B). No difference in APP levels was detected between 5XFAD and 5XFAD $\mathrm{Gr}^{-/-}$ mice at this age (data not shown). Taken together, our results indicate a specific role of PGRN in regulating mutant human APP levels in the young male mice and a modest role of PGRN in regulating the dynamics of A $\beta$ plaques at older ages.

\section{PGRN deficiency results in enhanced microglial activation near the Aß plaques}

To dissect molecular pathways affected by the loss of PGRN, we performed RNA-Seq analysis of hippocampus samples from 4.5-month-old WT, $\mathrm{Grn}^{-/}$, 5XFAD and 5XFAD $\mathrm{Grn}^{-/}$mice. Loss of PGRN alone results in minimal changes in gene expression at this young age, but loss of PGRN in the 5XFAD background leads to differential expression of many genes in the hippocampus (Fig. S5). Among the 14 genes upregulated in the 5XFAD $\mathrm{Gr}^{-/-}$hippocampus samples, inflammation and lysosome pathways are identified (Fig. S5A and S5B).

Many genes upregulated in 5XFAD $\mathrm{Gr}^{-/-}$samples belong to the gene signature associated with microglia activation during neurodegeneration, so called diseased associated microglia (DAM) or neurodegenerative microglia (mGnD) (Deczkowska et al., 2018; Krasemann et al., 2017), including Lyz2, Tyrobp, Lgals3, Cd68, and Gpnmb (Fig. S5). Lgals3 (encoding Galectin-3 protein) and GPNMB are two most upregulated genes in the 5XFAD $\mathrm{Grn}^{-/}$samples (Fig. S5B), consistent with a recent proteomic study identifying Galectin-3 and GPNMB as the two proteins most upregulated in response to PGRN loss (Huang et al., 2020). The upregulation of Galectin-3 and GPNMB was confirmed by Western blot analysis of brain lysates. Both Galectin-3 and GPNMB show a specific upregulation in the 4.5- and 10-month-old 5XFAD $\mathrm{Grn}^{-/-}$brain lysates, with minimal changes in the 5XFAD or $\mathrm{Gr}^{-/-}$samples (Fig. 4A-D and Fig. 5A-D), supporting that the simultaneous loss of PGRN and $A \beta$ stimulation result in excessive microglia activation. Although the male mice show significantly reduced numbers of $A \beta$ plaques, immunostaining shows a significant upregulation of Galectin-3 in the IBA1 positive microglia near $A \beta$ plaques in both male and female mice (Fig. 4E-F), indicating that PGRN does not have a sex specific effect regarding microglial responses to $A \beta$ plaques. GPNMB expression is also specifically upregulated in the microglia near the $A \beta$ plaques in the absence of PGRN (Fig. 5E-F). In addition, an overlap in the expression pattern of Galectin-3 and GMNPB is observed (Fig. 5G), suggesting that these two 
genes might be subject to regulation by the same pathway. Next, we examined whether levels of TREM2, a master regulation of microglia homeostasis (Deczkowska et al., 2020), are affected in 5XFAD $\mathrm{Grn}^{-/-}$mice. Costaining of IBA1, TREM2, and 6E10 indicates PGRN deficiency results in increased TREM2 levels in the microglia near the $\mathrm{A} \beta$ plaques (Fig. 6A,6B). Taken together, these results indicate that several DAM proteins, including Galectin-3, GPNMB and TREM2, are upregulated in microglia around A $\beta$ plaques in response to PGRN loss.

Loss of PGRN alone is known to cause microglial activation in an age dependent manner (Kao et al., 2017). Consistently, immunostaining of IBA1, a microglia marker, and CD68, a marker for activated microglia also showed enhanced microglia activation in the cortex region in both male and female PGRN-deficient mice at 10month of age (Fig. 6C, 6D). However, this difference is much more pronounced in the 5XFAD $\mathrm{Grn}^{-/-}$mice compared to age matched 5XFAD mice (Fig. 6C, 6D). Additionally, an enrichment of CD68 signals is observed in the microglia near A $\beta$ plaques in the PGRN deficient mice (Fig. 6C, 6E). These data further support that $\mathrm{A} \beta$ stimulation exacerbates microglial activation in the absence of PGRN.

\section{Increased levels of lysosome proteins near the A $\beta$ plaques in the PGRN deficient mice}

Since PGRN deficiency is known to cause lysosome dysfunction (Paushter et al., 2018), we next examined alterations in lysosome proteins in 4.5-month-old and 10-month-old 5XFAD mice with and without PGRN expression. The levels of several lysosome proteins including cathepsin B (CathB), cathepsin D (CathD), cathepsin L (CathL), LAMP1 and LAMP2 were significantly increased in the brain lysates from 5XFAD $\mathrm{Grn}^{-/}$ mice compared to 5XFAD mice, at both 4.5 month and 10 months of age, with more pronounced differences at 10 months old (Fig. 7 and Fig. S6, S7), suggesting a progressive lysosomal response to A $\beta$-accumulation and PGRN loss. These changes were not observed in the 5XFAD or $\mathrm{Grn}^{-/-}$mice, supporting that the combination of PGRN loss and $A \beta$ stimulation drives the expression changes of lysosome genes.

Next, we examined which cell types upregulate the expression of lysosome genes in 5XFAD $\mathrm{Grn}^{-/}$mice. Costaining of $6 \mathrm{E} 10$ and $\mathrm{CathB}$, with microglia markers IBA1 indicates significant upregulation of the lysosome protease CathB in microglia in the brain sections of 5XFAD $\mathrm{Gr}^{-/-}$mice, especially around A $\beta$ plaques (Fig. 8AC). Immunostaining with antibodies against IBA1, Galectin-3, and CathB, shows Galectin-3 and CathB are coregulated in the microglia in 5XFAD $\mathrm{Gr}^{-/-}$mice (Fig. 8D). In addition, the lysosome protease CathD is abnormally upregulated in the CD68 positive microglia around $\mathrm{A} \beta$ plaques in the both male and female 5XFAD $\mathrm{Grn}^{-/-}$mice (Fig. 9A-C), supporting that PGRN is critical for maintaining lysosome homeostasis in microglia in response to $\mathrm{A} \beta$ stimulation.

Many of the lysosome genes are under the transcriptional control of the members of melanocyte inducing transcription factor (MiTF) family, including MiTF, TFEB and TFE3. Under starvation or lysosome stress, 
these transcriptional factors are translocated into the nucleus to induce the expression of many genes in the autophagy lysosome pathway (Bajaj et al., 2019; Napolitano and Ballabio, 2016; Saftig and Puertollano, 2021). To determine whether this pathway is activated in the 5XFAD $\mathrm{Gr}^{-/-}$mice, we stained brain sections with antibodies against TFE3 and IBA1. A significant increase of nuclear TFE3 signals was observed in the microglia in the brain sections of 5XFAD $\mathrm{Gr}^{-/-}$mice, compared to 5XFAD controls (Fig. 9D-E). These data suggest that lysosome abnormalities in microglia results in a feedback loop through the TFE3/TFEB pathway to upregulate the expression of lysosome genes and possibly also inflammation genes. Interestingly, activation of TFE3/TFEB has been shown to drive the expression of inflammation genes in several studies (Brady et al., 2018; Nabar and Kehrl, 2017). However, we did not detect a direct correlation between the increase in TFE3 nuclear staining intensity and the upregulation of Galectin-3 expression in the microglia near the plaque, indicating that there are other transcription factors involved in regulating galectin-3 expression.

\section{A $\beta$ treatment leads to enhanced inflammation and lysosomal abnormalities in PGRN deficient microglia}

To further dissect the connection between lysosome abnormalities and inflammatory responses in PGRN deficient microglia, we examined the role of PGRN in lysosomal and inflammatory responses to A $\beta$ plaques in cell culture. We deleted PGRN in the macrophage cell line Raw 264.7 using the CRISPR/Cas9 technique and examined the lysosomal membrane permeabilization (LMP) using Galectin-3 as a marker. Upon LMP, intracellular Galectin-3 has been shown to be recruited to damaged lysosomes, forming discernible puncta (Aits et al., 2015). L-leucyl-L-leucine methyl ester (LLOME), a lysosome damaging reagent was used to induce LMP. A significantly higher overlap of Galectin-3 and LAMP1 was observed in PGRN-deficient Raw 264.7 cells compared to control cells upon LLOME treatment (Fig. 10 A and B). Similar results were obtained from primary microglia cultured from WT and PGRN deficient mice, indicating that PGRN deficiency affects lysosome membrane integrity (Fig. 10C and D).

Next, we examined the effect of A $\beta$ fibril treatment on lysosome changes in WT and Grn-/- primary microglia. A significant increase in the levels of Galectin-3, cathepsin D and GPNMB was observed in PGRN-deficient primary microglia (Fig. 11 and Fig. 12A-B). To determine whether the transcription factor TFE3 is involved in response to $\mathrm{A} \beta$ fibrils, we stained primary microglia with antibodies against TFE3. A significant increase in the ratio of nuclear to cytoplasmic TFE3 signals was observed in PGRN-deficient primary microglia, compared to WT controls (Fig. 12C and D). This result indicates that $\mathrm{A} \beta$ fibril treatment results in lysosome abnormalities in $\mathrm{Grn}^{-/-}$microglia, which results in activation of the TFE3/TFEB pathway to upregulate the expression of lysosome genes. Next, we assessed whether the lysosome abnormalities caused by PGRN deficiency contributed to enhanced inflammatory responses. $A \beta$ fibril treatment leads to a significant increase in the levels of the proinflammatory marker tumor necrosis factor- $\alpha$ (TNF- $\alpha$ ) in the $G r n^{-/-}$Raw macrophages and microglia 
compared to WT microglia (Fig. 12E and 12F). Taken together, our studies support that A $\beta$ fibril treatment leads to enhanced inflammation and lysosomal responses in PGRN deficient microglia.

\section{Discussion}

\section{A sex specific role of PGRN in regulating human mutant APP metabolism in young male mice}

Although PGRN has been implicated in AD, the exact role of PGRN in AD disease progression remains unclear. Conflicting results have been obtained regarding the effect of PGRN in AD in mouse models. PGRN deficiency has been demonstrated to exacerbate pathological phenotypes, including A $\beta$ plaque burden, neuroinflammatory markers, and memory impairment in AD mouse models in some studies (Minami et al., 2014; Van Kampen and Kay, 2017). Other studies, however, have demonstrated that some AD phenotypes are improved by PGRN deficiency (Hosokawa et al., 2018; Takahashi et al., 2017).

In this study, we examined the role of PGRN in A $\beta$ dynamics using the 5XFAD mice which express human APP and Presenilin1 transgenes containing five AD-linked mutations [APP K670N/M671L (Swedish) + I716V (Florida) + V717I (London) and PS1 M146L + L286V]. We found that PGRN deficiency results in decreased $\mathrm{A} \beta$ plaque accumulation in the young males but not in females (Fig 1, Fig, 2). Furthermore, we demonstrated that the reduction of $A \beta$ plaques in the 4.5-month-old male mice is due to a reduction in the levels of human mutant APP (Fig. 2B-C). The nature of this sex dimorphic regulation of mutant APP by PGRN is unclear at this moment, but the sex specific role of PGRN has been reported. Genetic variability in the GRN gene has been shown to influence the risk for developing AD in a male-specific manner in Finnish population (Viswanathan et al., 2009), which might be explained by the results from our study. PGRN is known as a sex steroid-responsible gene that may be involved in masculinization of the perinatal rat brain (Chiba et al., 2007; Suzuki et al., 2009; Suzuki and Nishiahara, 2002; Suzuki et al., 1998). In adult rats, PGRN gene expression is up-regulated by estrogen in the hippocampus and PGRN may mediate the mitogenic effects of estrogen in the active area of neurogenesis. PGRN deficiency has been shown to affect sexual behavior and anxiety in mice in a male specific manner, possibly through reducing the levels of serotonergic receptor 5-HT1A (Kayasuga et al., 2007; Petkau et al., 2012). Additionally, females have been reported to have increased A $\beta$ load compared to males (Bundy et al., 2019; Oakley et al., 2006).

It should be noted that APP and A $\beta$ levels were not altered by PGRN loss in the 6-month-old male APPswe/PS1 1 E9 (APP/PS1) mice (Takahashi et al., 2017). Another study found that PGRN deficiency does not affect APP levels and processing in cortical lysates of 9-13-month-old PDGF-APP Sw,Ind $_{\text {J9 }}\left(\mathrm{APP}^{\text {low }}\right.$ ) mice, although mice of mixed sex were used (Minami et al., 2014). While causes for the differences in these studies remain to be determined, it is possible that PGRN only affects the metabolism of specific APP variants at a 
certain age. PGRN might interacts with factors involved in APP trafficking, processing and turnover in a sex and age dependent manner to regulate the levels of specific APP variants in neurons.

In addition to $\mathrm{AD}, G R N$ haplotypes may influence the risk of other neurodegenerative disease like primary progressive multiple sclerosis (PPMS) in a gender-specific manner (Fenoglio et al., 2010). Gender related risk factors might modulate PGRN-mediated phenotypic expression (Curtis et al., 2017; Piscopo et al., 2013).

Due to the drastic effect of PGRN on A $\beta$ pathology in males, we have analyzed microglial responses to A $\beta$ plaques in female and male mice separately, but we did not detect any sex difference in microglial responses to $\mathrm{A} \beta$ plaques (Fig. 4F, 9B). In both males and females, PGRN deficiency leads to an upregulation of lysosomal enzyme cathepsins, lysosome membrane protein CD68, and the cell surface receptor TREM2, as well as GPMNB, Galectin-3 specifically in microglia around $\mathrm{A} \beta$ plaques (Fig. 4F, 9B and data not shown). Furthermore, our data show that PGRN deficiency in primary microglia results in impairment of lysosome membrane integrity and increased lysosomal and inflammatory responses after $A \beta$ fibrils treatment. Our results support that PGRN regulates microglia mediated inflammation through modulating lysosome homeostasis.

Despite increased microglial inflammation in the absence of PGRN, PGRN loss does not seem to have a major effect on $A \beta$ levels in the 10-month-old mice, although a reduction in the number and area of $A \beta$ plaques was observed (Fig. 3), indicating that $A \beta$ concentration might be higher at each plaque in PGRN deficient mice. It is possible that microglia internalize $A \beta$ but not necessarily degrade $A \beta$ due to poor lysosomal acidification (SoleDomenech et al., 2016). In addition, PGRN deficiency has been shown to increase microglia mediated synaptic pruning (Lui et al., 2016), which could have detrimental effects in AD mouse models.

\section{Lysosomal abnormalities and enhanced inflammation in PGRN deficient mice}

Our data support that PGRN help maintain proper lysosome homeostasis in microglia upon A $\beta$ stimulation. First, we found that PGRN is highly expressed in microglia near A $\beta$ plaques (Fig. S1A and B). Secondly, PGRN deficiency leads to increased expression of lysosome proteins near the A $\beta$ plaques in vivo (Fig. 8A-C and Fig 9A-C). Furthermore, we found that lysosome abnormalities caused by PGRN deficiency are correlated with an increase in several genes associated with microglial activation, including CD68, Galectin-3, TREM2 and GPNMB, which are upregulated specifically in the microglia near the plaque (Figs. 4-6). These genes are part of the DAM signature initially identified in 5XFAD mouse model, however, their characteristics were since further validated in other AD mouse models, such as the PS2APP and APP/PS1 (Deczkowska et al., 2018; Friedman et al., 2018; Kamphuis et al., 2016; Mrdjen et al., 2018). Accumulating evidence show that the DAM phenotype is a common signature of microglial response to CNS pathology, irrespective of the disease etiology (Deczkowska et al., 2018). However, recent studies found human microglia had an AD-related gene signature distinct from the DAM signature seen in mouse models (Zhou et al., 2020). Despite the differences between 
DAM and Human Alzheimer's Microglia (HAM), the researchers also noted some commonalities. Both DAM and HAM genes overlap, including many genes involved in lipid and lysosomal biology, indicating that lysosomal related pathways play a critical role in AD pathogenesis (Del-Aguila et al., 2019; Masuda et al., 2019; Mathys et al., 2019; Srinivasan et al., 2019).

We have found an upregulation of Galectin-3, a $\beta$-galactoside-binding cytosolic lectin, used as a marker for damaged lysosomes (Aits et al., 2015; Chauhan et al., 2016), in PGRN deficient microglia in response to A $\beta$ fibril in vivo and in vitro. We demonstrated that PGRN deficient primary microglia are more susceptible to lysosome damage (Fig. 10). Moreover, we found that Galectin-3 is upregulated in $\mathrm{Grn}^{-/}$microglia upon A $\beta$ stimulation (Fig 11). Recently, it has been reported that Galectin-3 is more than a marker of lysosomal damage and that it unifies and coordinates ESCRT and autophagy responses to lysosomal damage (Jia et al., 2020), which could suggest that PGRN loss results in increased lysosome damage and enhanced Galectin-3 dependent responses attempting to repair lysosomes or clear damaged lysosomes in response to A $\beta$ stimulation. The mechanism involved in Galectin-3 upregulation is still unclear. TREM2 has been shown to be required for transcriptional activation of a set of DAM genes. However, Galectin-3 is not among the list (Deczkowska et al., 2018; Friedman et al., 2018; Kamphuis et al., 2016; Mrdjen et al., 2018).

Another DAM marker upregulated in the microglia near the A $\beta$ plaque in the PGRN deficient mice is GPNMB (glycoprotein nonmetastatic melanoma protein B), a type I transmembrane protein that contains an $\mathrm{N}$-terminal signal peptide, an integrin-binding (RGD) motif and a polycystic kidney disease (PKD) domain in its extracellular domain (ECD), a single pass transmembrane domain and a short cytoplasmic tail harboring a lysosomal/endosomal sorting signal (Maric et al., 2013). GPNMB was first discovered in the bone of an osteopetrotic rat model (Safadi et al., 2001). Aside from its anabolic function in the bone, emerging evidence suggests that GPNMB has anti-inflammatory and reparative functions (Budge et al., 2018). GPNMB has also been demonstrated to be neuroprotective in an animal model of amyotrophic lateral sclerosis (ALS), cerebral ischemia, and other disease models (Neal et al., 2018; Srinivasan et al., 2016). The expression of GPNMB is upregulated in several lysosomal storage diseases and is correlated with lipid accumulation in the lysosome (van der Lienden et al., 2018). In terms of neurodegenerative diseases, the levels of GPNMB are elevated in brain samples of sporadic AD patients and in the substantia nigra (SN) of sporadic Parkinson's disease (PD) patient brains (Hüttenrauch et al., 2018; Moloney et al., 2018). We found that GPNMB is specifically up-regulated in $\mathrm{Grn}^{-/}$microglia near the A $\beta$ plaques and overlaps with Galectin-3 in the microglia (Fig. 5E-G). While the function of GPNMB in microglial responses remains to be determined, our results indicate a connection between PGRN deficiency and GPNMB function.

It should be noted that a recent proteomic study has found that Galectin-3 and GPNMB are among the two most up-regulated proteins in $G r n^{-/}$mouse brain and FTLD patients with GRN mutations and the authors have 
proposed that GPNMB could be used as a specific marker for FTLD-GRN (Huang et al., 2020). Our results are consistent with these findings and suggest a connection between Galectin-3, GPNMB and PGRN function at the lysosome.

\section{Crosstalk between lysosomal abnormalities and inflammatory responses}

Microglia are tissue-resident immune cells of the central nervous system (CNS), which constantly survey their microenvironment with their processes. They regulate immune homeostasis in the healthy and degenerating CNS. Microglia detect damage-associated molecular patterns (DAMPs) from dying neurons and chronic microglia activation is a hallmark shared in many neurodegenerative diseases (Hanisch and Kettenmann, 2007; Heneka et al., 2014).

However, how lysosome abnormalities contribute to microglia activation is still unclear. In this study, we examined the connection between lysosome abnormality and microglia activation in PGRN deficient conditions. First, we showed that PGRN deficient microglia are more susceptible to lysosome membrane permeabilization (LMP) upon treatment with A $\beta$ fibrils and LLOME. LMP has been shown to result in the release of lysosomal enzymes into the cytosol, which often leads to inflammasome activation (Katsnelson et al., 2016; Nebel et al., 2017; Weber and Schilling, 2014). Thus, lysosome membrane integrity is closely linked to inflammation. Furthermore, we demonstrated that PGRN deficiency causes increased inflammatory responses upon A $\beta$ fibril treatment. In vivo, PGRN deficiency leads to enhanced microglia activation near the A $\beta$ plaques (Figs. 4, 5 and 6). In vitro, deletion of PGRN in microglia results in higher level of TNF- $\alpha$ upon A $\beta$ fibril treatment (Fig. 12E and F). We have found increased levels of TFE3 in the PGRN deficient microglia in response to A $\beta$ both in vivo and in vitro and activation of TFE3/TFEB has been shown to drive the expression of not only lysosomal genes but also inflammation genes in several studies (Brady et al., 2018; Nabar and Kehrl, 2017). Unfortunately, we cannot determine the levels of TFEB and MiTF in PGRN deficient microglia due to availability of specific antibodies suitable for tissue section staining. Another transcription factor that might connect lysosomal dysfunction to inflammation is Stat3. It has been that substrate accumulation and lysosome stress can activate Stat3, which is known to mediate the transcription of many genes involved in inflammatory responses (Martinez-Fabregas et al., 2018).

In summary, we show that PGRN deficiency results in a reduction in the levels of human mutant APP in males but not females at the early stage. PGRN deficiency leads to enhanced lysosome abnormalities and inflammatory responses in response to $\mathrm{A} \beta$ in vivo and in vitro. These studies provide novel insights into understanding of neurodegenerative diseases associated with PGRN haploinsufficiency or polymorphism, including FTLD and AD.

\section{Material and Methods}




\section{Primary Antibodies and Reagents}

The following antibodies were used in this study: Mouse anti- $\beta$-Amyloid (BioLegend, SIG-39320), rabbit anti- $\beta$-Amyloid (Proteintech Group, 25524-1-AP), mouse anti-Galectin-3 (BioLegend, 126702), goat antiGalectin-3 (R\&D Systems, AF1154), goat anti-GPNMB (R\&D Systems, AF2330), mouse anti-GAPDH (Proteintech Group, 60004-1-Ig), rat anti-mouse LAMP1 (BD Biosciences, 553792), LAMP2 (Developmental Studies Hybridoma Bank, GL2A7-c), goat anti-CathB (R\&D Systems, AF965), goat anti-CathD (R\&D Systems, AF1029), goat anti-CathL (R\&D Systems, AF1515), sheep anti-TREM2 (R\&D Systems, AF1729), rabbit anti IBA-1 (Wako, 01919741), goat anti-AIF-1/Iba1 (Novus Biologicals, NB100-1028), rat anti-CD68 (Bio-Rad, MCA1957), rabbit anti-TFE3 (Sigma, HPA023881), and sheep anti-PGRN (R\&D Systems, AF2557). PS1-related peptides were detected using Ab14, a rabbit polyclonal antibody generated against amino acids 1-25 of PS1. Rabbit anti-BACE1 antibody were raised against the sequence CLRQQHDDFADDISLLK from 485 to 501 of BACE1 protein (Yan et al., 2001).

The following reagents were also used in the study: Dulbecco's modified Eagle's medium (DMEM)(Cellgro, 10-017-CV), Hanks' Balanced Salt Solution (HBSS) (Cellgro, 21-020-CV), Dulbecco's modified Eagle's medium/Ham's F-12 (DMEM/F-12)(Cellgro, 10-092-CV), 0.25\% Trypsin (Corning, 25-053-CI), betaAmyloid (1-42) (Anaspec, AS-60883), Thioflavin S (Sigma T1892), TrueBlack Lipofuscin Autofluorescence Quencher (Biotium, 23007), L-Leucyl-L-Leucine methyl ester (LLOME) (Cayman, 16008), Odyssey blocking buffer (LI-COR Biosciences, 927-40000), protease inhibitor (Roche, 05056489001), Pierce BCA Protein Assay Kit (Thermo scientific, 23225), O.C.T compound (Electron Microscopy Sciences, 62550-01) and mouse TNF- $\alpha$ ELISA Kit (BioLegend, 430901).

\section{Mouse Strains}

C57/BL6, Grn ${ }^{-/}$(Yin et al., 2010) and 5X FAD (Oakley et al., 2006) mice were obtained from the Jackson Laboratory. Both male and female mice were used and analyzed in separate groups. All the mice were housed in the Weill Hall animal facility at Cornell. All animal procedures have been approved by the Institutional Animal Care and Use Committee (IACUC) at Cornell.

\section{Behavioral test}

4.5-month-old male and female WT, $\mathrm{Grn}^{-/}$, 5XFAD and 5XFAD $\mathrm{Gr}^{-/}$mice in the C57/BL6 background (612 mice/group) were subject to the following behavioral tests: (1) Open-field test: Mice were placed in a clear plastic chamber $(30 \times 30 \times 30 \mathrm{~cm})$ for $5 \mathrm{~min}$. The total track distance, center track distance, center time and center entries were tracked by the Viewer III software (Biobserve, Bonn, Germany). The apparatus was thoroughly cleaned with $70 \%$ ethanol between trials. (2) Y maze test: Spatial working memory performance 
was assessed by recording spontaneous alternation behavior in a Y-maze. The Y-maze was made of light grey plastic and consisted of three arms at $120^{\circ}$. Each arm was 6-cm wide and 36-cm long and had $12.5-\mathrm{cm}$ high walls. Each mouse was placed in the Y maze and allowed to move freely during an 8 min session. The series of arm entries was recorded visually and arm entry was considered to be completed when the hind paws of the mouse were completely placed in the arm. The maze was cleaned with $70 \%$ ethanol after each mouse. Alternation was defined as successive entries into the three arms on overlapping triplet sets (e.g., ABC, BCA). The percentage alternation was calculated as the ratio of actual to possible alternations (defined as the total number of arm entries minus two). For all behavioral analyses, experimenters were blind to the genotypes of the mice.

\section{Cell Culture and biochemical assays}

Raw 264.7 cells were maintained in Dulbecco's Modified Eagle's Medium (Cellgro) supplemented with 10\% fetal bovine serum (Sigma) in a humidified incubator at $37^{\circ} \mathrm{C}$ with $5 \% \mathrm{CO}_{2}$. Raw 264.7 cells with PGRN deletion or controls were generated by infecting the cells with lentivirus expressing Cas 9 and guide RNAs (GCTCCCTGGGAGGCATCTGG and CGGACCCCGACGCAGGTAGG) targeted to mouse PGRN exon 1 (oligos with 5'-cacc gGCTCCCTGGGAGGCATCTGG-3' and 5'-aaac CCAGATGCCTCCCAGGGAGCc-3' or 5'-cacc gCGGACCCCGACGCAGGTAGG-3' and 5'-aaac CCTACCTGCGTCGGGGTCCGc-3' were ligated to pLenti-CRISPRv2 (Addgene)) or Cas9 only. Cells were selected with puromycin (8ug/ml) 2 days after infection and the knockout is confirmed by Western blot and immunostaining.

WT and $\mathrm{Gr}^{-/-}$mouse primary microglia were isolated from P0 to P2 pups and grown on astrocytes for 14 days before being shaken off according to a published protocol (Zhou et al., 2017c).

For LLOME treatment assays, $500 \mu \mathrm{M}$ LLOME (Cayman) was added to Raw 264.7 cells and primary microglia for two hours before fixation.

\section{Tissue Preparation for Western blot analysis}

Mice were perfused with PBS and tissues were dissected and snap-frozen with liquid nitrogen and kept at $80^{\circ} \mathrm{C}$. On the day of the experiment, frozen tissues were thawed and homogenized on ice with bead homogenizer (Moni International) in ice cold RIPA buffer (150 mM NaCl, $50 \mathrm{mM}$ Tris- $\mathrm{HCl}$ [pH 8.0], 1\% Triton X-100, 0.5\% sodium deoxycholate, $0.1 \%$ SDS) with $1 \mathrm{mM} \mathrm{PMSF}$, and 1x protease inhibitors (Roche). After centrifugation at $14,000 \times \mathrm{g}$ for 15 minutes at $4^{\circ} \mathrm{C}$, supernatants were collected as the RIPA-soluble fraction (soluble fraction).. The insoluble pellets were washed with RIPA buffer and extracted in guanidine buffer (5 M Guanidine, $50 \mathrm{mM}$ Tris- $\mathrm{HCl}$ [pH 8.0], and 1x protease inhibitors). After all pellets were dissolved 
completely, samples were centrifuged at $20,000 \times \mathrm{g}$ for 15 minutes at $24^{\circ} \mathrm{C}$ and the supernatants were collected as the guanidine-soluble fraction (insoluble fraction). Protein concentrations were determined via BCA assay, then standardized. Samples were run on $12 \%$ or $15 \%$ polyacrylamide gels, then transferred to Immobilon-FL polyvinylidene fluoride membranes (Millipore Corporation). Membranes were blocked with either 5\% non-fat milk in PBS or Odyssey Blocking Buffer (LI-COR Biosciences) for 1 hour and then incubated with primary antibodies, rocking overnight at $4^{\circ} \mathrm{C}$. Membranes were then washed with Trisbuffered saline with $0.1 \%$ Tween-20 (TBST) three times, 10 minutes each, and incubated with fluorescently tagged secondary antibodies (LI-COR Biosciences) for one hour at room temperature, followed by three washes. Membranes were scanned using an Odyssey Infrared Imaging System (LI-COR Biosciences). Densitometry was performed using Image Studio (LI-COR Biosciences) and Image J.

\section{Thioflavin S staining}

Thioflavin S staining was performed as previously reported (Au - Ly et al., 2011). 20- $\mu$ m-thick mice brain cryosections were stained with thioflavin $\mathrm{S}$ solution $(1 \%$, in $80 \%$ Ethanol) for 15 minutes, followed by washing with $80 \%$ Ethanol, $70 \%$ Ethanol and water. For double and triple staining with antibodies, after thioflavin S staining, sections were incubated with primary antibodies overnight at $4^{\circ} \mathrm{C}$. The next day, sections were incubated with secondary antibodies, Hoechst at room temperature for 1 hour and mounted onto cover slips. Images were acquired using a 20xobjective on a Leica DMi8 inverted microscope. Images were captured from the cerebral cortex and hippocampus regions and images from $\geq 5$ brains per genotype were used for quantitative analysis.

\section{Immunofluorescence staining, image acquisition and analysis}

Cells were fixed, permeabilized with $0.05 \%$ saponin, and visualized using immunofluorescence microscopy as previously described (Brady et al., 2013). For brain section staining, mice were perfused with cold PBS and tissues were post-fixed with $4 \%$ paraformaldehyde. After dehydration in 30\% sucrose buffer, tissues were embedded in O.C.T compound (Electron Microscopy Sciences). 20- $\mu$ m-thick brain sections were cut with cryotome. Tissue sections were blocked and permeabilized with $0.1 \%$ saponin in Odyssey blocking buffer or $0.2 \%$ Trion X-100 in Odyssey blocking buffer before incubating with primary antibodies overnight at $4^{\circ} \mathrm{C}$. The next day, sections were washed $3 \mathrm{x}$ with cold PBS followed by incubation with secondary fluorescent antibodies and Hoechst at room temperature for one hour. The slides were then mounted using mounting medium (Vector laboratories). To block the autofluorescence, all sections were incubated with $1 \times$ TrueBlack Lipofuscin Autofluorescence Quencher (Biotium) in 70\% ethanol for 30 seconds at room temperature after the staining process. Antigen retrieval was performed by microwaving in sodium citrate buffer ( $\mathrm{pH}$ 6.0) for 10 min. Images were acquired on a CSU-X spinning disc confocal microscope (Intelligent Imaging Innovations) 
with an HQ2 CCD camera (Photometrics) using 40x and 100x objectives, eight to ten different random images were captured. Lower magnification images were captured by 10x or 20x objectives on a Leica DMi8 inverted microscope, three to five images were captured from each sample. Data from $\geq 3$ brains in each genotype were used for quantitative analysis.

To quantify ThioS-positive plaques and $\mathrm{A} \beta$ plaques, plaque area, plaque number and intensity were calculated using the "analyze particles" function of ImageJ. For the quantitative analysis of IBA1 and CD68 levels in the brain sections, the fluorescence intensity and area were measured directly using ImageJ after a threshold application. The protein levels determined by the total fluorescence signals. For the quantitative analysis of IBA1 levels near $A \beta$ plaques, the $A \beta$ plaques were selected using the ROI tool after the data channels were separated (ImagelColorlSplit Channels). Next, all IBA1-positive microglia that fully or partially overlap with the $A \beta$ plaques signal were selected (Analyzeltools\ROI manager), Subsequently, the fluorescence area and intensity were measured. For CD68, Galectin-3, GPNMB, TREM2, cathepsin B (CathB) and cathepsin D $(\mathrm{CathD})$ levels near $\mathrm{A} \beta$ plaques, the images were analyzed using the same procedure in ImageJ. To quantify nuclear TFE3 levels in the microglia, the nucleus was selected based on Hoescht staining and the fluorescence intensity was measured directly by ImageJ. Three brain sections per mouse, separated by $100 \mu \mathrm{m}$ were used for quantification. The mean from the three sections was used to be representative of each mouse. Data were normalized to age-matched 5XFAD controls.

For the quantitative analysis of intracellular levels of Galectin-3, CathD and GPNMB in primary microglia culture, the entire cell body was selected, and the fluorescence intensity was measured directly using ImageJ after a threshold application. To quantify the degree of colocalization between Galectin-3 and the lysosomal marker LAMP1, the JACoP plugin was used to generate Manders' coefficients. To quantify nuclear to cytoplasmic TFE3 ratio, the nucleus and the entire cell were selected, and the fluorescence intensity was measured directly by ImageJ. Intensity from the entire cell were subtracted from nuclear to calculate cytoplasmic TFE3 intensity. For each experiment, at least 12 pairs of cells were measured and the data from three to five independent experiments were used for statistical analysis.

\section{Preparation of A $\beta$ Fibrils}

$\mathrm{A} \beta$ fibrils were prepared as described previously with slight modification (Solé-Domènech et al., 2018). One milligram of $\mathrm{A} \beta$ (Anaspec) was solubilized at $1 \mathrm{mg} / \mathrm{mL}$ in $1 \mathrm{~mL}$ of $50 \mathrm{mM}$ sodium tetraborate, $\mathrm{pH}$ 9.3. To form fibrils, $\mathrm{A} \beta$ was immediately diluted in $\mathrm{pH} 7.4$ PBS buffer $(50 \mu \mathrm{M})$. The fibrillation mixture was prepared in sealed polycarbonate ultracentrifuge tubes and incubated for 24 hours at $37{ }^{\circ} \mathrm{C}$ under constant rotation. After aggregation, centrifuge the mixture at $15,000 \times \mathrm{g}$ for 30 minutes and carefully discard the 
supernatant without disturbing the pellet, the pellets were resuspended in $\mathrm{pH} 7.4$ PBS buffer $(125 \mu \mathrm{M})$. A $\beta$ fibrils were then added to cells at the indicated concentrations for $24 \mathrm{~h}$ and cells were collected for subsequent experiments.

\section{Enzyme-linked immunosorbent assay}

A 342 peptides in cortical lysates were captured by $A \beta_{33-42}$ specific antibody (21F12). A $\beta 40$ peptides in cortical lysates were captured by $A \beta_{40}$ specific antibody (2G3). Both captured $A \beta 42$ and $A \beta 40$ were detected by biotinylated mouse anti-A $\beta_{1-16}$ antibody (6E10) followed by streptavidin HRP (The Jacksonimmuno). All ELISAs were developed using ELISA TMB (Sigma-Aldrich) and absorbance read on a Bio-Tek plate reader. The synthetic human $A \beta_{1-42}$ or $A \beta_{40}$ peptide (AnaSpec) was used for standard curves for each assay. To determine the inflammatory responses, WT, Grn-/- primary microglia and control, Grn-/- Raw 264.7 cells were treated with $10 \mu \mathrm{M}$ A $\beta$ fibrils for 24 hours. To measure TNF- $\alpha$ levels, conditioned medium was collected and analyzed using mouse TNF- $\alpha$ ELISA kit (BioLegend) according to the manufacturer's instruction.

\section{RNA Seq analysis}

RNAs were extracted from brain hippocampus region using Trizol (Thermoscientific). RNA quality was checked using nanodrop, gel electrophoresis and Agilent 4200 TapeStation. cDNA library was then generated using the QuantSeq 3' mRNA-Seq Library Prep Kit FWD for Illumina (Lexogen). 86 bp single-end sequencing was performed on an Illumina NextSeq500 (Illumina) using services provided by the Cornell Biotech Facilities. Data quality was assessed using FastQC (https://www.bioinformatics.babraham.ac.uk/projects/fastqc/). Reads that passed quality control were aligned to reference genome (Ensembl 98.38)(Zerbino et al., 2018) using STAR(Dobin et al., 2013). The number of reads in each gene was obtained using HTSeq-count(Anders et al., 2015). Differential expression analysis was performed using the R package edgeR (Robinson et al., 2010), followed by the limma package with its voom method (Law et al., 2014). Genes with FDR control $p$ value $\leq 0.05$ and log fold change $\geq 0.5$ were identified as differentially expressed genes. Heatmaps were made using the R package gplots.

\section{Statistical analysis}

All statistical analyses were performed using GraphPad Prism 8. The normality of data was tested by the Shapiro-Wilk test $(\mathrm{P}>0.05)$. All data are presented as mean \pm SEM. Statistical significance was assessed by unpaired Student's $t$ test (for two groups comparison), one-way ANOVA tests or two-way ANOVA tests with 
Bonferroni's multiple comparisons (for multiple comparisons). $\mathrm{P}$ values less than or equal to 0.05 were considered statistically significant. $* \mathrm{p}<0.05 ; * \mathrm{p}<0.01$.

\title{
Supplemental Material
}

Figure S1: PGRN expression in the 5XFAD mice.

Figure S2: PGRN deficiency does not cause obvious behavioral changes in the open field and Y-maze tests.

Figure S3: PGRN deficiency does not have any effect on the levels of endogenous APP, PS1 or BACE1 in 4.5month-old mice.

Figure S4: PGRN deficiency affects A $\beta$ plaques load in the 10-month-old 5XFAD mice.

Figure S5: PGRN deficiency leads to increased expression of lysosome and inflammation genes.

Figure S6: PGRN deficiency leads to an increase in the levels of lysosome proteins in the 5XFAD mice.

Figure S7: Western blot to confirm the specificity of cathepsin antibodies used in the study.

\section{Author contributions}

H.D. performed all the experiments and analyzed the data. T.Z. helped with behavioral tests. M.N.S. generated PGRN deficient Raw264.7 cells and helped with primary microglia culture. C. H helped with genotyping. M.Y.W performed ELISA under the supervision of W.L. J. Z. performed bioinformatic analysis for the RNA Seq data under the supervision of H.Y. F.H. supervised the project and wrote the manuscript together with H.D. All authors have read and edited the manuscript.

\section{Acknowledgements}

We would like to thank Xiaochun Wu for technical assistance, Dr. Tony Bretscher's lab for assistance with confocal microscope, Dr. Tobias Dörr's lab for assistance with Leica DMi8 inverted microscope, Dr. Thomas Cleland's lab and Dr. Chris Schaffer and Dr. Nozomi Nishimura's lab for assistance with behavioral tests. We would like to thank Dr. Steven M. Paul and Dr. Ronald Demattos from Eli Lilly for providing 2G3 and $21 \mathrm{~F} 12$ antibodies. This work is supported by NINDS/NIA (R01NS088448 \& R01NS095954) and the Bluefield project to cure frontotemporal dementia to F.H., and NIA (R01AG064239) to W.L.

\author{
Abbreviations \\ Alzheimer's disease (AD) \\ Cathepsin D (CathD)
}




\section{Cathepsin B (CathB)}

Differentially Expressed Genes (DEGs)

Disease associated microglia (DAM)

Frontotemporal Lobar Degeneration (FTLD)

Granulin (GRN)

Progranulin (PGRN) 


\section{References}

Ahmed, Z., H. Sheng, Y.F. Xu, W.L. Lin, A.E. Innes, J. Gass, X. Yu, C.A. Wuertzer, H. Hou, S. Chiba, K. Yamanouchi, M. Leissring, L. Petrucelli, M. Nishihara, M.L. Hutton, E. McGowan, D.W. Dickson, and J. Lewis. 2010. Accelerated lipofuscinosis and ubiquitination in granulin knockout mice suggest a role for progranulin in successful aging. Am J Pathol 177:311-324.

Aits, S., J. Kricker, B. Liu, A.M. Ellegaard, S. Hämälistö, S. Tvingsholm, E. Corcelle-Termeau, S. Høgh, T. Farkas, A. Holm Jonassen, I. Gromova, M. Mortensen, and M. Jäättelä. 2015. Sensitive detection of lysosomal membrane permeabilization by lysosomal galectin puncta assay. Autophagy 11:1408-1424.

Aldana, B.I. 2019. Microglia-Specific Metabolic Changes in Neurodegeneration. J Mol Biol 431:1830-1842.

Almeida, M.R., M.C. Macario, L. Ramos, I. Baldeiras, M.H. Ribeiro, and I. Santana. 2016. Portuguese family with the co-occurrence of frontotemporal lobar degeneration and neuronal ceroid lipofuscinosis phenotypes due to progranulin gene mutation. Neurobiol Aging 41:200 e201-205.

Anders, S., P.T. Pyl, and W. Huber. 2015. HTSeq--a Python framework to work with high-throughput sequencing data. Bioinformatics 31:166-169.

Arrant, A.E., J.R. Roth, N.R. Boyle, S.N. Kashyap, M.Q. Hoffmann, C.F. Murchison, E.M. Ramos, A.L. Nana, S. Spina, L.T. Grinberg, B.L. Miller, W.W. Seeley, and E.D. Roberson. 2019. Impaired betaglucocerebrosidase activity and processing in frontotemporal dementia due to progranulin mutations. Acta Neuropathol Commun 7:218.

$\mathrm{Au}$ - Ly, P.T.T., F. Au - Cai, and W. Au - Song. 2011. Detection of Neuritic Plaques in Alzheimer's Disease Mouse Model. JoVE e2831.

Bajaj, L., P. Lotfi, R. Pal, A.D. Ronza, J. Sharma, and M. Sardiello. 2019. Lysosome biogenesis in health and disease. J Neurochem 148:573-589.

Baker, M., I.R. Mackenzie, S.M. Pickering-Brown, J. Gass, R. Rademakers, C. Lindholm, J. Snowden, J. Adamson, A.D. Sadovnick, S. Rollinson, A. Cannon, E. Dwosh, D. Neary, S. Melquist, A. Richardson, D. Dickson, Z. Berger, J. Eriksen, T. Robinson, C. Zehr, C.A. Dickey, R. Crook, E. McGowan, D. Mann, B. Boeve, H. Feldman, and M. Hutton. 2006. Mutations in progranulin cause tau-negative frontotemporal dementia linked to chromosome 17. Nature 442:916-919.

Bateman, A., and H.P. Bennett. 2009. The granulin gene family: from cancer to dementia. Bioessays 31:12451254.

Beel, S., M. Moisse, M. Damme, L. De Muynck, W. Robberecht, L. Van Den Bosch, P. Saftig, and P. Van Damme. 2017. Progranulin functions as a cathepsin D chaperone to stimulate axonal outgrowth in vivo. Hum Mol Genet 26:2850-2863.

Brady, O.A., J.A. Martina, and R. Puertollano. 2018. Emerging roles for TFEB in the immune response and inflammation. Autophagy 14:181-189.

Brady, O.A., Y. Zheng, K. Murphy, M. Huang, and F. Hu. 2013. The frontotemporal lobar degeneration risk factor, TMEM106B, regulates lysosomal morphology and function. Hum Mol Genet 22:685-695.

Budge, K.M., M.L. Neal, J.R. Richardson, and F.F. Safadi. 2018. Glycoprotein NMB: an Emerging Role in Neurodegenerative Disease. Molecular neurobiology 55:5167-5176.

Bundy, J.L., C. Vied, C. Badger, and R.S. Nowakowski. 2019. Sex-biased hippocampal pathology in the 5XFAD mouse model of Alzheimer's disease: A multi-omic analysis. The Journal of comparative neurology 527:462-475.

Butler, V.J., W.A. Cortopassi, A.R. Argouarch, S.L. Ivry, C.S. Craik, M.P. Jacobson, and A.W. Kao. 2019. Progranulin Stimulates the In Vitro Maturation of Pro-Cathepsin D at Acidic pH. J Mol Biol 431:1038-1047.

Chauhan, S., S. Kumar, A. Jain, M. Ponpuak, M.H. Mudd, T. Kimura, S.W. Choi, R. Peters, M. Mandell, J.A. Bruun, T. Johansen, and V. Deretic. 2016. TRIMs and Galectins Globally Cooperate and TRIM16 and Galectin-3 Co-direct Autophagy in Endomembrane Damage Homeostasis. Developmental cell 39:13-27.

Chiba, S., M. Suzuki, K. Yamanouchi, and M. Nishihara. 2007. Involvement of granulin in estrogen-induced neurogenesis in the adult rat hippocampus. The Journal of reproduction and development 53:297-307. 
Colonna, M., and O. Butovsky. 2017. Microglia Function in the Central Nervous System During Health and Neurodegeneration. Annu Rev Immunol 35:441-468.

Cruts, M., I. Gijselinck, J. van der Zee, S. Engelborghs, H. Wils, D. Pirici, R. Rademakers, R. Vandenberghe, B. Dermaut, J.J. Martin, C. van Duijn, K. Peeters, R. Sciot, P. Santens, T. De Pooter, M. Mattheijssens, M. Van den Broeck, I. Cuijt, K. Vennekens, P.P. De Deyn, S. Kumar-Singh, and C. Van Broeckhoven. 2006. Null mutations in progranulin cause ubiquitin-positive frontotemporal dementia linked to chromosome 17q21. Nature 442:920-924.

Curtis, A.F., M. Masellis, G.R. Hsiung, R. Moineddin, K. Zhang, B. Au, G. Millett, I. Mackenzie, E. Rogaeva, and M.C. Tierney. 2017. Sex differences in the prevalence of genetic mutations in FTD and ALS: A meta-analysis. Neurology 89:1633-1642.

Deczkowska, A., H. Keren-Shaul, A. Weiner, M. Colonna, M. Schwartz, and I. Amit. 2018. DiseaseAssociated Microglia: A Universal Immune Sensor of Neurodegeneration. Cell 173:1073-1081.

Deczkowska, A., A. Weiner, and I. Amit. 2020. The Physiology, Pathology, and Potential Therapeutic Applications of the TREM2 Signaling Pathway. Cell 181:1207-1217.

Del-Aguila, J.L., Z. Li, U. Dube, K.A. Mihindukulasuriya, J.P. Budde, M.V. Fernandez, L. Ibanez, J. Bradley, F. Wang, K. Bergmann, R. Davenport, J.C. Morris, D.M. Holtzman, R.J. Perrin, B.A. Benitez, J. Dougherty, C. Cruchaga, and O. Harari. 2019. A single-nuclei RNA sequencing study of Mendelian and sporadic AD in the human brain. Alzheimers Res Ther 11:71.

Dobin, A., C.A. Davis, F. Schlesinger, J. Drenkow, C. Zaleski, S. Jha, P. Batut, M. Chaisson, and T.R. Gingeras. 2013. STAR: ultrafast universal RNA-seq aligner. Bioinformatics 29:15-21.

Fenoglio, C., D. Scalabrini, F. Esposito, C. Comi, P. Cavalla, M. De Riz, V. Martinelli, L.M. Piccio, E. Venturelli, G. Fumagalli, R. Capra, L. Collimedaglia, A. Ghezzi, M.E. Rodegher, M. Vercellino, M. Leone, M.T. Giordana, N. Bresolin, F. Monaco, G. Comi, E. Scarpini, F. Martinelli-Boneschi, and D. Galimberti. 2010. Progranulin gene variability increases the risk for primary progressive multiple sclerosis in males. Genes \& Immunity 11:497-503.

Friedman, B.A., K. Srinivasan, G. Ayalon, W.J. Meilandt, H. Lin, M.A. Huntley, Y. Cao, S.H. Lee, P.C.G. Haddick, H. Ngu, Z. Modrusan, J.L. Larson, J.S. Kaminker, M.P. van der Brug, and D.V. Hansen. 2018. Diverse Brain Myeloid Expression Profiles Reveal Distinct Microglial Activation States and Aspects of Alzheimer's Disease Not Evident in Mouse Models. Cell reports 22:832-847.

Gass, J., A. Cannon, I.R. Mackenzie, B. Boeve, M. Baker, J. Adamson, R. Crook, S. Melquist, K. Kuntz, R. Petersen, K. Josephs, S.M. Pickering-Brown, N. Graff-Radford, R. Uitti, D. Dickson, Z. Wszolek, J. Gonzalez, T.G. Beach, E. Bigio, N. Johnson, S. Weintraub, M. Mesulam, C.L. White, 3rd, B.

Woodruff, R. Caselli, G.Y. Hsiung, H. Feldman, D. Knopman, M. Hutton, and R. Rademakers. 2006. Mutations in progranulin are a major cause of ubiquitin-positive frontotemporal lobar degeneration. Hum Mol Genet 15:2988-3001.

Gotzl, J.K., A.V. Colombo, K. Fellerer, A. Reifschneider, G. Werner, S. Tahirovic, C. Haass, and A. Capell. 2018. Early lysosomal maturation deficits in microglia triggers enhanced lysosomal activity in other brain cells of progranulin knockout mice. Mol Neurodegener 13:48.

Gotzl, J.K., K. Mori, M. Damme, K. Fellerer, S. Tahirovic, G. Kleinberger, J. Janssens, J. van der Zee, C.M. Lang, E. Kremmer, J.J. Martin, S. Engelborghs, H.A. Kretzschmar, T. Arzberger, C. Van Broeckhoven, C. Haass, and A. Capell. 2014. Common pathobiochemical hallmarks of progranulinassociated frontotemporal lobar degeneration and neuronal ceroid lipofuscinosis. Acta Neuropathol 127:845-860.

Gowrishankar, S., P. Yuan, Y. Wu, M. Schrag, S. Paradise, J. Grutzendler, P. De Camilli, and S.M. Ferguson. 2015. Massive accumulation of luminal protease-deficient axonal lysosomes at Alzheimer's disease amyloid plaques. Proc Natl Acad Sci U S A 112:E3699-3708.

Guan, Z., Z. Chen, S. Fu, L. Dai, and Y. Shen. 2020. Progranulin Administration Attenuates beta-Amyloid Deposition in the Hippocampus of 5xFAD Mice Through Modulating BACE1 Expression and Microglial Phagocytosis. Front Cell Neurosci 14:260.

Hammond, T.R., S.E. Marsh, and B. Stevens. 2019. Immune Signaling in Neurodegeneration. Immunity 50:955-974. 
Hanisch, U.-K., and H. Kettenmann. 2007. Microglia: active sensor and versatile effector cells in the normal and pathologic brain. Nature Neuroscience 10:1387-1394.

Hansen, D.V., J.E. Hanson, and M. Sheng. 2018. Microglia in Alzheimer's disease. J Cell Biol 217:459-472.

Heneka, M.T., M.P. Kummer, and E. Latz. 2014. Innate immune activation in neurodegenerative disease. Nature reviews. Immunology 14:463-477.

Hickman, S., S. Izzy, P. Sen, L. Morsett, and J. El Khoury. 2018. Microglia in neurodegeneration. Nat Neurosci 21:1359-1369.

Holler, C.J., G. Taylor, Q. Deng, and T. Kukar. 2017. Intracellular Proteolysis of Progranulin Generates Stable, Lysosomal Granulins that Are Haploinsufficient in Patients with Frontotemporal Dementia Caused by GRN Mutations. eNeuro 4:

Hosokawa, M., Y. Tanaka, T. Arai, H. Kondo, H. Akiyama, and M. Hasegawa. 2018. Progranulin haploinsufficiency reduces amyloid beta deposition in Alzheimer's disease model mice. Exp Anim 67:63-70.

Hsiung, G.Y., A. Fok, H.H. Feldman, R. Rademakers, and I.R. Mackenzie. 2011. rs5848 polymorphism and serum progranulin level. J Neurol Sci 300:28-32.

Hu, F., T. Padukkavidana, C.B. Vaegter, O.A. Brady, Y. Zheng, I.R. Mackenzie, H.H. Feldman, A. Nykjaer, and S.M. Strittmatter. 2010. Sortilin-mediated endocytosis determines levels of the frontotemporal dementia protein, progranulin. Neuron 68:654-667.

Huang, M., E. Modeste, E. Dammer, P. Merino, G. Taylor, D.M. Duong, Q. Deng, C.J. Holler, M. Gearing, D. Dickson, N.T. Seyfried, and T. Kukar. 2020. Network analysis of the progranulin-deficient mouse brain proteome reveals pathogenic mechanisms shared in human frontotemporal dementia caused by GRN mutations. Acta neuropathologica communications 8:163.

Hüttenrauch, M., I. Ogorek, H. Klafki, M. Otto, C. Stadelmann, S. Weggen, J. Wiltfang, and O. Wirths. 2018. Glycoprotein NMB: a novel Alzheimer's disease associated marker expressed in a subset of activated microglia. Acta Neuropathol Commun 6:108.

Jia, J., A. Claude-Taupin, Y. Gu, S.W. Choi, R. Peters, B. Bissa, M.H. Mudd, L. Allers, S. Pallikkuth, K.A. Lidke, M. Salemi, B. Phinney, M. Mari, F. Reggiori, and V. Deretic. 2020. Galectin-3 Coordinates a Cellular System for Lysosomal Repair and Removal. Developmental cell 52:69-87.e68.

Kamalainen, A., J. Viswanathan, T. Natunen, S. Helisalmi, T. Kauppinen, M. Pikkarainen, J.P. Pursiheimo, I. Alafuzoff, M. Kivipelto, A. Haapasalo, H. Soininen, S.K. Herukka, and M. Hiltunen. 2013. GRN variant rs 5848 reduces plasma and brain levels of granulin in Alzheimer's disease patients. $J$ Alzheimers Dis 33:23-27.

Kamphuis, W., L. Kooijman, S. Schetters, M. Orre, and E.M. Hol. 2016. Transcriptional profiling of CD11cpositive microglia accumulating around amyloid plaques in a mouse model for Alzheimer's disease. Biochimica et biophysica acta 1862:1847-1860.

Kao, A.W., A. McKay, P.P. Singh, A. Brunet, and E.J. Huang. 2017. Progranulin, lysosomal regulation and neurodegenerative disease. Nat Rev Neurosci 18:325-333.

Katsnelson, M.A., K.M. Lozada-Soto, H.M. Russo, B.A. Miller, and G.R. Dubyak. 2016. NLRP3 inflammasome signaling is activated by low-level lysosome disruption but inhibited by extensive lysosome disruption: roles for $\mathrm{K}+$ efflux and $\mathrm{Ca} 2+$ influx. American journal of physiology. Cell physiology 311:C83-c100.

Kayasuga, Y., S. Chiba, M. Suzuki, T. Kikusui, T. Matsuwaki, K. Yamanouchi, H. Kotaki, R. Horai, Y. Iwakura, and M. Nishihara. 2007. Alteration of behavioural phenotype in mice by targeted disruption of the progranulin gene. Behav Brain Res 185:110-118.

Krasemann, S., C. Madore, R. Cialic, C. Baufeld, N. Calcagno, R. El Fatimy, L. Beckers, E. O'Loughlin, Y. Xu, Z. Fanek, D.J. Greco, S.T. Smith, G. Tweet, Z. Humulock, T. Zrzavy, P. Conde-Sanroman, M. Gacias, Z. Weng, H. Chen, E. Tjon, F. Mazaheri, K. Hartmann, A. Madi, J.D. Ulrich, M. Glatzel, A. Worthmann, J. Heeren, B. Budnik, C. Lemere, T. Ikezu, F.L. Heppner, V. Litvak, D.M. Holtzman, H. Lassmann, H.L. Weiner, J. Ochando, C. Haass, and O. Butovsky. 2017. The TREM2-APOE Pathway Drives the Transcriptional Phenotype of Dysfunctional Microglia in Neurodegenerative Diseases. Immunity 47:566-581 e569. 
Law, C.W., Y. Chen, W. Shi, and G.K. Smyth. 2014. voom: Precision weights unlock linear model analysis tools for RNA-seq read counts. Genome Biol 15:R29.

Lee, C.W., J.N. Stankowski, J. Chew, C.N. Cook, Y.W. Lam, S. Almeida, Y. Carlomagno, K.F. Lau, M. Prudencio, F.B. Gao, M. Bogyo, D.W. Dickson, and L. Petrucelli. 2017. The lysosomal protein cathepsin L is a progranulin protease. Mol Neurodegener 12:55.

Lie, P.P.Y., and R.A. Nixon. 2019. Lysosome trafficking and signaling in health and neurodegenerative diseases. Neurobiol Dis 122:94-105.

Lui, H., J. Zhang, S.R. Makinson, M.K. Cahill, K.W. Kelley, H.Y. Huang, Y. Shang, M.C. Oldham, L.H. Martens, F. Gao, G. Coppola, S.A. Sloan, C.L. Hsieh, C.C. Kim, E.H. Bigio, S. Weintraub, M.M. Mesulam, R. Rademakers, I.R. Mackenzie, W.W. Seeley, A. Karydas, B.L. Miller, B. Borroni, R. Ghidoni, R.V. Farese, Jr., J.T. Paz, B.A. Barres, and E.J. Huang. 2016. Progranulin Deficiency Promotes Circuit-Specific Synaptic Pruning by Microglia via Complement Activation. Cell 165:921935.

Maric, G., A.A. Rose, M.G. Annis, and P.M. Siegel. 2013. Glycoprotein non-metastatic b (GPNMB): A metastatic mediator and emerging therapeutic target in cancer. OncoTargets and therapy 6:839-852.

Martens, L.H., J. Zhang, S.J. Barmada, P. Zhou, S. Kamiya, B. Sun, S.W. Min, L. Gan, S. Finkbeiner, E.J. Huang, and R.V. Farese, Jr. 2012. Progranulin deficiency promotes neuroinflammation and neuron loss following toxin-induced injury. J Clin Invest 122:3955-3959.

Martinez-Fabregas, J., A. Prescott, S. van Kasteren, D.L. Pedrioli, I. McLean, A. Moles, T. Reinheckel, V. Poli, and C. Watts. 2018. Lysosomal protease deficiency or substrate overload induces an oxidativestress mediated STAT3-dependent pathway of lysosomal homeostasis. Nat Commun 9:5343.

Masuda, T., R. Sankowski, O. Staszewski, C. Böttcher, L. Amann, Sagar, C. Scheiwe, S. Nessler, P. Kunz, G. van Loo, V.A. Coenen, P.C. Reinacher, A. Michel, U. Sure, R. Gold, D. Grün, J. Priller, C. Stadelmann, and M. Prinz. 2019. Spatial and temporal heterogeneity of mouse and human microglia at single-cell resolution. Nature 566:388-392.

Mathys, H., J. Davila-Velderrain, Z. Peng, F. Gao, S. Mohammadi, J.Z. Young, M. Menon, L. He, F. Abdurrob, X. Jiang, A.J. Martorell, R.M. Ransohoff, B.P. Hafler, D.A. Bennett, M. Kellis, and L.H. Tsai. 2019. Single-cell transcriptomic analysis of Alzheimer's disease. Nature 570:332-337.

Mendsaikhan, A., I. Tooyama, and D.G. Walker. 2019. Microglial Progranulin: Involvement in Alzheimer's Disease and Neurodegenerative Diseases. Cells 8:

Minami, S.S., S.-W. Min, G. Krabbe, C. Wang, Y. Zhou, R. Asgarov, Y. Li, L.H. Martens, L.P. Elia, M.E. Ward, L. Mucke, R.V. Farese, and L. Gan. 2014. Progranulin protects against amyloid $\beta$ deposition and toxicity in Alzheimer's disease mouse models. Nature Medicine 20:1157-1164.

Moisse, K., K. Volkening, C. Leystra-Lantz, I. Welch, T. Hill, and M.J. Strong. 2009. Divergent patterns of cytosolic TDP-43 and neuronal progranulin expression following axotomy: implications for TDP-43 in the physiological response to neuronal injury. Brain Res 1249:202-211.

Moloney, E.B., A. Moskites, E.J. Ferrari, O. Isacson, and P.J. Hallett. 2018. The glycoprotein GPNMB is selectively elevated in the substantia nigra of Parkinson's disease patients and increases after lysosomal stress. Neurobiol Dis 120:1-11.

Mrdjen, D., A. Pavlovic, F.J. Hartmann, B. Schreiner, S.G. Utz, B.P. Leung, I. Lelios, F.L. Heppner, J. Kipnis, D. Merkler, M. Greter, and B. Becher. 2018. High-Dimensional Single-Cell Mapping of Central Nervous System Immune Cells Reveals Distinct Myeloid Subsets in Health, Aging, and Disease. Immunity 48:380-395.e386.

Nabar, N.R., and J.H. Kehrl. 2017. The Transcription Factor EB Links Cellular Stress to the Immune Response. Yale J Biol Med 90:301-315.

Naphade, S.B., K.A. Kigerl, L.B. Jakeman, S.K. Kostyk, P.G. Popovich, and J. Kuret. 2010. Progranulin expression is upregulated after spinal contusion in mice. Acta Neuropathol 119:123-133.

Napolitano, G., and A. Ballabio. 2016. TFEB at a glance. J Cell Sci 129:2475-2481.

Neal, M.L., A.M. Boyle, K.M. Budge, F.F. Safadi, and J.R. Richardson. 2018. The glycoprotein GPNMB attenuates astrocyte inflammatory responses through the CD44 receptor. Journal of Neuroinflammation 15:73. 
Nebel, C., A. Aslanidis, K. Rashid, and T. Langmann. 2017. Activated microglia trigger inflammasome activation and lysosomal destabilization in human RPE cells. Biochemical and biophysical research communications 484:681-686.

Nelson, P.T., D.W. Dickson, J.Q. Trojanowski, C.R. Jack, P.A. Boyle, K. Arfanakis, R. Rademakers, I. Alafuzoff, J. Attems, C. Brayne, I.T.S. Coyle-Gilchrist, H.C. Chui, D.W. Fardo, M.E. Flanagan, G. Halliday, S.R.K. Hokkanen, S. Hunter, G.A. Jicha, Y. Katsumata, C.H. Kawas, C.D. Keene, G.G. Kovacs, W.A. Kukull, A.I. Levey, N. Makkinejad, T.J. Montine, S. Murayama, M.E. Murray, S. Nag, R.A. Rissman, W.W. Seeley, R.A. Sperling, C.L. White Iii, L. Yu, and J.A. Schneider. 2019. Limbicpredominant age-related TDP-43 encephalopathy (LATE): consensus working group report. Brain

Nicholson, A.M., J. Gass, L. Petrucelli, and R. Rademakers. 2012. Progranulin axis and recent developments in frontotemporal lobar degeneration. Alzheimers Res Ther 4:4.

Oakley, H., S.L. Cole, S. Logan, E. Maus, P. Shao, J. Craft, A. Guillozet-Bongaarts, M. Ohno, J. Disterhoft, L. Van Eldik, R. Berry, and R. Vassar. 2006. Intraneuronal $\beta$-Amyloid Aggregates, Neurodegeneration, and Neuron Loss in Transgenic Mice with Five Familial Alzheimer's Disease Mutations: Potential Factors in Amyloid Plaque Formation. 26:10129-10140.

Paushter, D.H., H. Du, T. Feng, and F. Hu. 2018. The lysosomal function of progranulin, a guardian against neurodegeneration. Acta Neuropathologica 136:1-17.

Pereson, S., H. Wils, G. Kleinberger, E. McGowan, M. Vandewoestyne, B. Van Broeck, G. Joris, I. Cuijt, D. Deforce, M. Hutton, C. Van Broeckhoven, and S. Kumar-Singh. 2009. Progranulin expression correlates with dense-core amyloid plaque burden in Alzheimer disease mouse models. 219:173-181.

Perry, D.C., M. Lehmann, J.S. Yokoyama, A. Karydas, J.J. Lee, G. Coppola, L.T. Grinberg, D. Geschwind, W.W. Seeley, B.L. Miller, H. Rosen, and G. Rabinovici. 2013. Progranulin mutations as risk factors for Alzheimer disease. JAMA Neurol 70:774-778.

Petkau, T.L., S.J. Neal, A. Milnerwood, A. Mew, A.M. Hill, P. Orban, J. Gregg, G. Lu, H.H. Feldman, I.R. Mackenzie, L.A. Raymond, and B.R. Leavitt. 2012. Synaptic dysfunction in progranulin-deficient mice. Neurobiol Dis 45:711-722.

Philips, T., L. De Muynck, H.N. Thu, B. Weynants, P. Vanacker, J. Dhondt, K. Sleegers, H.J. Schelhaas, M. Verbeek, R. Vandenberghe, R. Sciot, C. Van Broeckhoven, D. Lambrechts, F. Van Leuven, L. Van Den Bosch, W. Robberecht, and P. Van Damme. 2010. Microglial upregulation of progranulin as a marker of motor neuron degeneration. J Neuropathol Exp Neurol 69:1191-1200.

Pickford, F., J. Marcus, L.M. Camargo, Q. Xiao, D. Graham, J.R. Mo, M. Burkhardt, V. Kulkarni, J. Crispino, H. Hering, and M. Hutton. 2011. Progranulin is a chemoattractant for microglia and stimulates their endocytic activity. Am J Pathol 178:284-295.

Piscopo, P., R. Rivabene, D. Galimberti, A. Crestini, G. Talarico, N. Vanacore, E. Scarpini, G. Bruno, and A. Confaloni. 2013. Gender effects on plasma PGRN levels in patients with Alzheimer's disease: a preliminary study. Journal of Alzheimer's disease : JAD 35:313-318.

Podlesny-Drabiniok, A., E. Marcora, and A.M. Goate. 2020. Microglial Phagocytosis: A Disease-Associated Process Emerging from Alzheimer's Disease Genetics. Trends Neurosci 43:965-979.

Rhinn, H., and A. Abeliovich. 2017. Differential Aging Analysis in Human Cerebral Cortex Identifies Variants in TMEM106B and GRN that Regulate Aging Phenotypes. Cell Syst 4:404-415 e405.

Robinson, M.D., D.J. McCarthy, and G.K. Smyth. 2010. edgeR: a Bioconductor package for differential expression analysis of digital gene expression data. Bioinformatics 26:139-140.

Safadi, F.F., J. Xu, S.L. Smock, M.C. Rico, T.A. Owen, and S.N. Popoff. 2001. Cloning and characterization of osteoactivin, a novel cDNA expressed in osteoblasts. Journal of cellular biochemistry 84:12-26.

Saftig, P., and R. Puertollano. 2021. How Lysosomes Sense, Integrate, and Cope with Stress. Trends in biochemical sciences 46:97-112.

Sheng, J., L. Su, Z. Xu, and G. Chen. 2014. Progranulin polymorphism rs5848 is associated with increased risk of Alzheimer's disease. Gene 542:141-145.

Smith, K.R., J. Damiano, S. Franceschetti, S. Carpenter, L. Canafoglia, M. Morbin, G. Rossi, D. Pareyson, S.E. Mole, J.F. Staropoli, K.B. Sims, J. Lewis, W.L. Lin, D.W. Dickson, H.H. Dahl, M. Bahlo, and 
S.F. Berkovic. 2012. Strikingly different clinicopathological phenotypes determined by progranulinmutation dosage. Am J Hum Genet 90:1102-1107.

Sole-Domenech, S., D.L. Cruz, E. Capetillo-Zarate, and F.R. Maxfield. 2016. The endocytic pathway in microglia during health, aging and Alzheimer's disease. Ageing Res Rev 32:89-103.

Solé-Domènech, S., A.V. Rojas, G.G. Maisuradze, H.A. Scheraga, P. Lobel, and F.R. Maxfield. 2018. Lysosomal enzyme tripeptidyl peptidase 1 destabilizes fibrillar A $\beta$ by multiple endoproteolytic cleavages within the $\beta$-sheet domain. 115:1493-1498.

Srinivasan, K., B.A. Friedman, A. Etxeberria, M.A. Huntley, M.P. van der Brug, O. Foreman, J.S. Paw, Z. Modrusan, T.G. Beach, G.E. Serrano, and D.V. Hansen. 2019. Alzheimer's patient brain myeloid cells exhibit enhanced aging and unique transcriptional activation. 610345.

Srinivasan, K., B.A. Friedman, J.L. Larson, B.E. Lauffer, L.D. Goldstein, L.L. Appling, J. Borneo, C. Poon, T. Ho, F. Cai, P. Steiner, M.P. van der Brug, Z. Modrusan, J.S. Kaminker, and D.V. Hansen. 2016. Untangling the brain's neuroinflammatory and neurodegenerative transcriptional responses. Nat Commun 7:11295.

Suzuki, M., H.C. Lee, Y. Kayasuga, S. Chiba, T. Nedachi, T. Matsuwaki, K. Yamanouchi, and M. Nishihara. 2009. Roles of progranulin in sexual differentiation of the developing brain and adult neurogenesis. The Journal of reproduction and development 55:351-355.

Suzuki, M., and M. Nishiahara. 2002. Granulin precursor gene: a sex steroid-inducible gene involved in sexual differentiation of the rat brain. Molecular genetics and metabolism 75:31-37.

Suzuki, M., S. Yoshida, M. Nishihara, and M. Takahashi. 1998. Identification of a sex steroid-inducible gene in the neonatal rat hypothalamus. Neurosci Lett 242:127-130.

Takahashi, H., Z.A. Klein, S.M. Bhagat, A.C. Kaufman, M.A. Kostylev, T. Ikezu, S.M. Strittmatter, and I. Alzheimer's Disease Neuroimaging. 2017. Opposing effects of progranulin deficiency on amyloid and tau pathologies via microglial TYROBP network. Acta neuropathologica 133:785-807.

Tanaka, Y., J.K. Chambers, T. Matsuwaki, K. Yamanouchi, and M. Nishihara. 2014. Possible involvement of lysosomal dysfunction in pathological changes of the brain in aged progranulin-deficient mice. Acta Neuropathol Commun 2:78.

Tolkatchev, D., S. Malik, A. Vinogradova, P. Wang, Z. Chen, P. Xu, H.P. Bennett, A. Bateman, and F. Ni. 2008. Structure dissection of human progranulin identifies well-folded granulin/epithelin modules with unique functional activities. Protein Sci 17:711-724.

Valdez, C., Y.C. Wong, M. Schwake, G. Bu, Z.K. Wszolek, and D. Krainc. 2017. Progranulin-mediated deficiency of cathepsin D results in FTD and NCL-like phenotypes in neurons derived from FTD patients. Hum Mol Genet 26:4861-4872.

Valdez, C., D. Ysselstein, T.J. Young, J. Zheng, and D. Krainc. 2019. Progranulin mutations result in impaired processing of prosaposin and reduced glucocerebrosidase activity. Hum Mol Genet 29:716726.

Van Damme, P., A. Van Hoecke, D. Lambrechts, P. Vanacker, E. Bogaert, J. van Swieten, P. Carmeliet, L. Van Den Bosch, and W. Robberecht. 2008. Progranulin functions as a neurotrophic factor to regulate neurite outgrowth and enhance neuronal survival. J Cell Biol 181:37-41.

van der Lienden, M.J.C., P. Gaspar, R. Boot, J. Aerts, and M. van Eijk. 2018. Glycoprotein Non-Metastatic Protein B: An Emerging Biomarker for Lysosomal Dysfunction in Macrophages. International journal of molecular sciences 20:

Van Kampen, J.M., and D.G. Kay. 2017. Progranulin gene delivery reduces plaque burden and synaptic atrophy in a mouse model of Alzheimer's disease. PLoS One 12:e0182896.

Viswanathan, J., P. Mäkinen, S. Helisalmi, A. Haapasalo, H. Soininen, and M. Hiltunen. 2009. An association study between granulin gene polymorphisms and Alzheimer's disease in Finnish population. 150B:747-750.

Wang, C., M.A. Telpoukhovskaia, B.A. Bahr, X. Chen, and L. Gan. 2018. Endo-lysosomal dysfunction: a converging mechanism in neurodegenerative diseases. Curr Opin Neurobiol 48:52-58.

Ward, M.E., R. Chen, H.Y. Huang, C. Ludwig, M. Telpoukhovskaia, A. Taubes, H. Boudin, S.S. Minami, M. Reichert, P. Albrecht, J.M. Gelfand, A. Cruz-Herranz, C. Cordano, M.V. Alavi, S. Leslie, W.W. 
Seeley, B.L. Miller, E. Bigio, M.M. Mesulam, M.S. Bogyo, I.R. Mackenzie, J.F. Staropoli, S.L. Cotman, E.J. Huang, L. Gan, and A.J. Green. 2017. Individuals with progranulin haploinsufficiency exhibit features of neuronal ceroid lipofuscinosis. Sci Transl Med 9:eaah5642.

Weber, K., and J.D. Schilling. 2014. Lysosomes integrate metabolic-inflammatory cross-talk in primary macrophage inflammasome activation. The Journal of biological chemistry 289:9158-9171.

Xu, H.M., L. Tan, Y. Wan, M.S. Tan, W. Zhang, Z.J. Zheng, L.L. Kong, Z.X. Wang, T. Jiang, L. Tan, and J.T. Yu. 2017. PGRN Is Associated with Late-Onset Alzheimer's Disease: a Case-Control Replication Study and Meta-analysis. Mol Neurobiol 54:1187-1195.

Yan, R., P. Han, H. Miao, P. Greengard, and H. Xu. 2001. The transmembrane domain of the Alzheimer's beta-secretase (BACE1) determines its late Golgi localization and access to beta -amyloid precursor protein (APP) substrate. The Journal of biological chemistry 276:36788-36796.

Yin, F., R. Banerjee, B. Thomas, P. Zhou, L. Qian, T. Jia, X. Ma, Y. Ma, C. Iadecola, M.F. Beal, C. Nathan, and A. Ding. 2010. Exaggerated inflammation, impaired host defense, and neuropathology in progranulin-deficient mice. J Exp Med 207:117-128.

Zerbino, D.R., P. Achuthan, W. Akanni, M.R. Amode, D. Barrell, J. Bhai, K. Billis, C. Cummins, A. Gall, C.G. Giron, L. Gil, L. Gordon, L. Haggerty, E. Haskell, T. Hourlier, O.G. Izuogu, S.H. Janacek, T. Juettemann, J.K. To, M.R. Laird, I. Lavidas, Z. Liu, J.E. Loveland, T. Maurel, W. McLaren, B. Moore, J. Mudge, D.N. Murphy, V. Newman, M. Nuhn, D. Ogeh, C.K. Ong, A. Parker, M. Patricio, H.S. Riat, H. Schuilenburg, D. Sheppard, H. Sparrow, K. Taylor, A. Thormann, A. Vullo, B. Walts, A. Zadissa, A. Frankish, S.E. Hunt, M. Kostadima, N. Langridge, F.J. Martin, M. Muffato, E. Perry, M. Ruffier, D.M. Staines, S.J. Trevanion, B.L. Aken, F. Cunningham, A. Yates, and P. Flicek. 2018. Ensembl 2018. Nucleic Acids Res 46:D754-D761.

Zhou, X., D.H. Paushter, T. Feng, C.M. Pardon, C.S. Mendoza, and F. Hu. 2017a. Regulation of cathepsin D activity by the FTLD protein progranulin. Acta Neuropathol 134:151-153.

Zhou, X., D.H. Paushter, T. Feng, L. Sun, T. Reinheckel, and F. Hu. 2017b. Lysosomal processing of progranulin. Mol Neurodegener 12:62.

Zhou, X., D.H. Paushter, M.D. Pagan, D. Kim, M. Nunez Santos, R.L. Lieberman, H.S. Overkleeft, Y. Sun, M.B. Smolka, and F. Hu. 2019. Progranulin deficiency leads to reduced glucocerebrosidase activity. PLoS One 14:e0212382.

Zhou, X., L. Sun, F. Bastos de Oliveira, X. Qi, W.J. Brown, M.B. Smolka, Y. Sun, and F. Hu. 2015. Prosaposin facilitates sortilin-independent lysosomal trafficking of progranulin. J Cell Biol 210:9911002.

Zhou, X., L. Sun, O. Bracko, J.W. Choi, Y. Jia, A.L. Nana, O.A. Brady, J.C.C. Hernandez, N. Nishimura, W.W. Seeley, and F. Hu. 2017c. Impaired prosaposin lysosomal trafficking in frontotemporal lobar degeneration due to progranulin mutations. Nat Commun 8:15277.

Zhou, Y., W.M. Song, P.S. Andhey, A. Swain, T. Levy, K.R. Miller, P.L. Poliani, M. Cominelli, S. Grover, S. Gilfillan, M. Cella, T.K. Ulland, K. Zaitsev, A. Miyashita, T. Ikeuchi, M. Sainouchi, A. Kakita, D.A. Bennett, J.A. Schneider, M.R. Nichols, S.A. Beausoleil, J.D. Ulrich, D.M. Holtzman, M.N. Artyomov, and M. Colonna. 2020. Human and mouse single-nucleus transcriptomics reveal TREM2-dependent and TREM2-independent cellular responses in Alzheimer's disease. Nature Medicine 26:131-142.

\section{Figure Legends}

Figure 1: PGRN deficiency affects A $\beta$ levels in the 4.5-month-old 5XFAD mice in a sex specific manner. (A) Representative images of Thioflavin $\mathrm{S}$ (ThioS) staining and $\mathrm{A} \beta$ (6E10) immunostaining of subiculum and frontal cortex of 4.5-month-old male and female 5XFAD, 5XFAD $\mathrm{Gr}^{-/-}$mice. Scale bar=100 $\mu \mathrm{m}$. (B) Quantification of 
ThioS-positive and A $\beta$ immunoreactive area, number and intensity in subiculum and cortex of 4.5-month-old male and female 5XFAD, 5XFAD $\mathrm{Grn}^{-/-}$mice. Mean \pm SEM, $\mathrm{n}=5-6$, student's $t$ test, **, $\mathrm{p}<0.01$.

Figure 2: PGRN deficiency decreases the levels of $A \beta$ and human APP in the 4.5-month-old male 5XFAD mice. (A) $A \beta 40$ and $A \beta 42$ levels in the RIPA-soluble fraction (soluble) and guanidine-soluble fraction (insoluble) from 4.5-month-old male and female 5XFAD, 5XFAD $\mathrm{Gr}^{-/-}$mice were measured by ELISA. Mean \pm SEM, $\mathrm{n}=3-6$, student's $t$ test, ${ }^{* *}, \mathrm{p}<0.01$. (B and C) Western blot analysis of APP, Presenilin1(PS1) and BACE1 in the soluble fractions of cortical lysates from 4.5-month-old male and female 5XFAD, 5XFAD $\mathrm{Gr}^{-/}$mice. 6E10 antibody was used to specifically detect human APP and a rabbit polyclonal antibody was used to detect mouse APP. The proteins levels were quantified and normalized to GAPDH. Mean \pm SEM, $\mathrm{n}=5$, student's $t$ test, **, $\mathrm{p}<0.01$.

Figure 3: The effect of PGRN on A $\beta$ plaque in the 10-month-old 5XFAD mice. (A) Quantification of ThioSpositive and $A \beta$ immunoreactive area, number and intensity in subiculum and cortex of 10-month-old male and female 5XFAD, 5XFAD Grn ${ }^{-/-}$mice. Mean \pm SEM, $\mathrm{n}=5$, student's $t$ test, *, p<0.05, **, p<0.01. (B) A $\beta 40$ and A 342 levels in the RIPA-soluble fraction (soluble) and guanidine-soluble fraction (insoluble) from 10-month-old male and female 5XFAD, 5XFAD $\mathrm{Gr}^{-/}$mice were measured by ELISA. Mean \pm SEM, $\mathrm{n}=4-5$, student's $t$ test.

Figure 4: PGRN deficiency leads to an increase in the levels of Galectin-3 in the microglia surrounding the Aß plaque in the 5XFAD mice. (A-D) Western blot analysis of Galectin-3 in the cortical lysates from 4.5-monthold (A and B) and 10-month-old (C and D) WT, $\mathrm{Gr}^{-/}$, 5XFAD and 5XFAD $\mathrm{Gr}^{-/-}$mice. Mean \pm SEM; n=3, oneway ANOVA, **, p<0.01. Female 4.5-month-old 5XFAD and 5XFAD $\mathrm{Gr}^{-/-}$mice were used. For other groups, mice of mixed sex were used. (E) Immunostaining of IBA1, Galectin-3, and ThioS in the brain sections from 4.5month-old female 5XFAD and 5XFAD $\mathrm{Grn}^{-/}$mice. Representative images from the cortex region were shown. Similar phenotypes were observed in the male 5XFAD and 5XFAD $\mathrm{Gr}^{-/-}$mice, although with reduced numbers of plaques. Scale bar=100 $\mu \mathrm{m}$. (F) Quantification of Galectin-3 levels in IBA1 positive microglia in the cortex region for experiment in (E). Mean \pm SEM; $\mathrm{n}=3-6$, student's $t$ test, **, $\mathrm{p}<0.01$.

Figure 5: PGRN deficiency leads to an increase in the levels of microglial GPNMB in the 5XFAD mice. (A and D) Western blot analysis of GPNMB in the cortical lysates from 4.5-month-old (A and B) and 10-month-old (C and D) WT, $\mathrm{Grn}^{-/}$, 5XFAD and 5XFAD $\mathrm{Grn}^{-/-}$mice. Female 4.5-month-old 5XFAD and 5XFAD $\mathrm{Grn}^{-/-}$mice were used. For other groups, mice of mixed sex were used. Mean \pm SEM; $n=3$, one-way ANOVA, *, p<0.05, **, $p<0.01$. The same samples were used for experiments in Figure 4 (A-D) and Figure 5 (A-D) and the experiments were performed simultaneously. (E) Immunostaining of IBA1, GPNMB, and A $\beta$ (6E10) in the brain sections from 4.5month-old female 5XFAD and 5XFAD $\mathrm{Gr}^{-/-}$mice. Representative images from the cortex region were shown. Scale bar=100 $\mu \mathrm{m}$. Representative high-resolution confocal images were shown in inset. Scale bar=10 $\mu \mathrm{m}$. (F) Quantification of GPNMB levels in IBA1 positive microglia in the cortex region for experiment in (E). Mean \pm 
SEM; $\mathrm{n}=6$, student's $t$ test, **, $\mathrm{p}<0.01$. (G) Representative confocal high-resolution images of GPNMB and Galectin-3 co-staining in the brain sections from 4.5-month-old 5XFAD and 5XFAD $\mathrm{Grn}^{-/}$mice. Scale bar=10 $\mu \mathrm{m}$.

Figure 6: PGRN deficiency leads to increase microglial activation around the A $\beta$ plaques in the 5XFAD mice. (A) Representative confocal high-resolution images of IBA1, TREM2, and ThioS co-staining in the brain sections from 4.5-month-old female 5XFAD and 5XFAD $\mathrm{Gr}^{-/-}$mice. Scale bar=50 $\mu \mathrm{m}$. (B) Quantification of TREM2 signals near $A \beta$ plaques for experiment in (A). Mean $\pm \mathrm{SEM} ; \mathrm{n}=3$, student's $t$ test, *, $\mathrm{p}<0.05$. (C) Brain sections from 10-month-old WT, $\mathrm{Grn}^{-/}$, 5XFAD and 5XFAD $\mathrm{Grn}^{-/-}$mice were stained with anti-A $\beta$ (6E10) and anti-IBA1 or anti-CD68 antibodies as indicated. Representative images from the cortex region were shown. Scale bar=100 $\mu \mathrm{m}$. (D) Quantification of IBA1 and CD68 signals in the cortex region for experiment in (C). Mixed female and male mice were used for the study. Mean \pm SEM; $n=5$, one-way ANOVA, *, $<<0.05$, **, $p<0.01$. (E) Quantification of IBA1 and CD68 signals near the A $\beta$ plaque in the cortex region for experiment in $(C)$. Mean $\pm \mathrm{SEM}$; $\mathrm{n}=5$, student's $t$ test, $* *, \mathrm{p}<0.01$.

Figure 7: PGRN deficiency leads to an increase in the levels of lysosome proteins in the 5XFAD mice. (A) Cortical lysates from 10-month-old WT, $\mathrm{Gr}^{-/}$, 5XFAD and 5XFAD $\mathrm{Gr}^{-/}$mice were subjected to Western blot with anti-cathepsin B (CathB), CathD, CathL, LAMP1, LAMP2, PGRN and GAPDH antibodies. Mixed female and male mice were used for the study. (B) Quantifications of lysosome proteins levels for experiment in (A). Mean \pm SEM; $\mathrm{n}=3$, one-way ANOVA, * $, \mathrm{p}<0.05, * *, \mathrm{p}<0.01$.

Figure 8: PGRN deficiency leads to an upregulation of cathepsin $B$ in the microglia near $A \beta$ plaque in the 5XFAD mice. (A) Immunostaining of IBA1, cathepsin B (CathB), and A $\beta$ (6E10) in the brain sections from 4.5month-old female 5XFAD and 5XFAD $\mathrm{Grn}^{-/-}$mice. Representative images from the cortex region were shown. Scale bar=100 $\mu \mathrm{m}$. (B) Quantification of CathB levels near A $\beta$ plaque for experiment in (A). Mean $\pm S E M$; $n=3$, student's $t$ test, **, p<0.01. (C) Representative confocal high-resolution images of IBA1, CathB, and A $\beta$ (6E10) costaining in the brain sections from 4.5-month-old 5XFAD and 5XFAD $\mathrm{Grn}^{-/-}$mice. Scale bar=10 $\mu \mathrm{m}$. (D) Representative confocal high-resolution images of Galectin-3, CathB, and IBA1 co-staining in the brain sections from 4.5-month-old 5XFAD and 5XFAD $\mathrm{Gr}^{-/-}$mice. Scale bar=10 $\mu \mathrm{m}$.

Figure 9: PGRN deficiency results in increased cathepsin D expression and TFE3 nuclear translocation in the microglia near the A $\beta$ plaque in the 5XFAD mice. (A) Immunostaining of CD68, CathD, and A $\beta$ (6E10) in the brain sections from 4.5-month-old female 5XFAD and 5XFAD $\mathrm{Grn}^{-/-}$mice. Representative images from the cortex region were shown. Similar phenotypes were seen in the male 5XFAD and 5XFAD $\mathrm{Grn}^{-/-}$mice, although with reduced numbers of plaques. Scale bar $=100 \mu \mathrm{m}$. (B) Quantification of CathD levels near A $\beta$ plaque for experiment in (A). Mean \pm SEM; $n=3$, student's $t$ test, **, $p<0.01$. (C) Representative confocal high-resolution images of CD68, CathD, and $\mathrm{A} \beta(6 \mathrm{E} 10)$ co-staining in the brain sections from 4.5-month-old 5XFAD and 5XFAD $\mathrm{Grn}^{-/-}$mice. Scale 
bar=10 $\mu \mathrm{m}$. (D) Immunostaining of IBA1, TFE3 in the brain sections from 4.5-month-old 5XFAD and 5XFAD $\mathrm{Grn}^{-/-}$mice. Representative images from the cortex region were shown. Scale bar=10 $\mu \mathrm{m}$. (E) Nuclear signals of TFE3 in IBA1 positive microglia were quantified for experiment in (D). Mean \pm SEM; $n=3$, student's $t$ test, *, $\mathrm{p}<0.05$.

Figure 10: PGRN deficient macrophage and microglia are more prone to lysosomal membrane leakage. (A) Representative confocal images of Raw 264.7 cells treated with $500 \mu \mathrm{M}$ LLOME for $2 \mathrm{~h}$ and stained with rat antiLAMP1 (red) and mouse anti-Galectin-3 antibodies (green). Scale bar=10 $\mu \mathrm{m}$. (B) Manders' coefficients for colocalization of Galectin-3 with LAMP1 for experiment in (A). Mean \pm SEM; $n=6$, student's $t$ test, **, $<<0.01$. (C) Representative confocal images of primary microglia treated with $500 \mu \mathrm{M}$ LLOME for $2 \mathrm{~h}$ and stained with rat antiLAMP1 (red) and mouse anti-Galectin-3 antibodies (green). Scale bar=10 $\mu \mathrm{m}$. (D) Manders' coefficients for colocalization of Galectin-3 with LAMP1 for experiment in (C). Mean \pm SEM; $n=6$, student's $t$ test, **, $<<0.01$.

Figure 11: PGRN deficient microglia are more susceptible to lysosome abnormalities in response to A $\beta$ fibrils. (A) Representative confocal images of primary microglia treated with $10 \mu \mathrm{M} \mathrm{A} \beta$ fibrils for $24 \mathrm{~h}$ and stained with anti-Galectin-3, anti-LAMP1 and anti-CathD antibodies as indicated. Scale bar=10 $\mu \mathrm{m}$. (B) Quantification of Galectin-3 and CathD levels per cell for experiment in (A). Mean \pm SEM; $n=3$, two-way ANOVA, *, p<0.05, **, $\mathrm{p}<0.01$. Quantification of Galectin-3 and CathD fold changes $\left(\mathrm{Grn}^{-/} / \mathrm{WT}\right)$ for experiment in (A): student's $t$ test, *, $\mathrm{p}<0.05$.

Figure 12: A $\beta$ treatment leads to enhanced inflammation and lysosomal responses in PGRN deficient microglia. (A) Representative confocal images of primary microglia treated with $10 \mu \mathrm{M} A \beta$ fibrils for $24 \mathrm{~h}$ and stained with anti-GPNMB and anti-LAMP1 antibodies. Scale bar=10 $\mu \mathrm{m}$. (B) Quantification of GPNMB levels per cell for experiment in (A). Mean \pm SEM; $n=3$, two-way ANOVA, **, $p<0.01$. Quantification of GPNMB fold changes $\left(\mathrm{Grn}^{-/} / \mathrm{WT}\right)$ for experiment in (A): student's $t$ test, ${ }^{*}, \mathrm{p}<0.05$. (C) Immunostaining of TFE3 in WT and Grn-/- primary microglia treated with and without $A \beta$ fibrils. Scale bar $=10 \mu \mathrm{m}$. (D) The ratio of nuclear to cytoplasmic TFE3 signals were quantified for experiment in (C). Mean \pm SEM; $n=3$, two-way ANOVA, **, $p<0.01$. (E) Raw 264.7 cells were either untreated or treated with $10 \mu \mathrm{M} \mathrm{A} \beta$ fibrils for $24 \mathrm{~h}$ and TNF- $\alpha$ levels in the medium were quantified. $n=4$, two-way ANOVA, **, $p<0.01$. (F) Primary microglia were either untreated or treated with 10 $\mu \mathrm{M} \mathrm{A} \beta$ fibrils for $24 \mathrm{~h}$ and TNF- $\alpha$ levels in the medium were quantified. $\mathrm{n}=5$, two-way ANOVA, $* *, p<0.01$. 


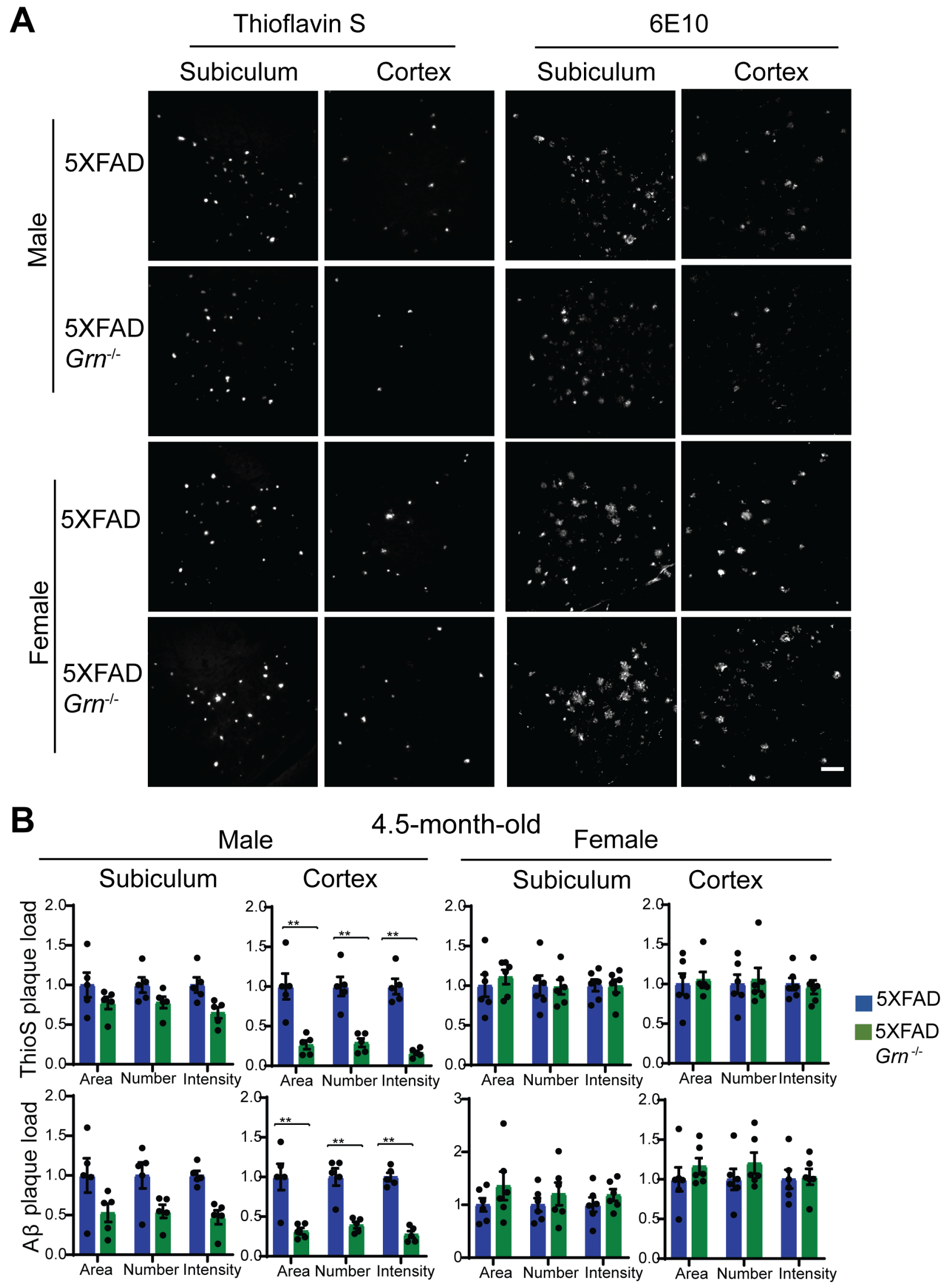

Fig. 1 
A

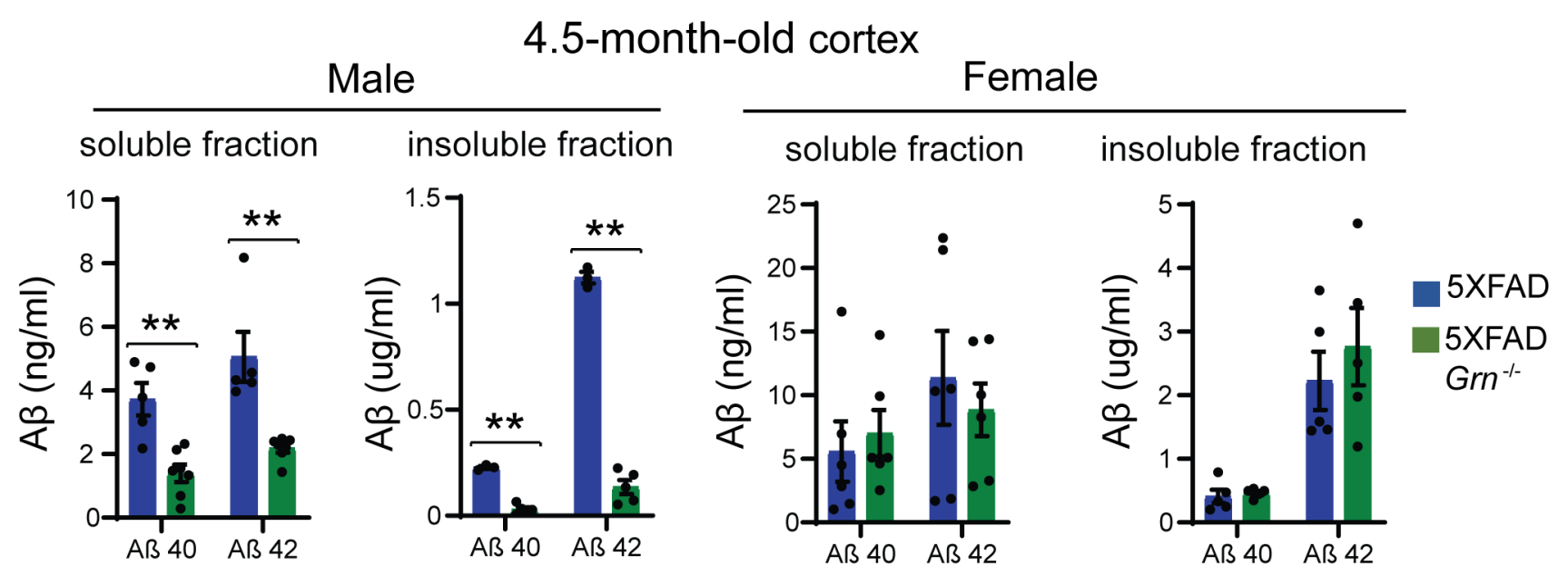

B

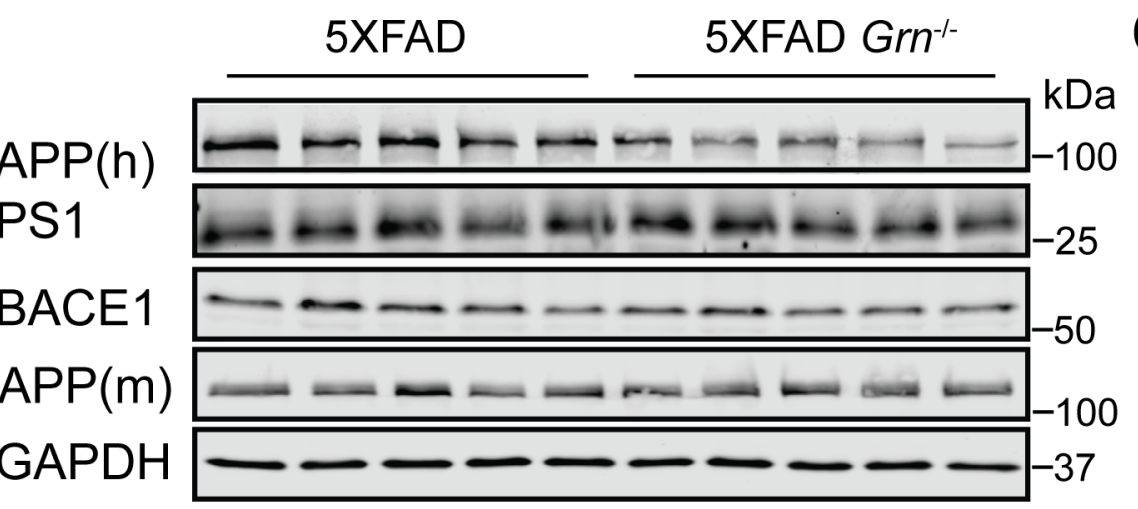

C

$\frac{0}{\frac{0}{2}}$

APP(h) PS1

BACE1 $\operatorname{APP}(\mathrm{m})$

GAPDH
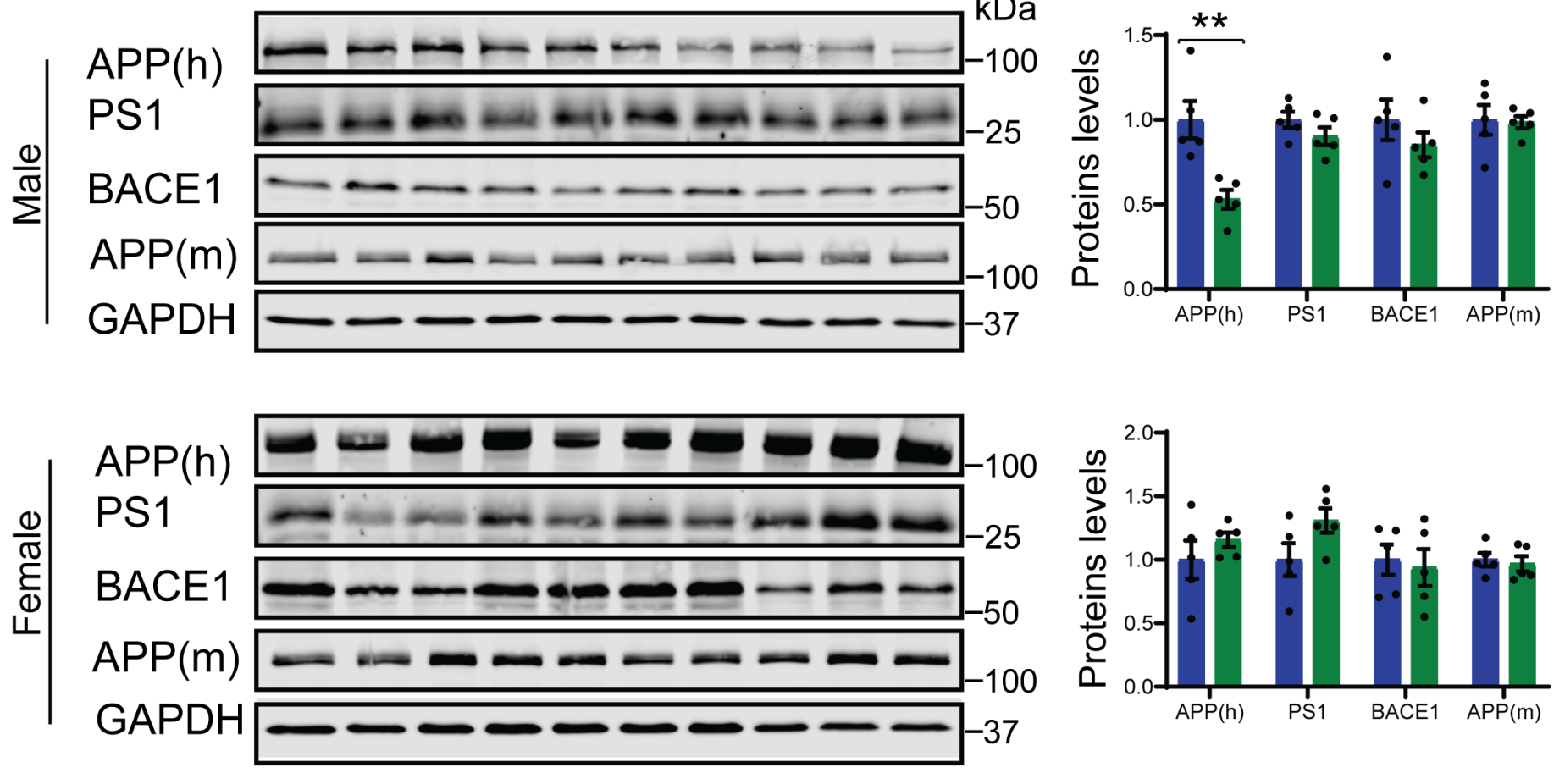

Fig. 2

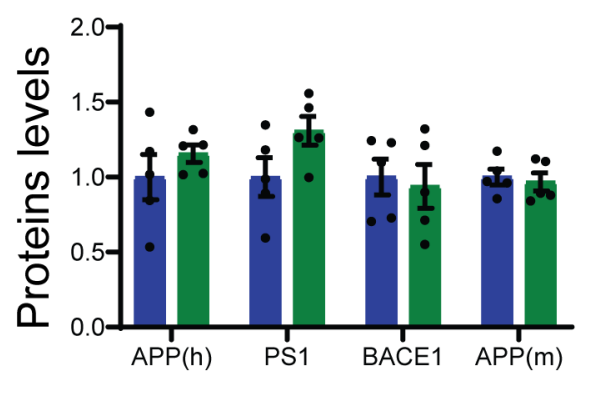




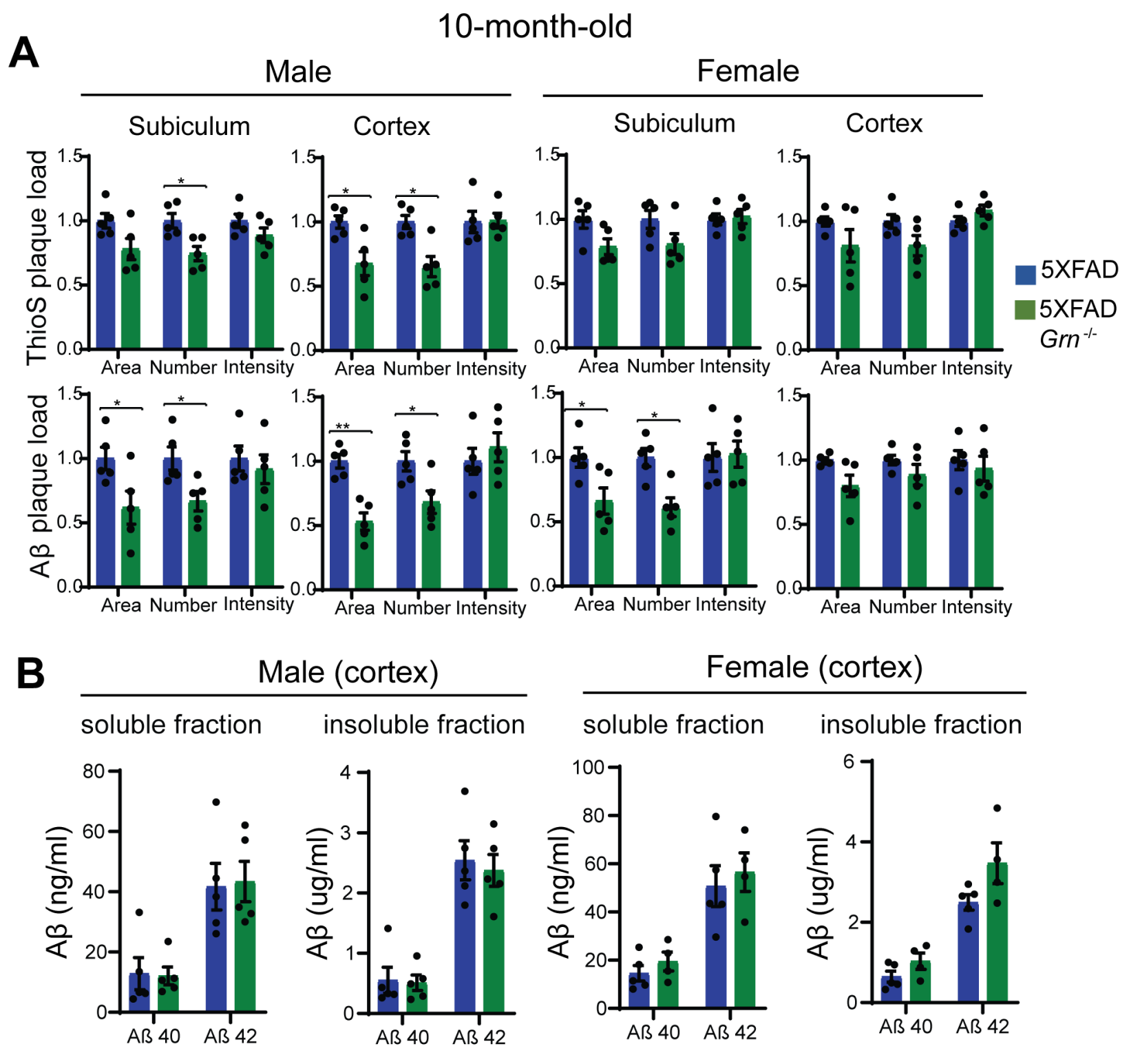

Fig. 3 


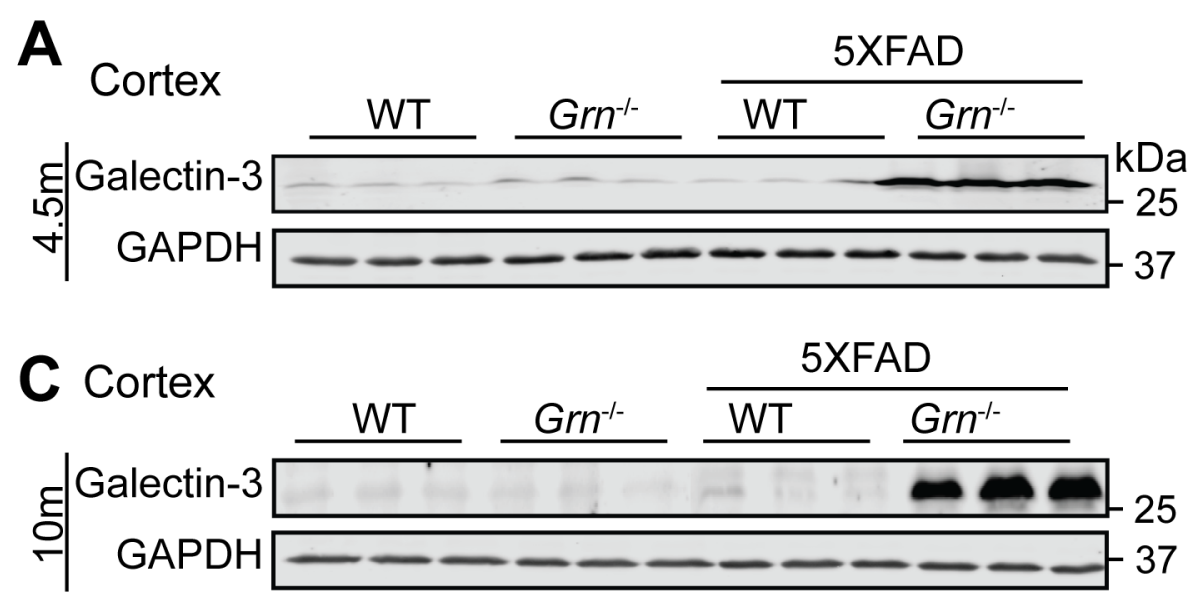

B

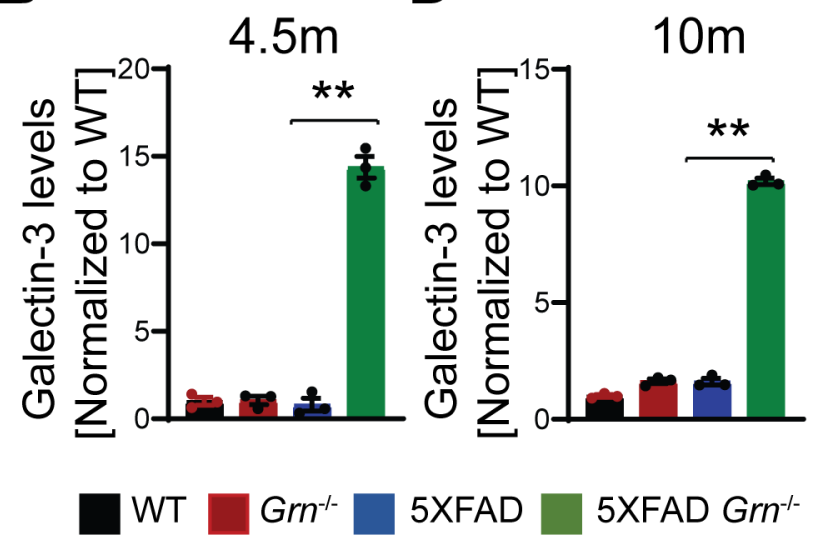

E

Cortex

IBA1

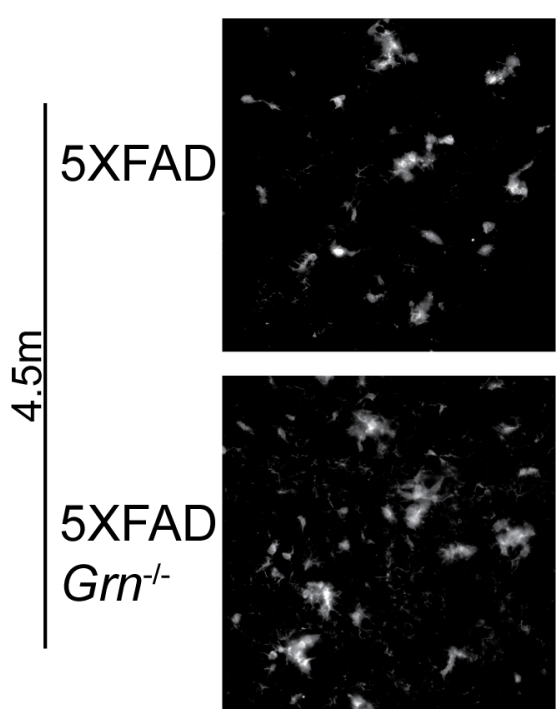

हกำ
Galectin-3
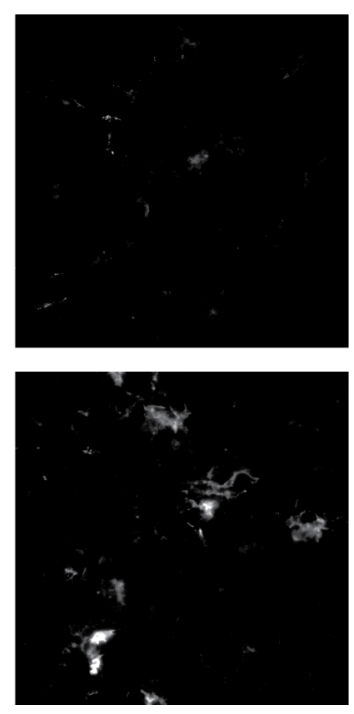

Thio-S
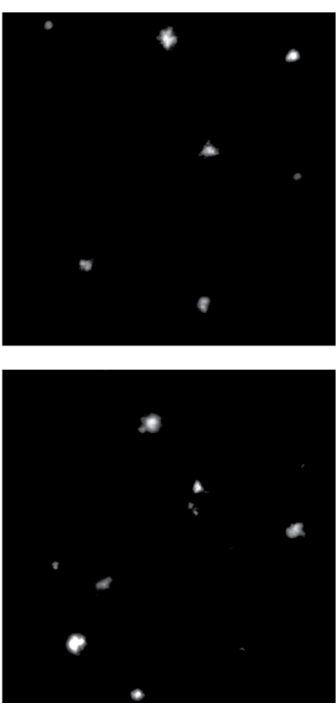

Merge
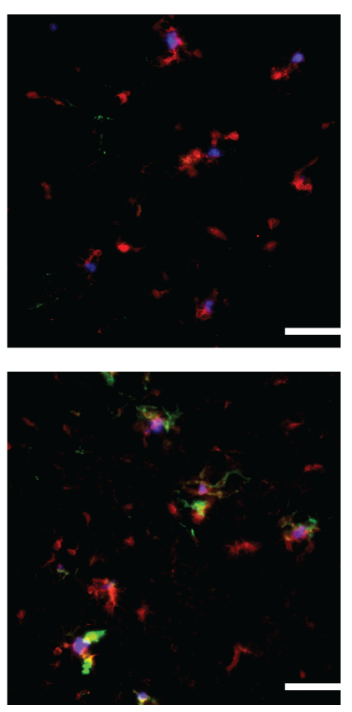

$\mathbf{F}$
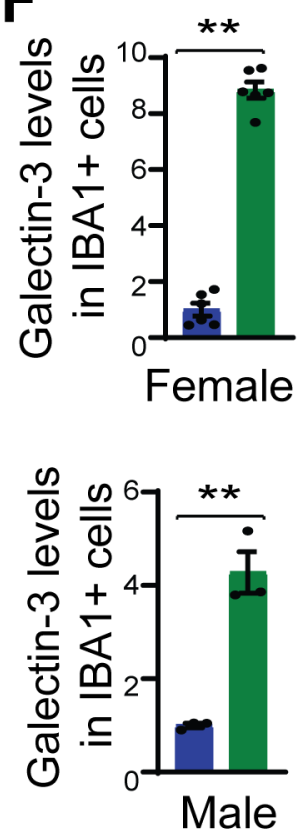

Fig 4 

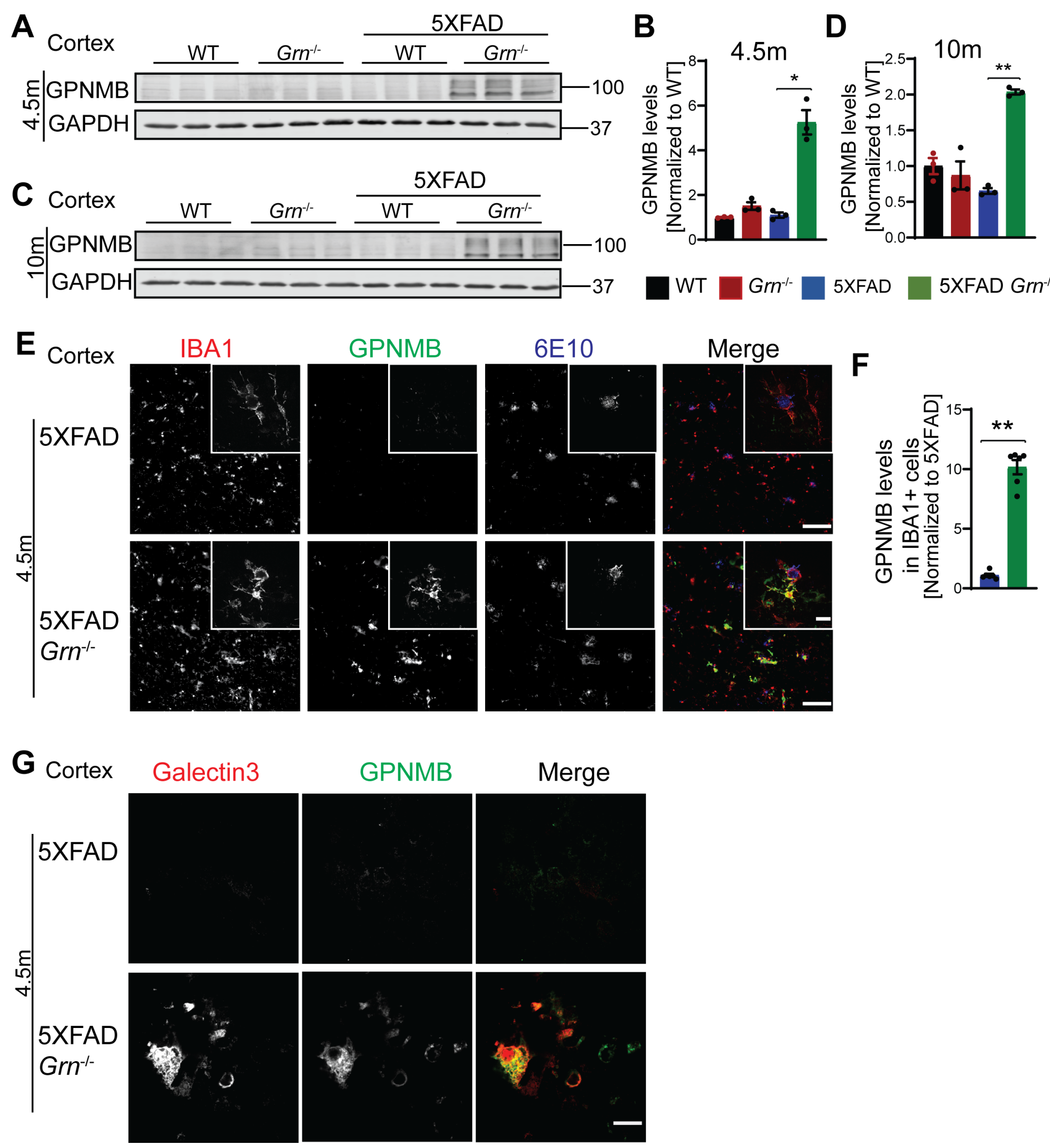

Fig 5 
A

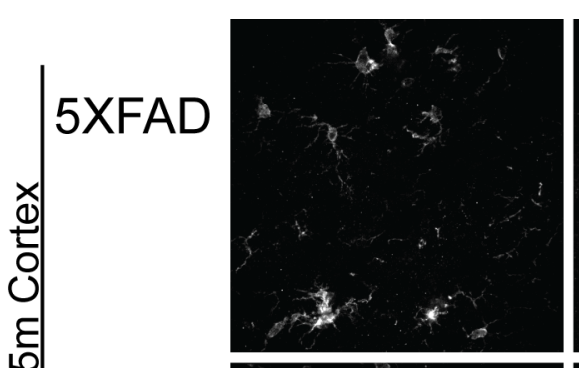

\section{TREM2}
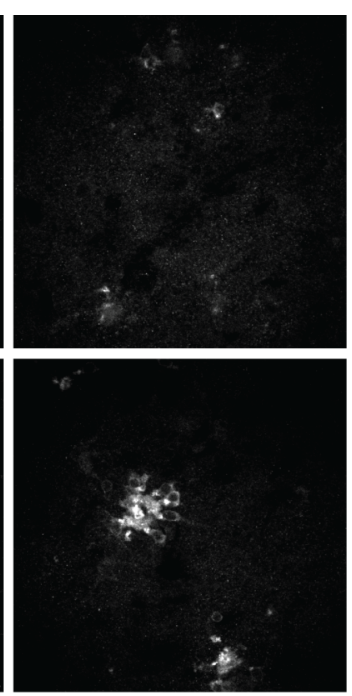

C

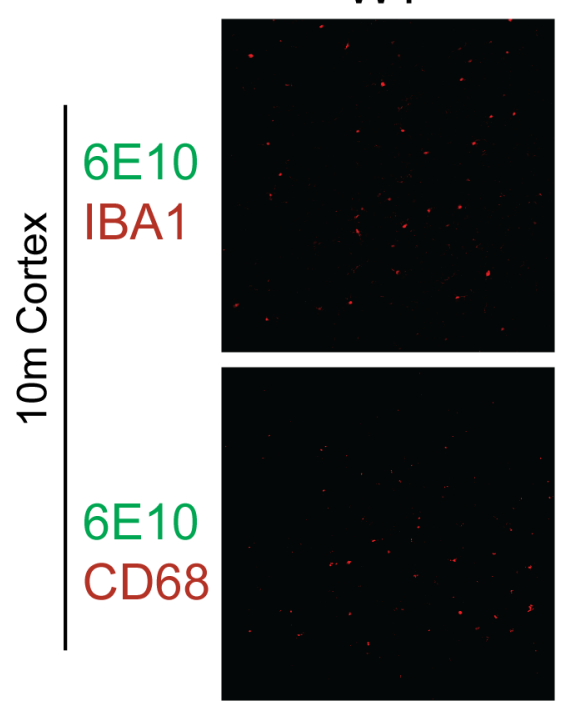

B

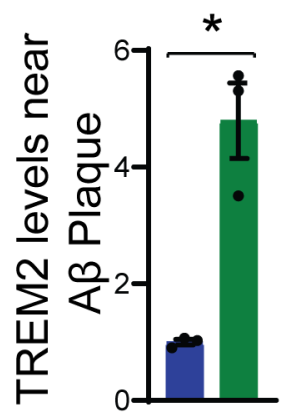

Thio-S
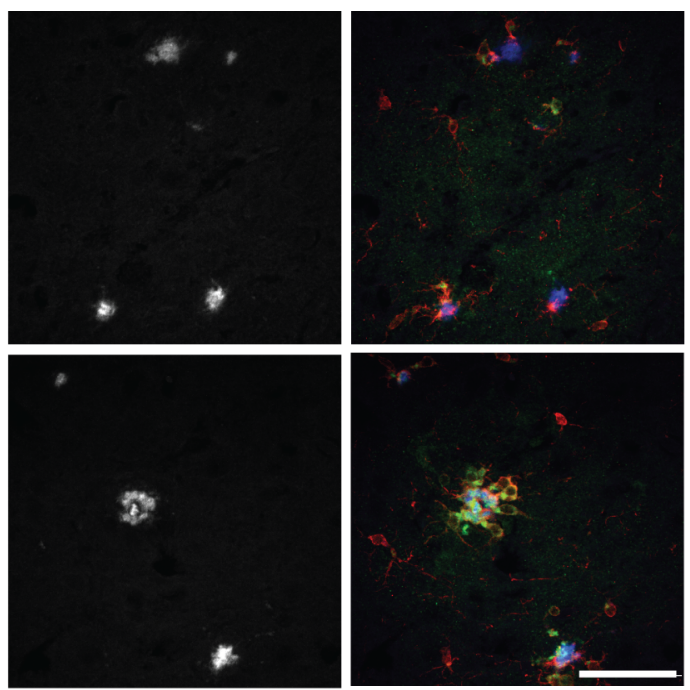

5XFAD
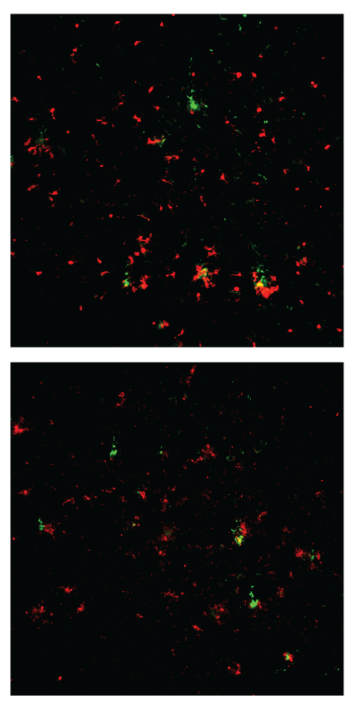

$\mathbf{E}$

\section{XFAD Grn ${ }^{-1-}$}
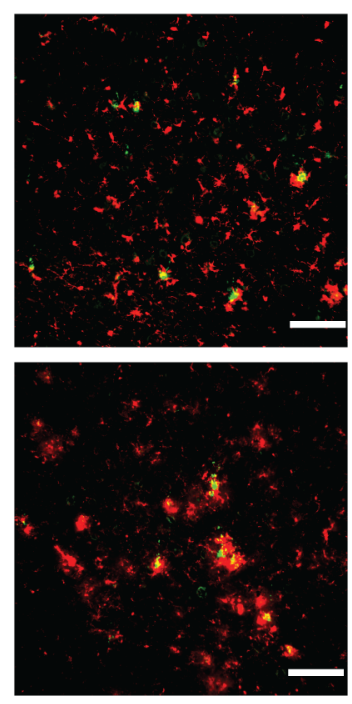

D
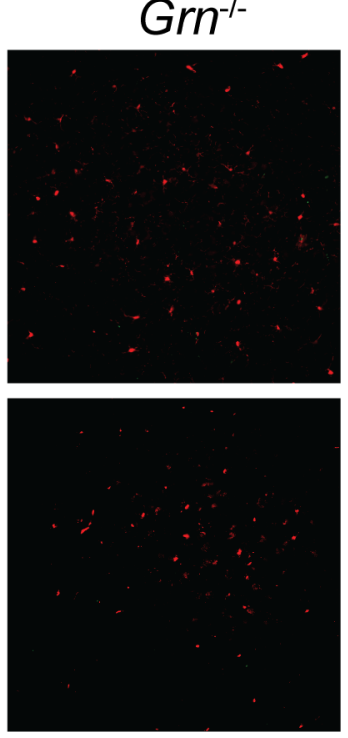

$\square$ WT $\square \mathrm{Grn}^{-1} \square$ 5XFAD 5XFAD $\mathrm{Gr}^{-1-}$
5XFAD $\square$ 5XFAD $\mathrm{Gr}^{-1-}$
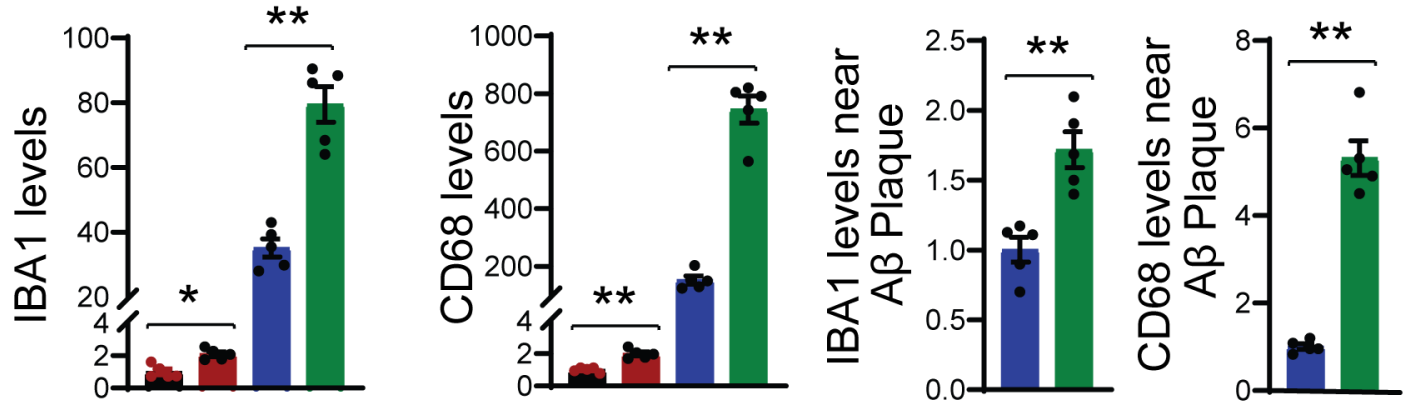

Fig 6 


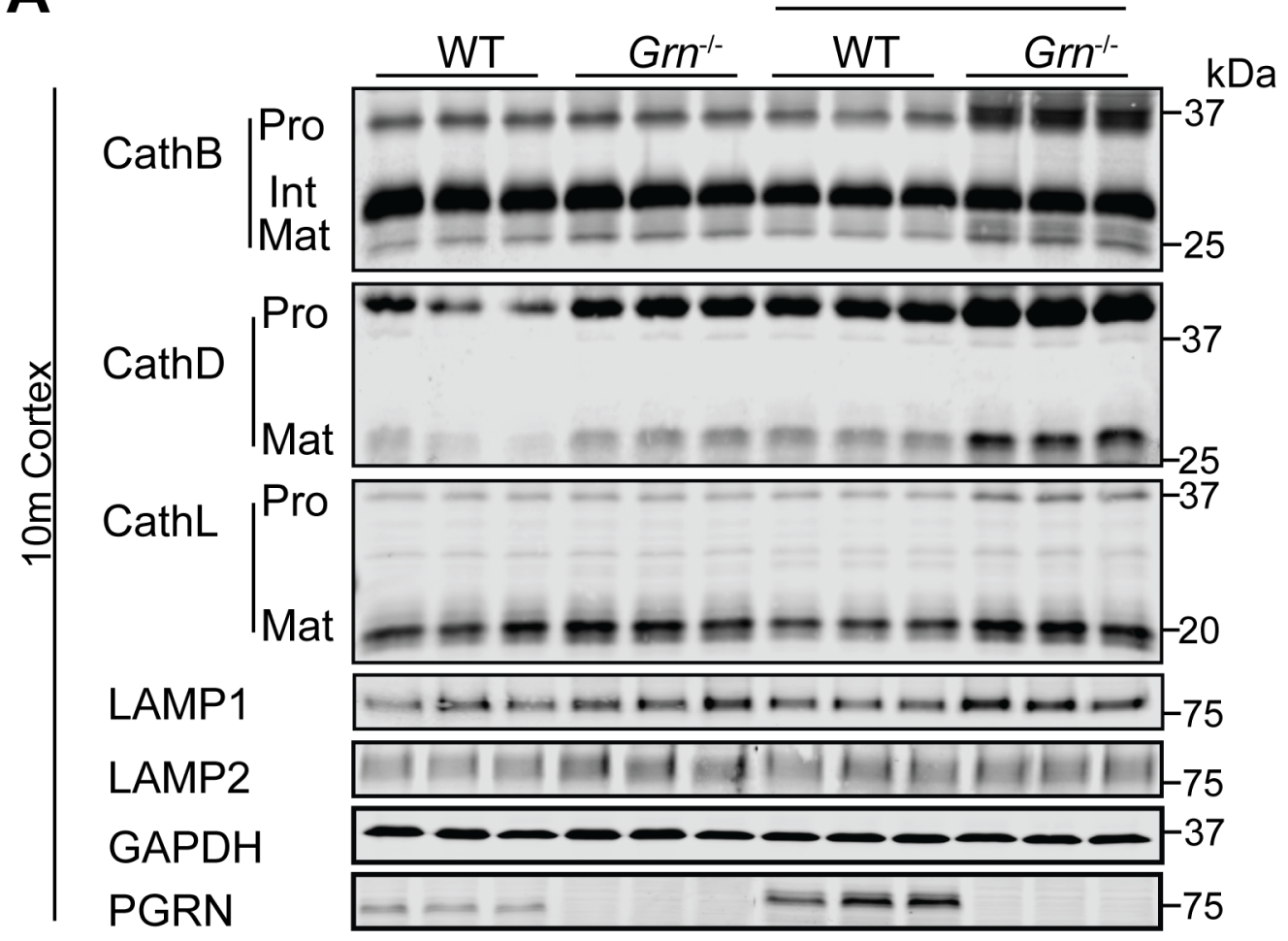

B

$\square$ WT $\square \mathrm{Gr}^{-1-} \square$ 5XFAD $\square$ 5XFAD $\mathrm{Gr}^{-1-}$
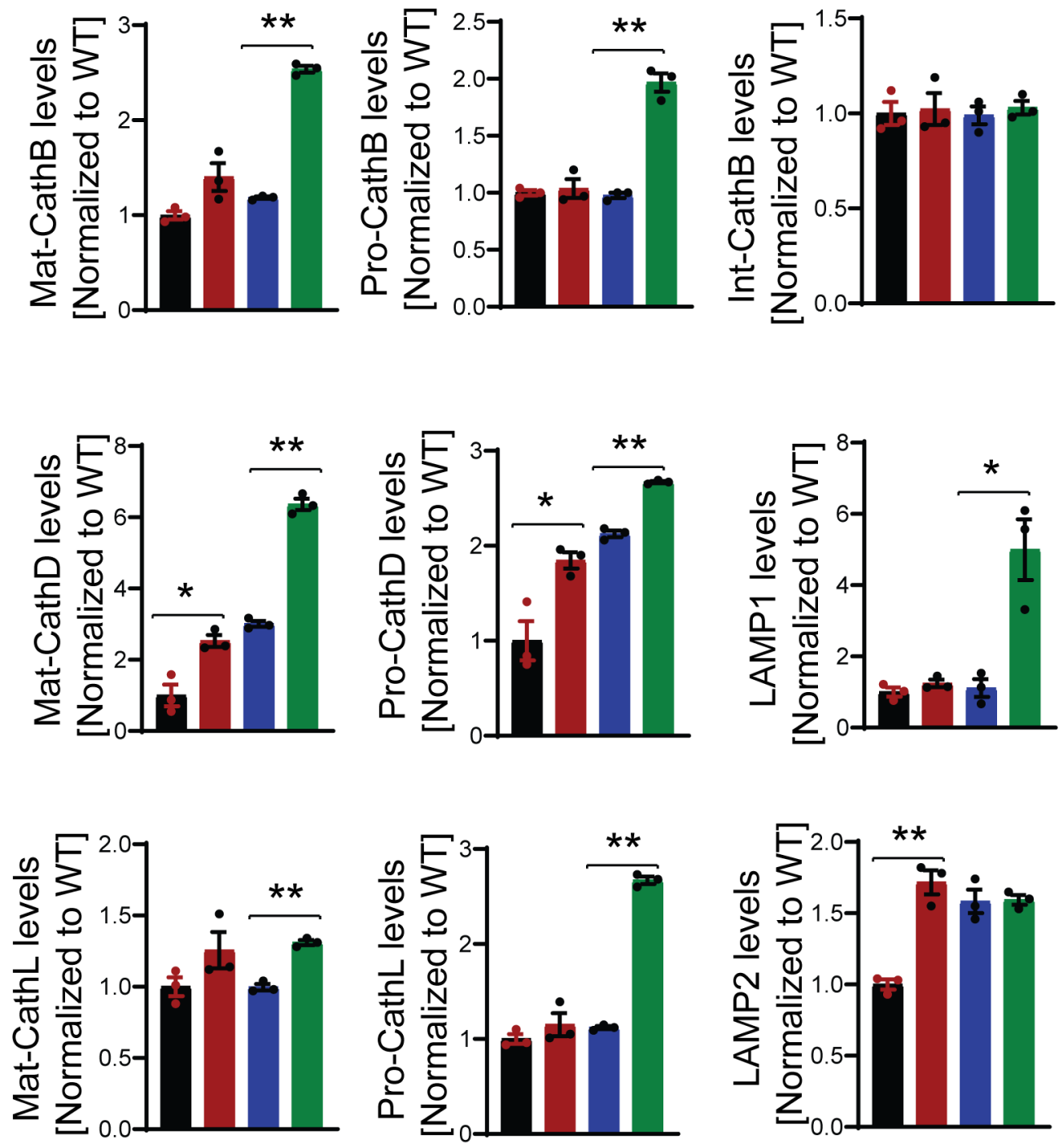

Fig 7 
A

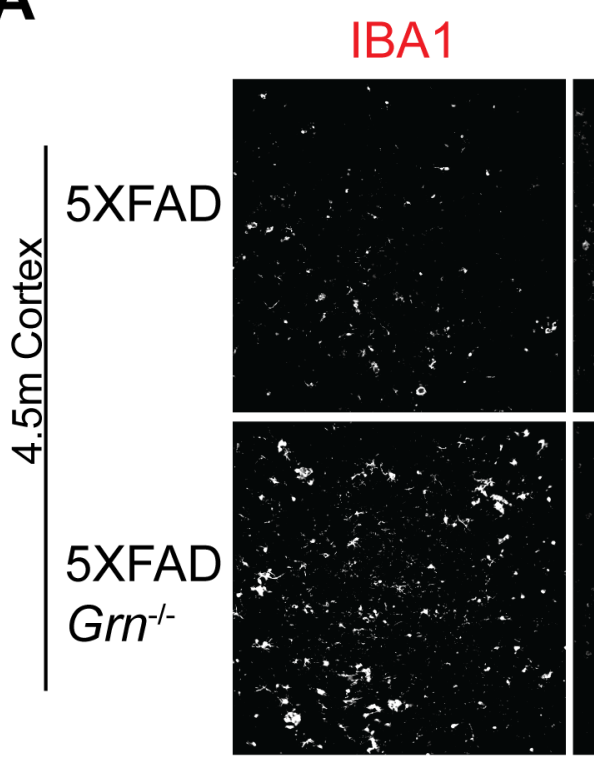

C

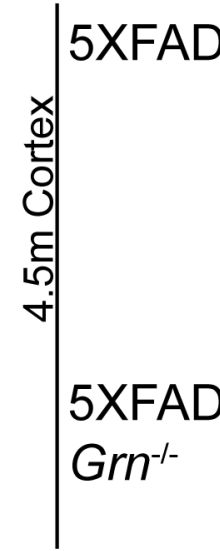

D

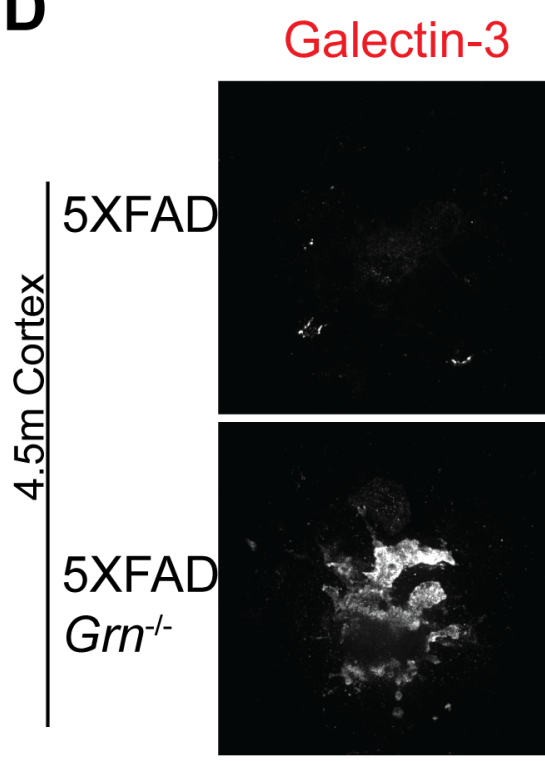

IBA1

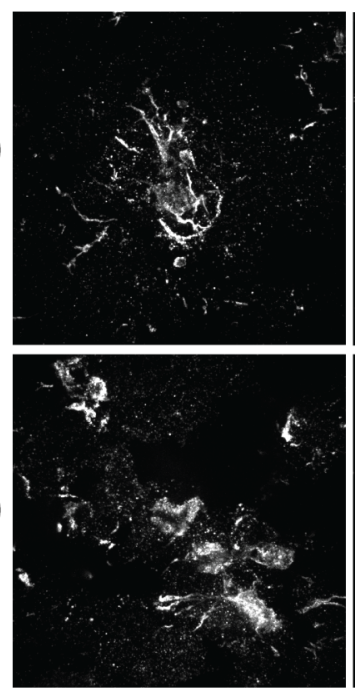

CathB
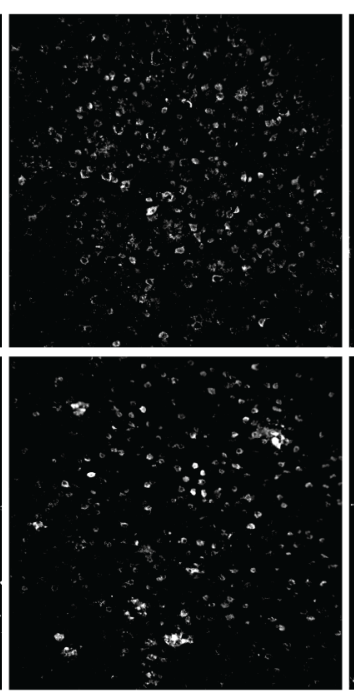

CathB

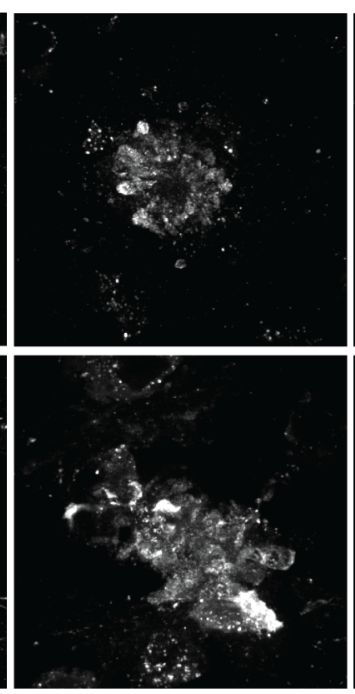

CathB

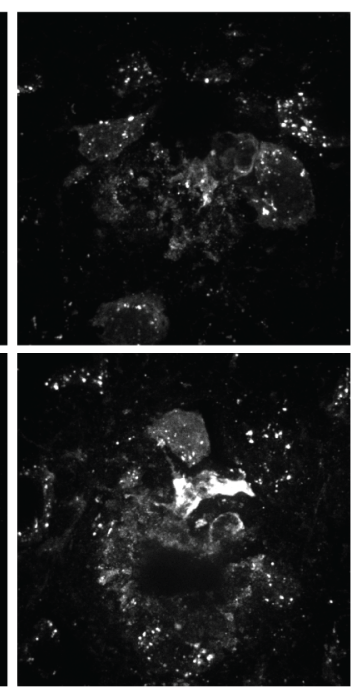

6E10

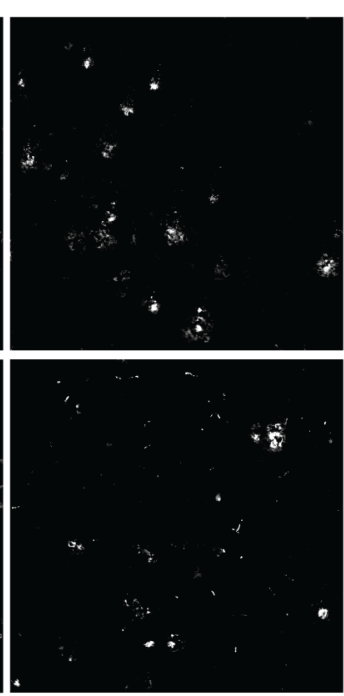

$6 \mathrm{E} 10$

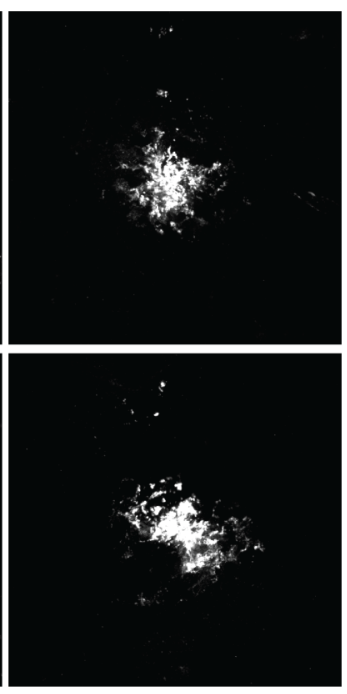

IBA1

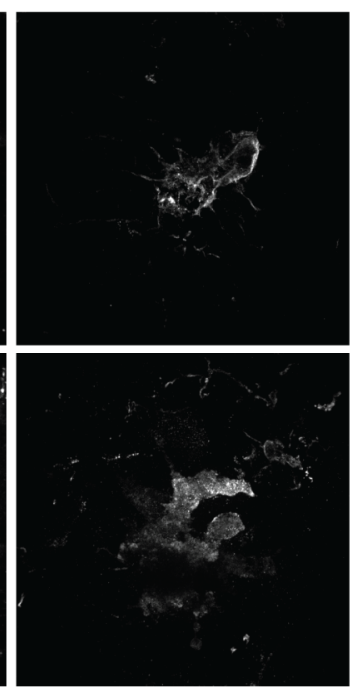

B

Merge
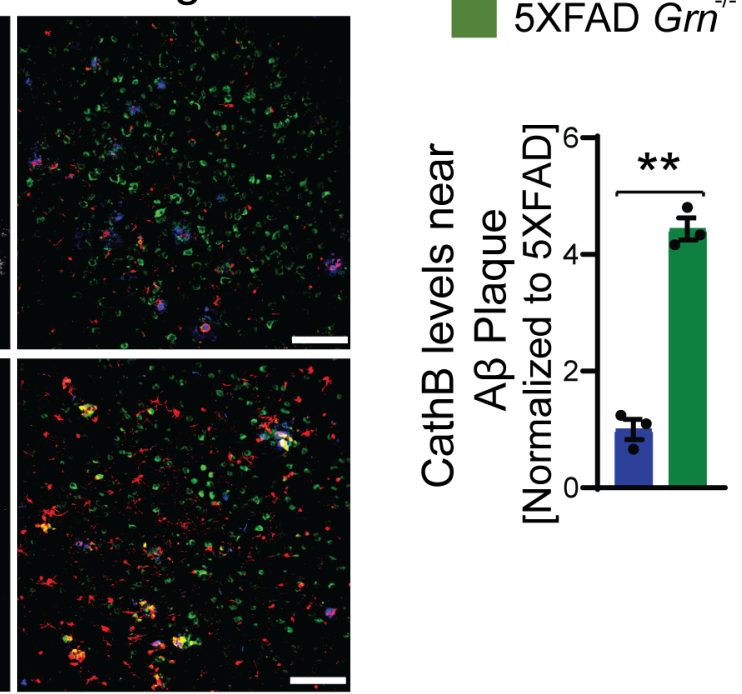

\section{Fig 8}


A
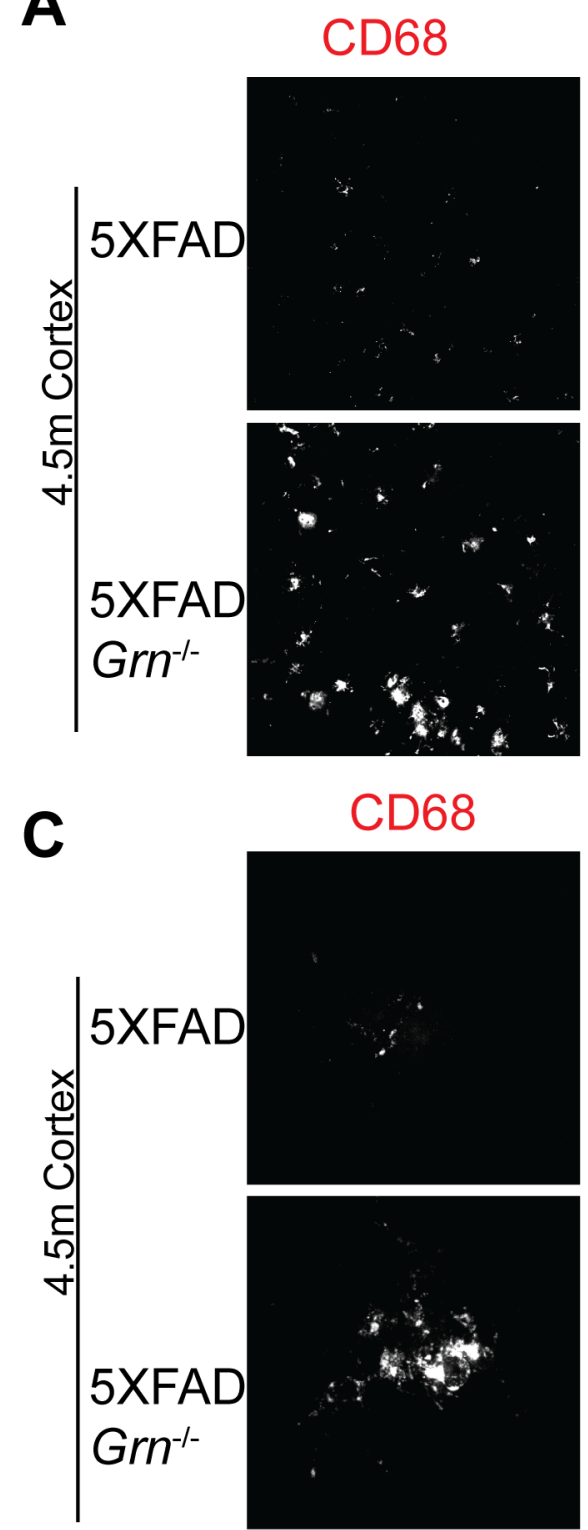

D

5XFAD

5XFAD

$\mathrm{Grn}^{-1-}$

\section{CD68}
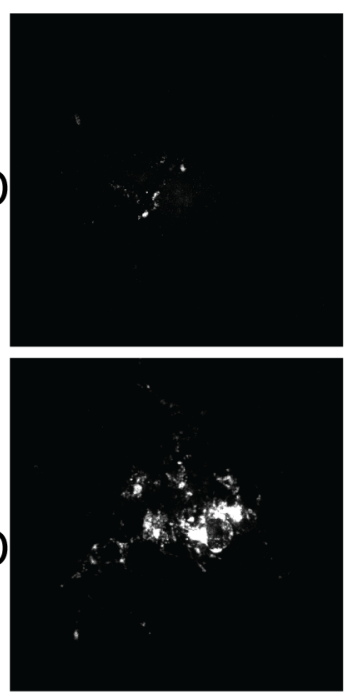

Hoechst

\section{CathD}
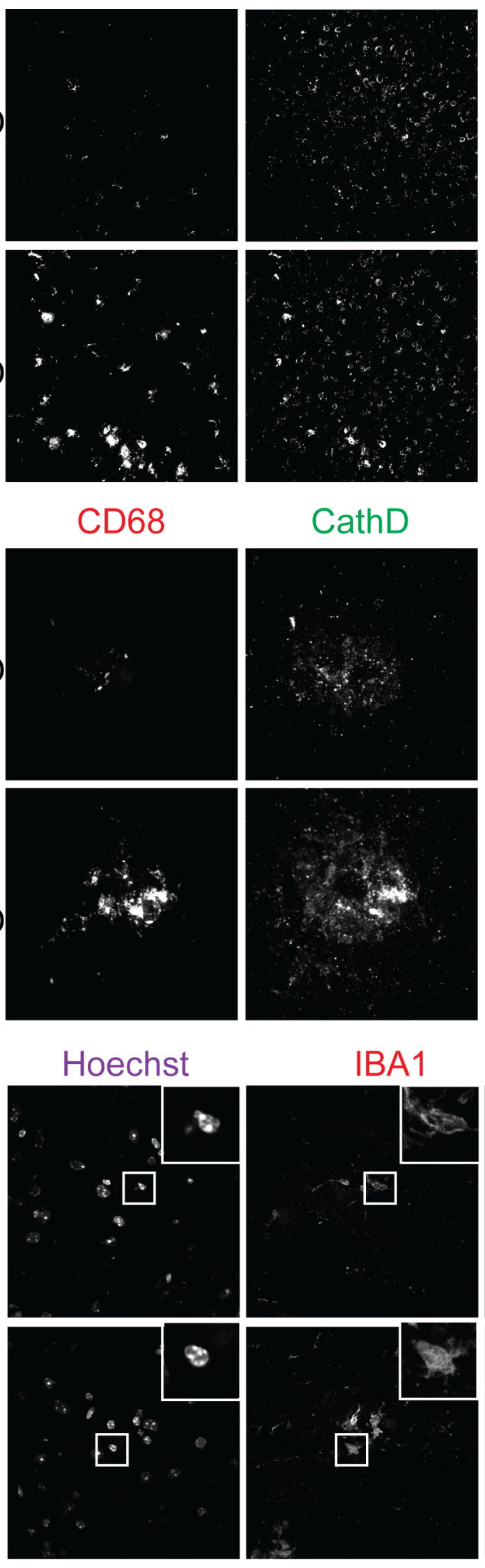

CathD
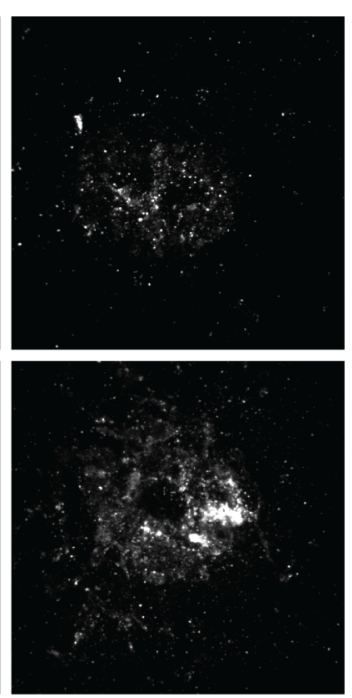

IBA1

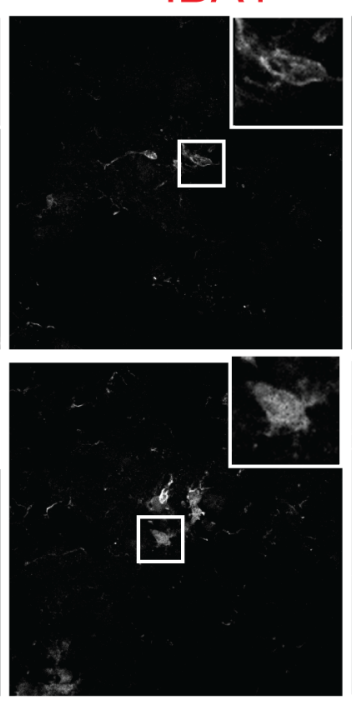

\section{E10}
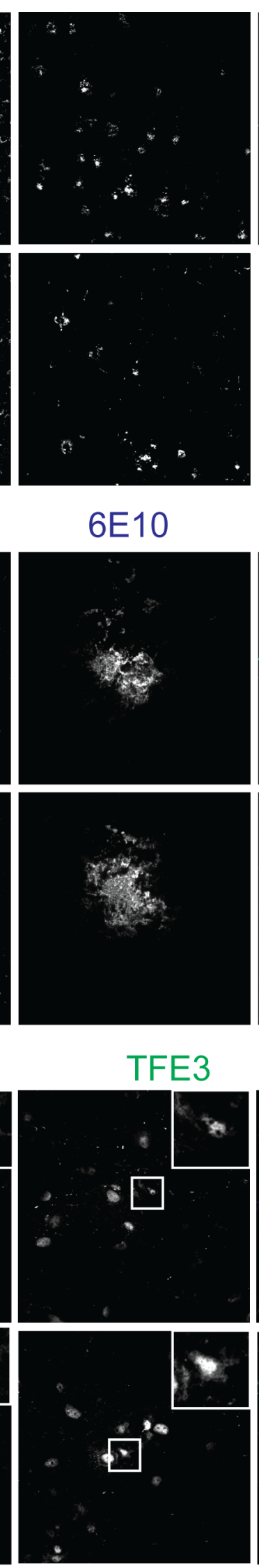

Merge

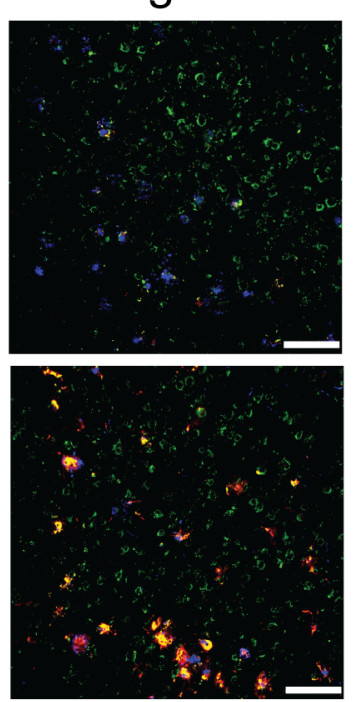

Merge
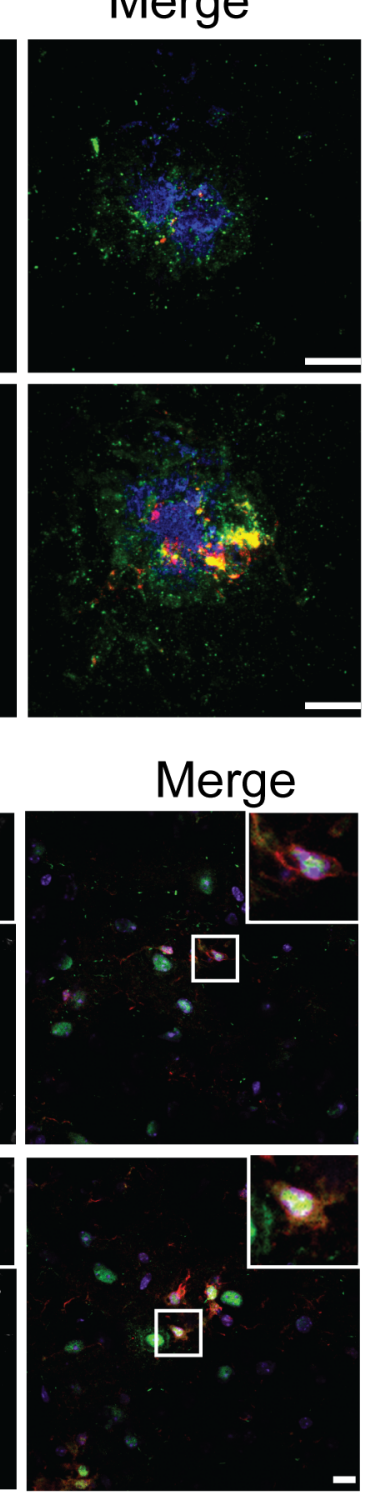

B
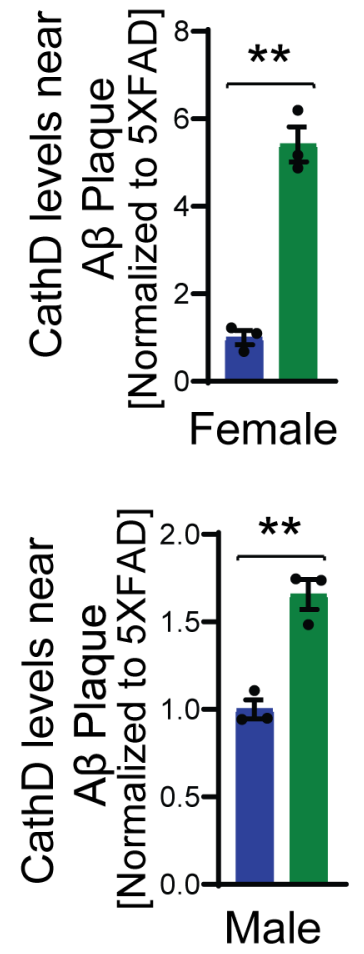

E

5XFAD

5XFAD $\mathrm{Grn}^{-1}$

Male

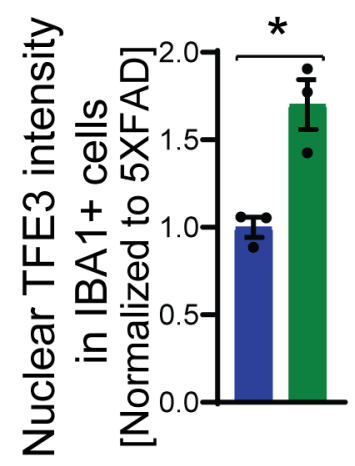


A
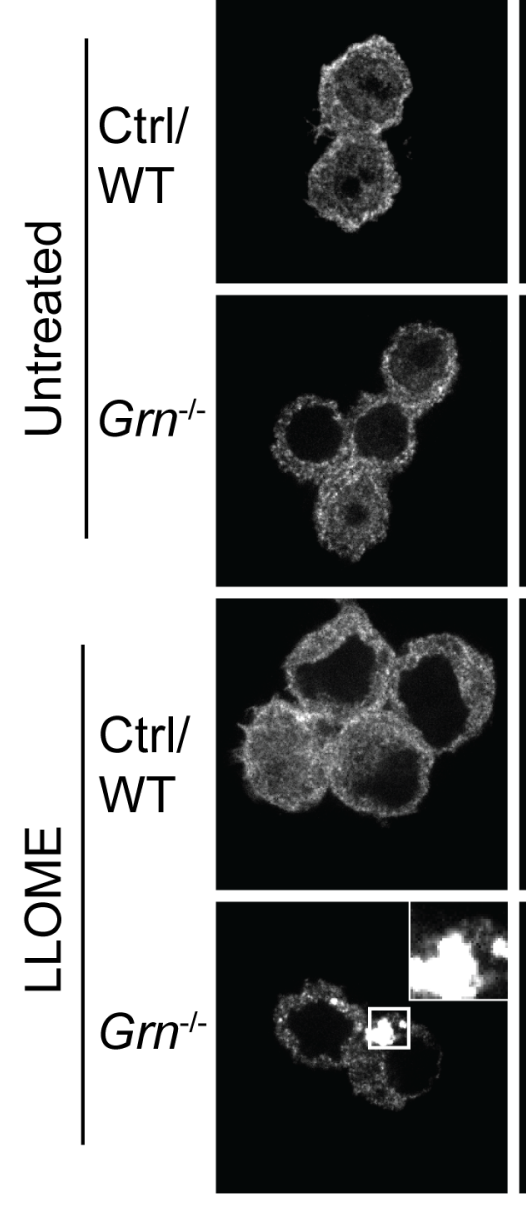

B
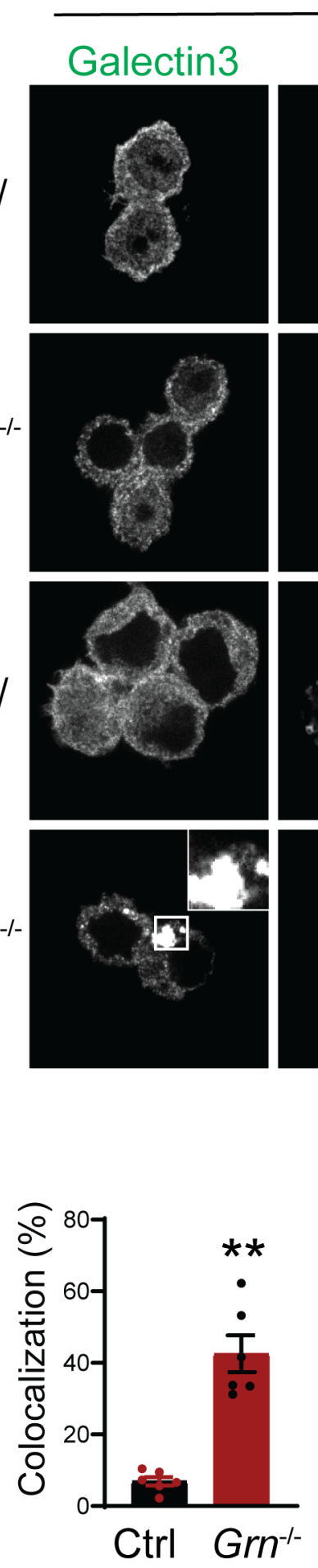

Raw264.7
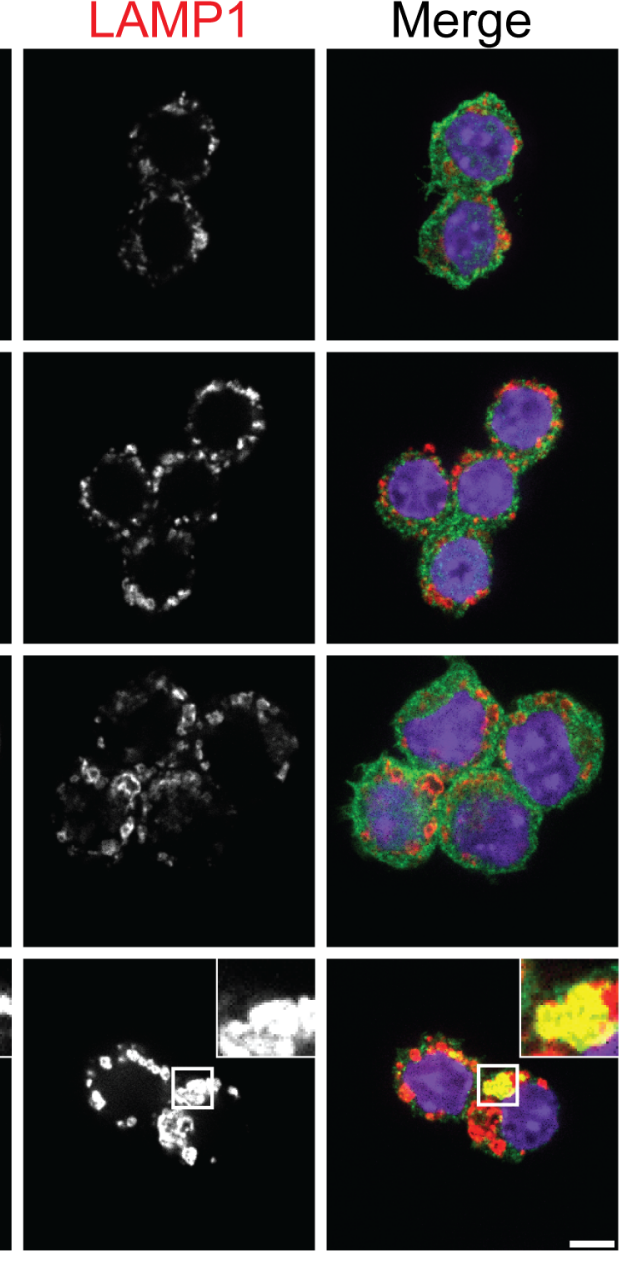

\section{D}

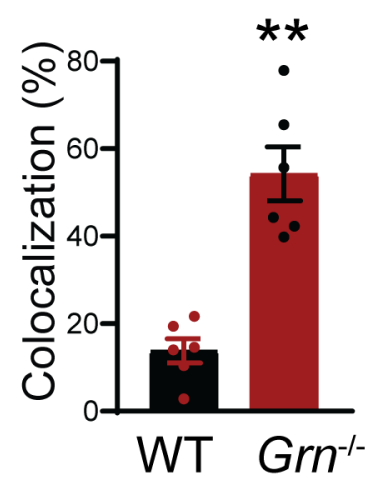

Fig 10 


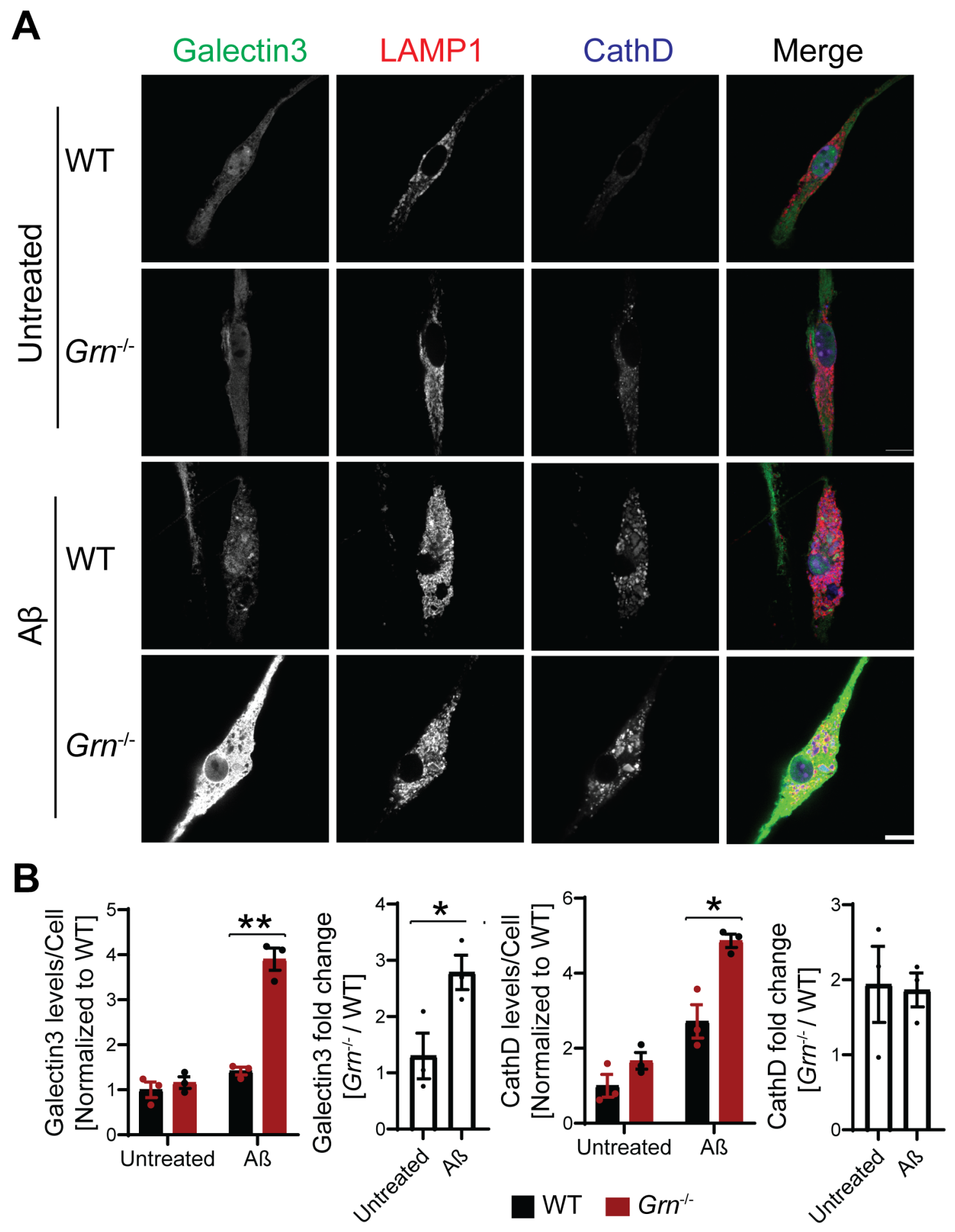

Fig 11 
bioRxiv preprint doi: https://doi.org/10.1101/2021.04.12.439509; this version posted April 14, 2021. The copyright holder for this preprint (which was not certified by peer review) is the author/funder. All rights reserved. No reuse allowed without permission.

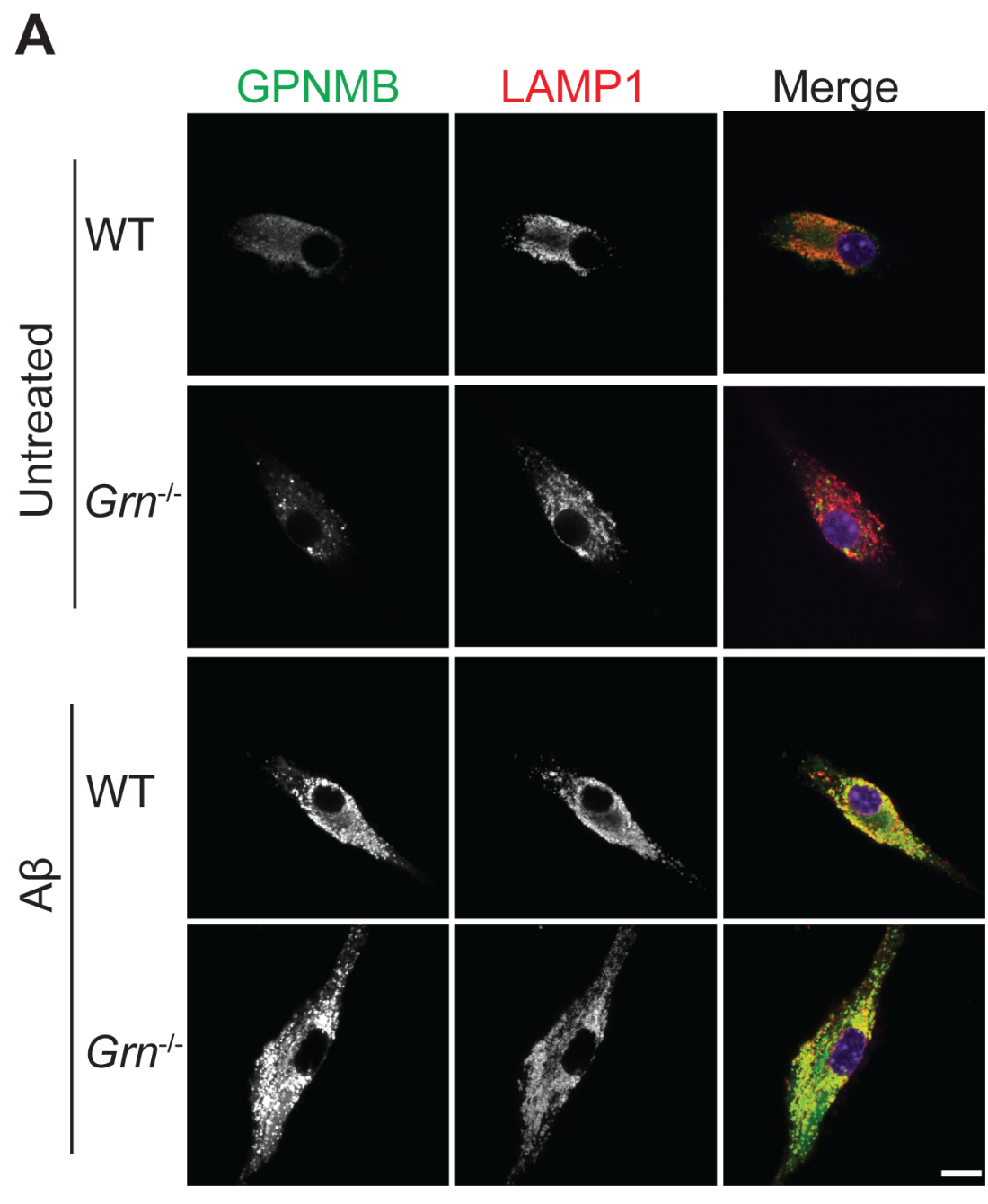

C

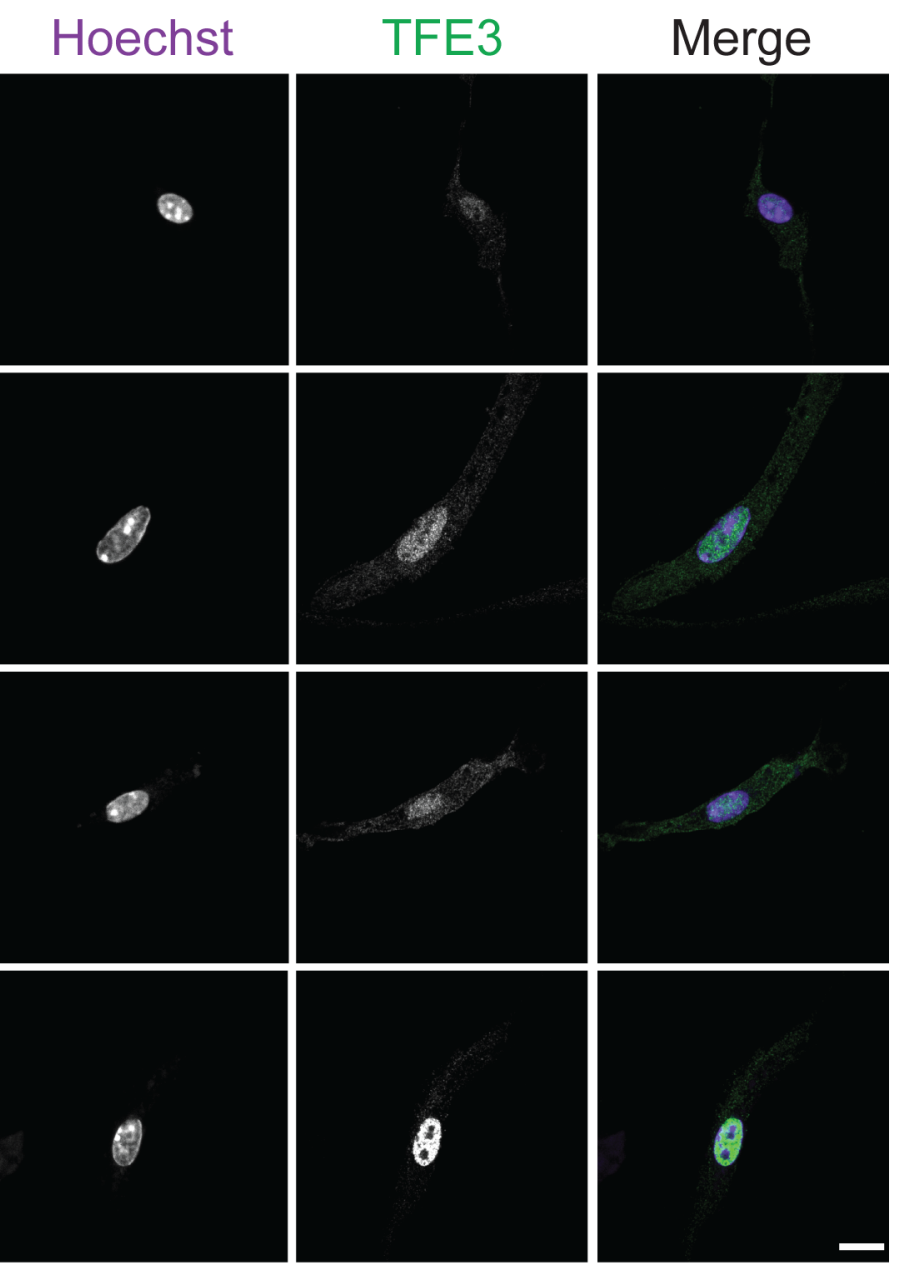

B
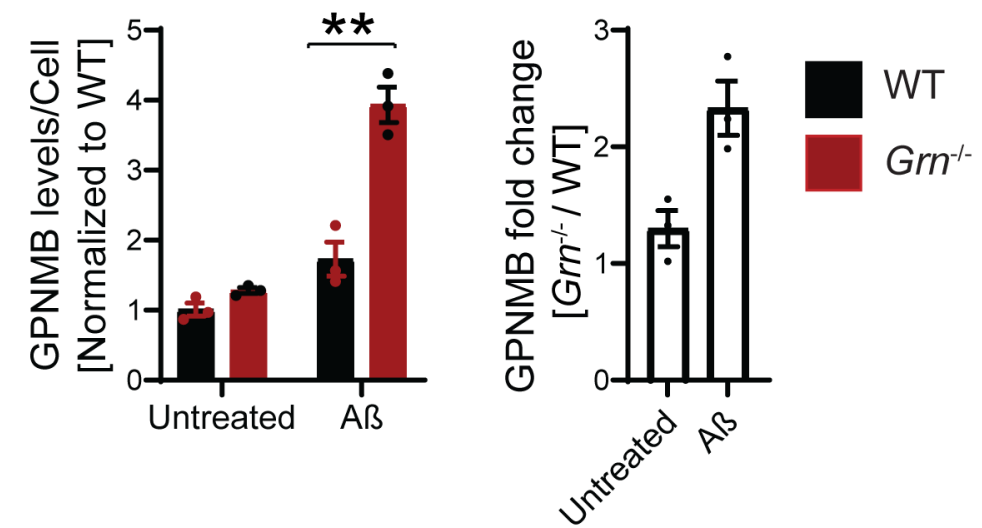

D 온

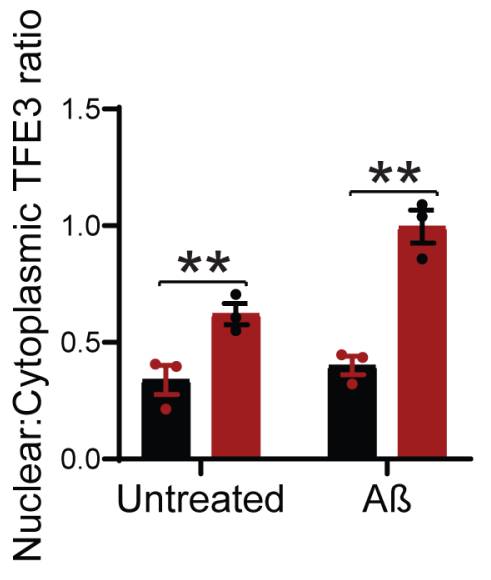

$\mathbf{E}$

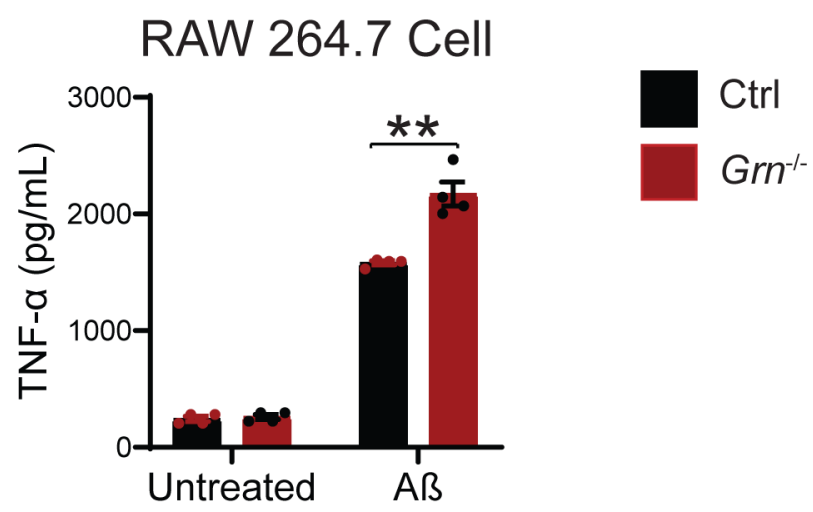

F

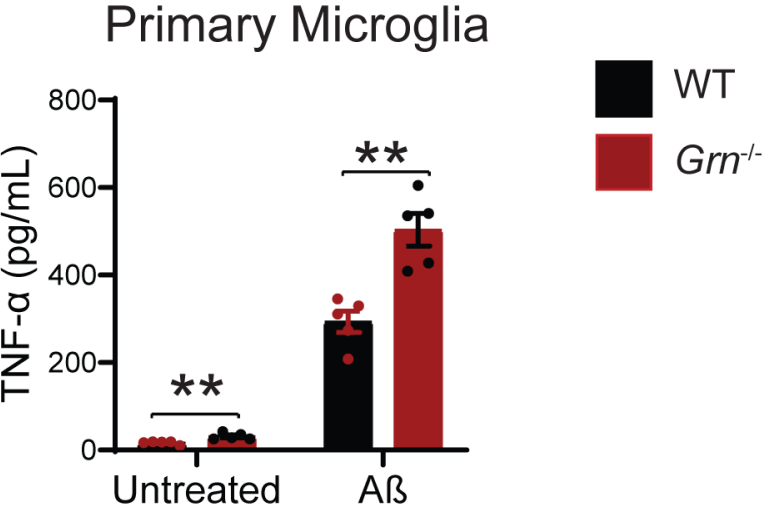

Fig 12 


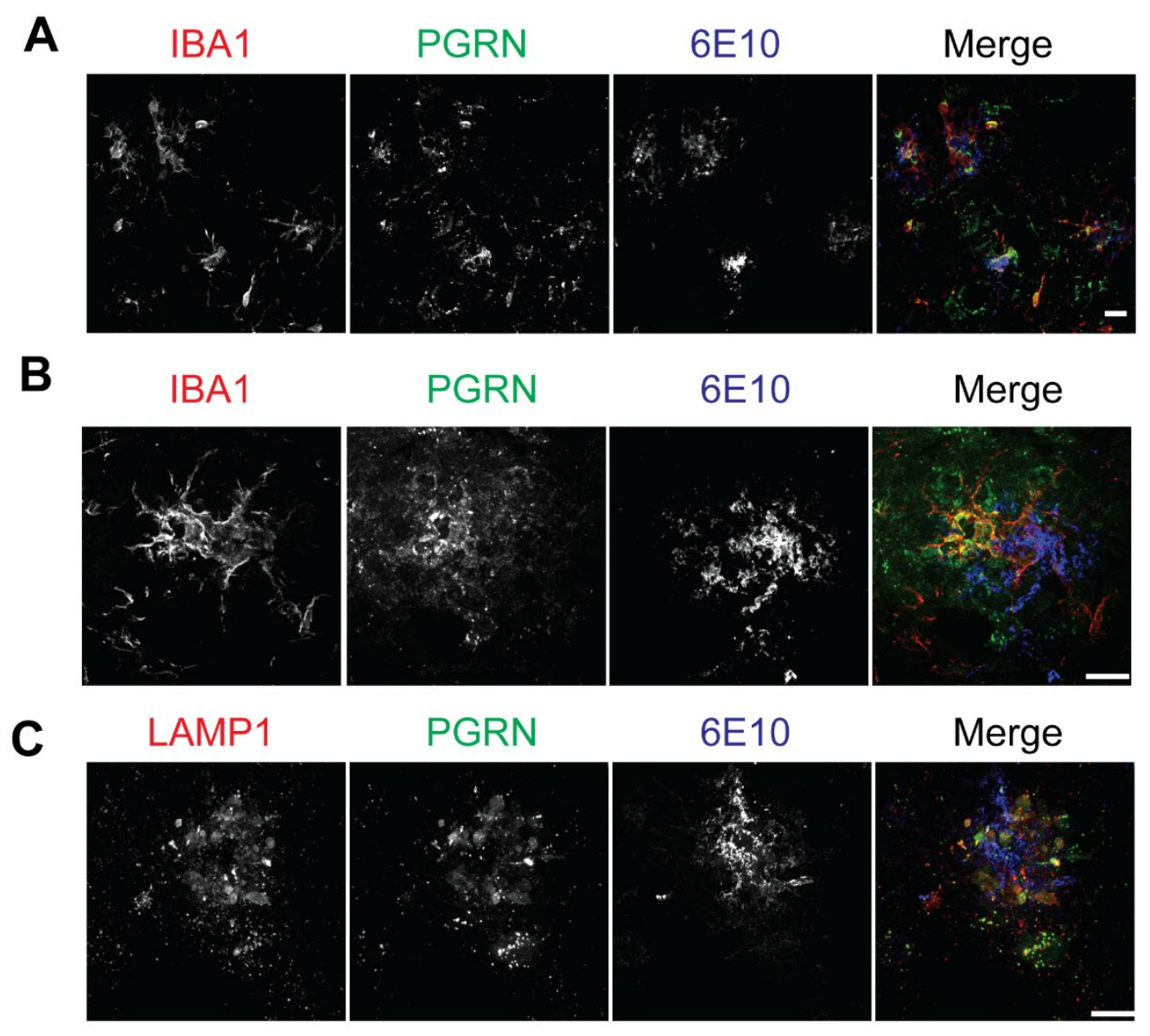

Figure S1: PGRN expression in the 5XFAD mice. (A and B) PGRN is highly expressed in the microglia near A $\beta$ plaques. Brain sections of 10-month-old 5XFAD mice were stained with anti- IBA1, PGRN and A $\beta(6 E 10)$ antibodies. Representative images from the cortex region were shown. Scale bar $=10 \mu \mathrm{m}$. (C) Immunostaining of LAMP1, PGRN and A $\beta(6 \mathrm{E} 10)$ in the brain sections from 10-month-old 5XFAD mice. Representative images from the cortex region were shown. Scale bar $=10 \mu \mathrm{m}$. 

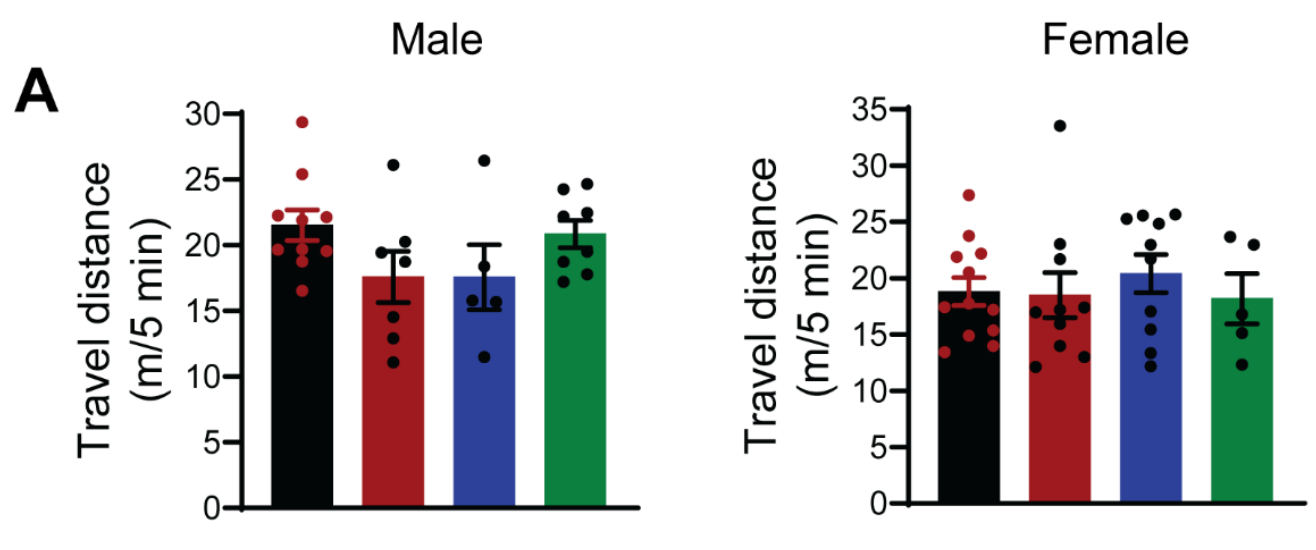

B
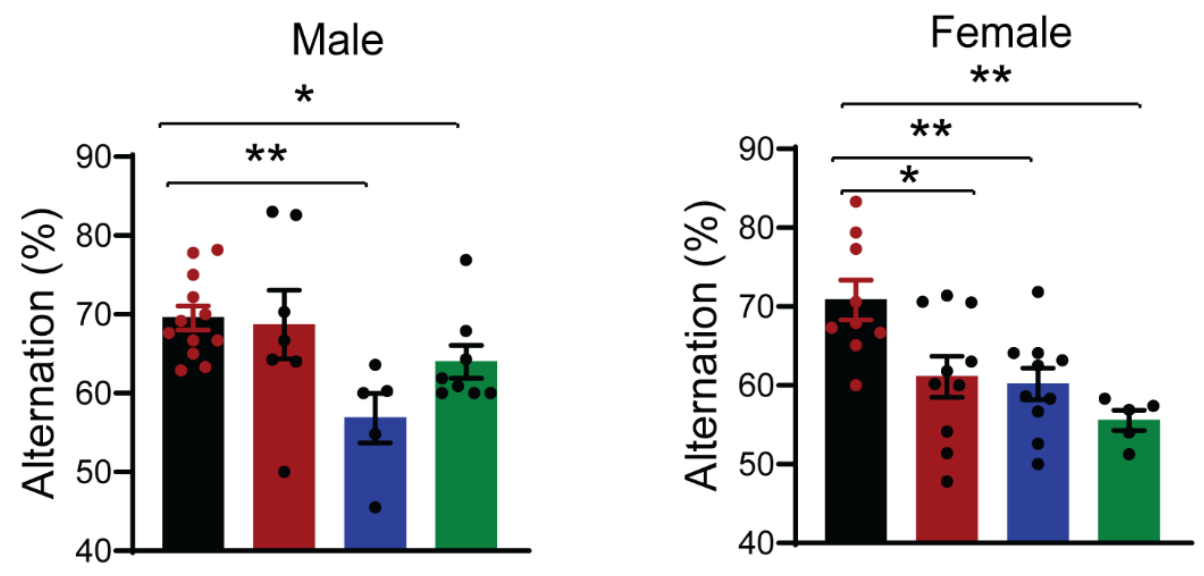

Figure S2: PGRN deficiency does not cause obvious behavioral changes in the open field and Y-maze tests. (A) 4.5-month-old WT, Grn-/-, 5XFAD and 5XFAD Grn-/- mice were subject to open-field test. Total distance travelled for 5 minutes were plotted. Data represented are mean \pm SEM, WT (male), $\mathrm{n}=10 ;$ Grn-/-(male), $\mathrm{n}=7$; 5XFAD (male), n= 5; 5XFAD Grn-/- (male), $\mathrm{n}=8$; WT (female), $\mathrm{n}=12$; Grn-/-(female), $\mathrm{n}=10$; 5XFAD (female), $\mathrm{n}=10$; 5XFAD Grn-/- (female), n= 5.one-way ANOVA. (B) 4.5-month-old WT, Grn-/-, 5XFAD and 5XFAD Grn-/- mice were subject to Y maze test. Percentage of spontaneous alternation behavior in the Y maze was plotted. Data represented are mean \pm SEM, WT (male), $\mathrm{n}=12$; Grn-/-(male), $\mathrm{n}=7 ;$ XXFAD (male), $\mathrm{n}=5 ;$ XXFAD Grn-/- (male), n= 8; WT (female), n=9; Grn-/-(female), n= 10; 5XFAD (female), n=10; 5XFAD Grn-/- (female), $\mathrm{n}=5$.one-way ANOVA, ${ }^{*}, \mathrm{p}<0.05, * *, \mathrm{p}<0.01$. 


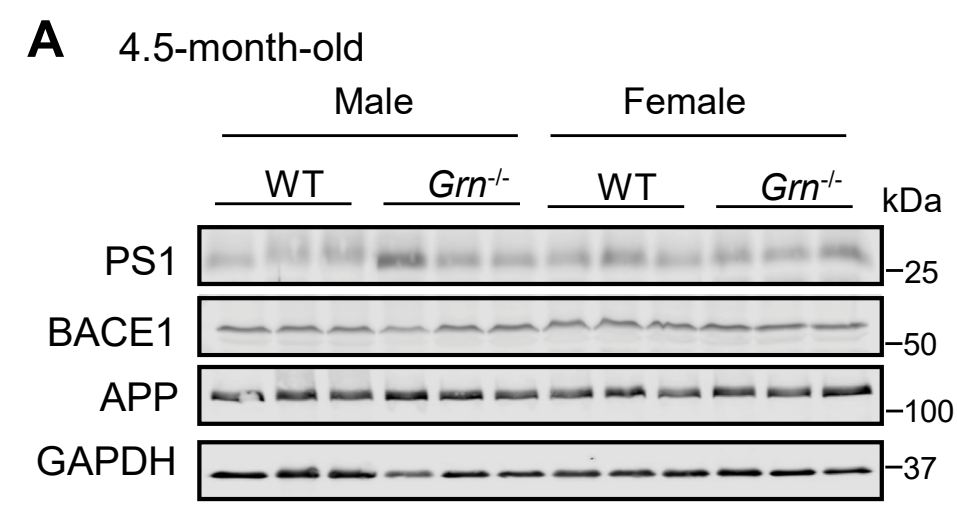

B 4.5-month-old male

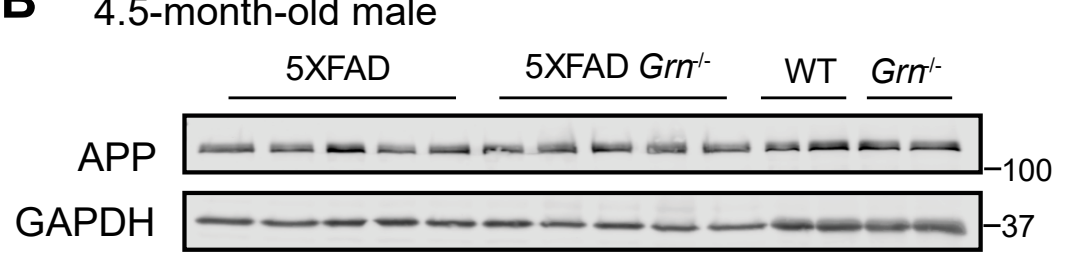

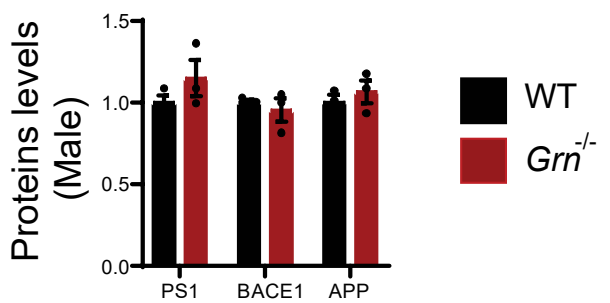

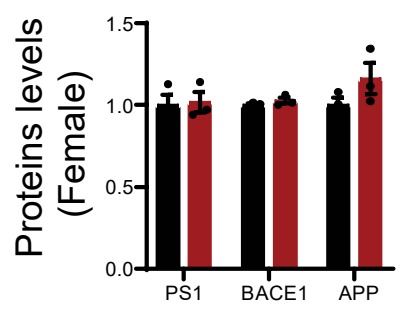

Figure S3: PGRN deficiency does not have any effect on the levels of endogenous APP, PS1 or BACE1 in 4.5-month-old mice. (A) Western blot analysis of APP, Presenilin1(PS1) and BACE1 in the soluble fractions of cortical lysates from 4.5-month-old male and female WT, $\mathrm{Gr}^{-/}$mice. The proteins levels were quantified and normalized to GAPDH. Mean \pm SEM; $n=3$, student's $t$ test. (B) Western blot analysis to show that mutant human expressed the young 5XFAD mice is not recognized or only weakly recognized by the APP antibody ((Proteintech Group, 25524-1-AP) used in panel (A). 


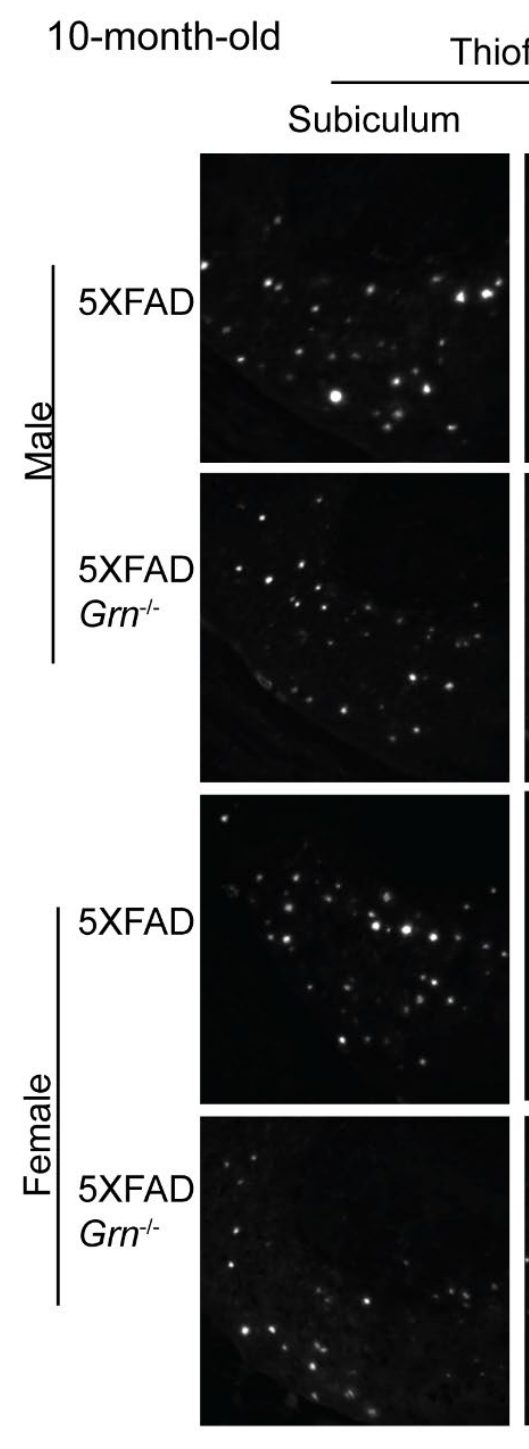

Thioflavin S
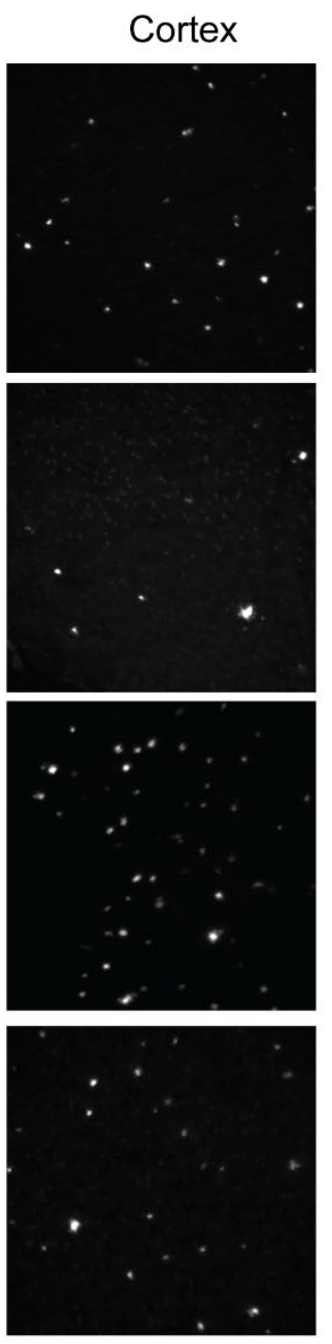
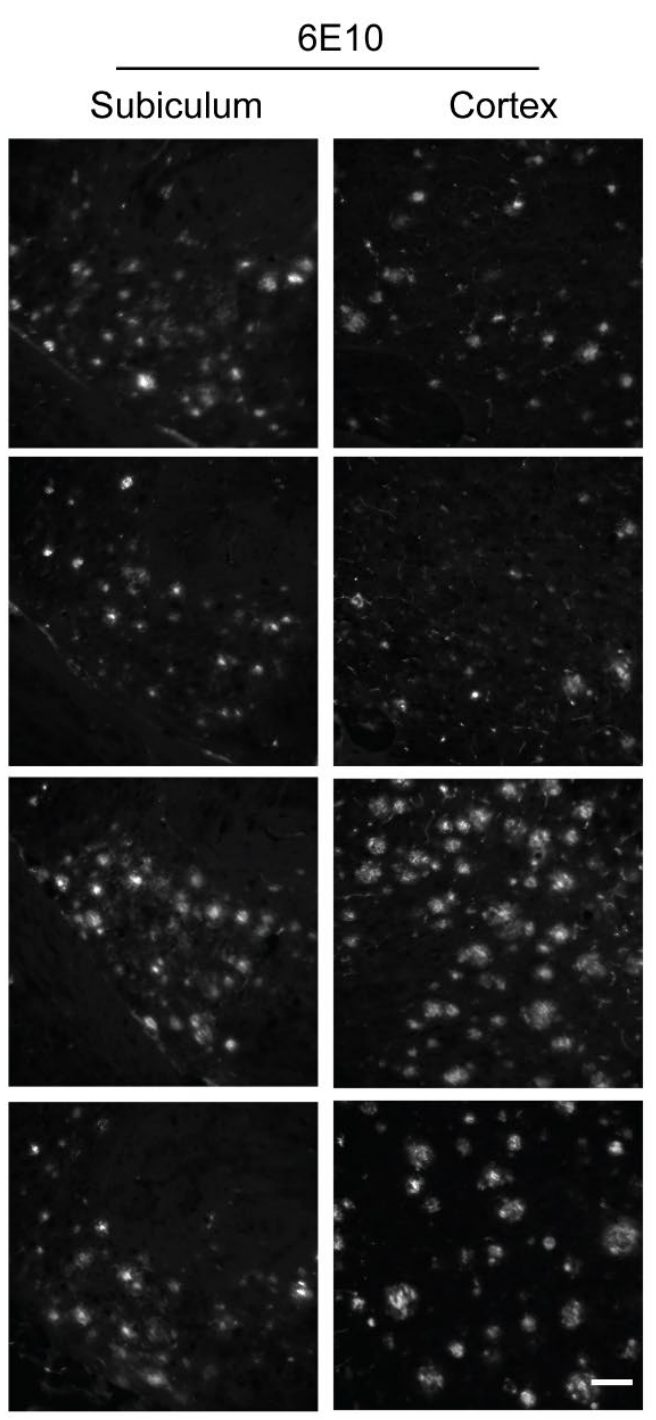

Figure S4: PGRN deficiency affects A $\beta$ plaques load in the 10-month-old 5XFAD mice. Representative images of Thioflavin $S$ staining and $A \beta(6 E 10)$ immunostaining of subiculum and frontal cortex of 10month-old male and female 5XFAD, 5XFAD $\mathrm{Grn}^{-/}$mice. Scale bar=100 $\mu \mathrm{m}$. 


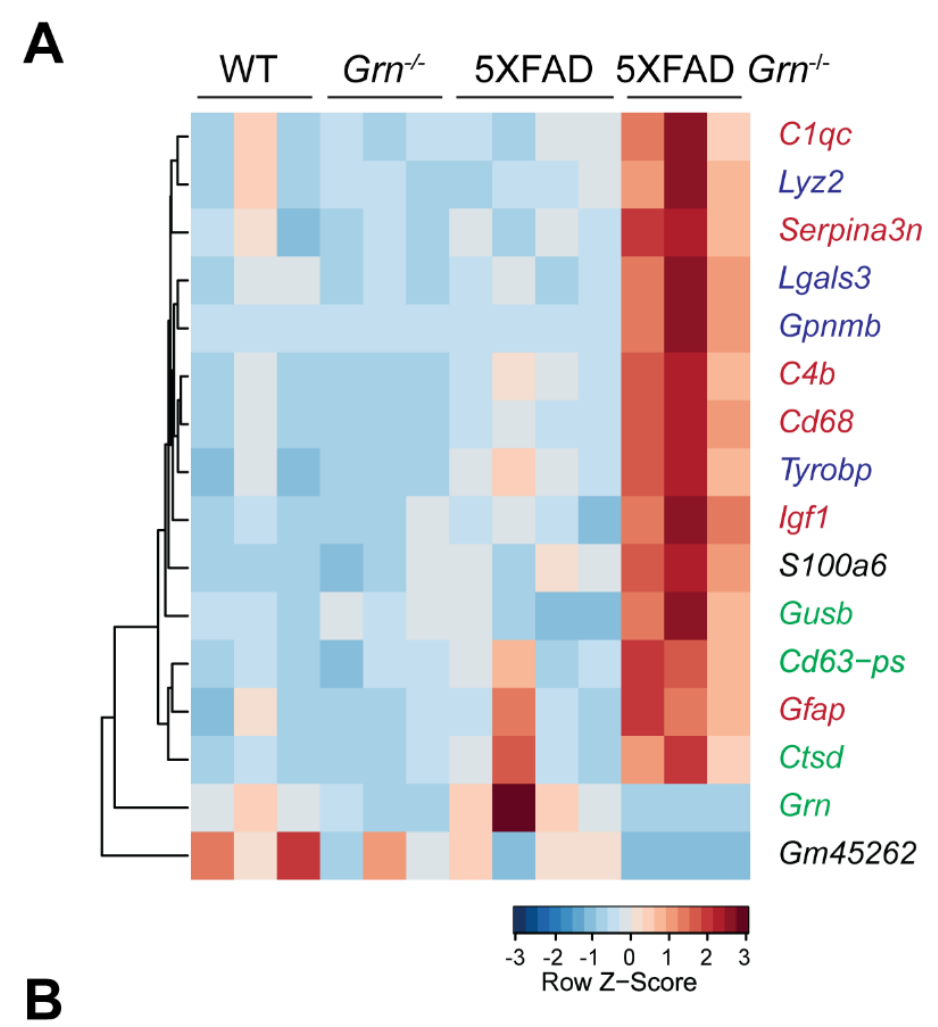

\begin{tabular}{|l|l|r|r|}
\hline Gene name & genes & Log FC & adj.P.Val \\
\hline Gpnmb & ENSMUSG00000029816 & 3.728064 & $5.43 \mathrm{E}-06$ \\
\hline Lgals3 & ENSMUSG00000050335 & 2.350303 & 0.000877 \\
\hline Cd68 & ENSMUSG00000018774 & 1.948977 & 0.000204 \\
\hline Igf1 & ENSMUSG00000020053 & 1.824962 & 0.004305 \\
\hline Lyz2 & ENSMUSG00000069516 & 1.810581 & 0.005541 \\
\hline Gfap & ENSMUSG00000020932 & 1.618956 & 0.004595 \\
\hline C4b & ENSMUSG00000073418 & 1.558624 & 0.001037 \\
\hline Ctsd & ENSMUSG00000007891 & 1.482379 & 0.004305 \\
\hline Tyrobp & ENSMUSG00000030579 & 1.391612 & 0.004305 \\
\hline Cd63-ps & ENSMUSG00000085939 & 1.239503 & 0.006984 \\
\hline Gusb & ENSMUSG00000025534 & 1.165778 & 0.042084 \\
\hline Serpina3n & ENSMUSG00000021091 & 1.084433 & 0.02463 \\
\hline C1qc & ENSMUSG00000036896 & 1.06545 & 0.021248 \\
\hline S100a6 & ENSMUSG00000001025 & 0.971536 & 0.03505 \\
\hline Gm45262 & ENSMUSG00000109942 & -3.74696 & 0.004326 \\
\hline Grn & ENSMUSG00000034708 & -4.76785 & 0.000386 \\
\hline
\end{tabular}

Figure S5: PGRN deficiency leads to increased expression of lysosome and inflammation genes. (A) RNA seq analysis was performed with the hippocampal samples from 4.5-months-old WT, $\mathrm{Frn}^{-1}$, 5XFAD and 5XFAD $\mathrm{Grn}^{-/}$mice (mixed male and females). Genes with FDR $\mathrm{p} \leq 0.05$, LogFC $\geq 0.5$ or $\leq 0.5$ between 5 XFAD and 5XFAD $\mathrm{Grn}^{-/}$groups are plotted based on hierarchical clustering analysis. Lysosomal genes are highlighted in green; DAM genes are highlighted in blue and other genes involved in inflammation genes are highlighted in red. (B) List of DEGs with FDR $\mathrm{p} \leq 0.05, \operatorname{LogFC} \geq 0.5$ between $5 \mathrm{XFAD} \mathrm{Grn}^{-/}$and $5 \mathrm{XFAD}$ groups for experiment in (A). 


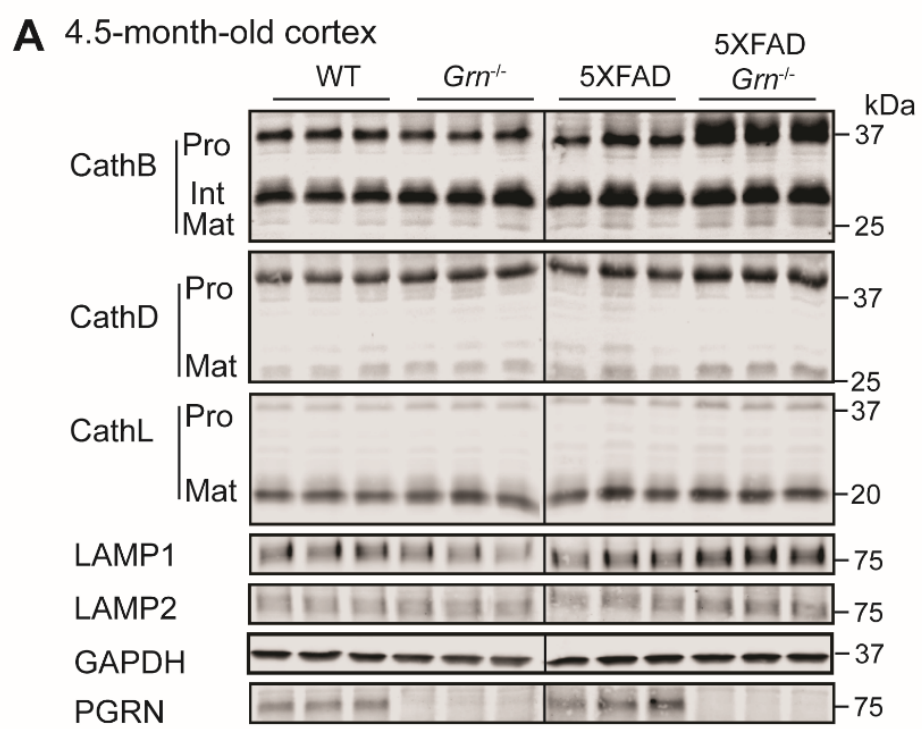

B

$\square$ WT $\square \mathrm{Grn}^{-1} \square$ 5XFAD $\square$ 5XFAD $\mathrm{Gr}^{-1}$
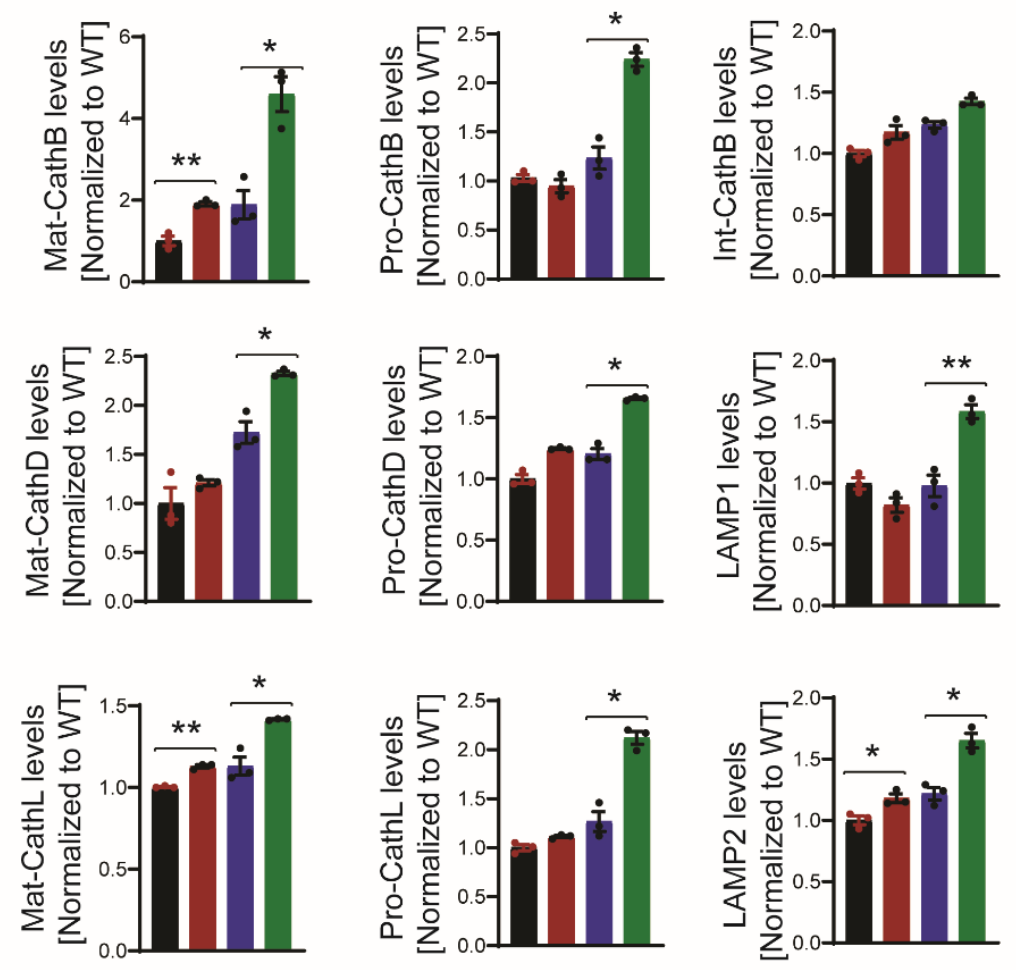

Fig S6

Figure S6: PGRN deficiency leads to an increase in the levels of lysosome proteins in the 5XFAD mice. (A) Cortical lysates from 4.5-month-old WT, $\mathrm{Grn}^{-/}, 5 \mathrm{XFAD}$ and 5XFAD $\mathrm{Grn}^{-/}$mice (mixed male and females) were subjected to western blot analysis with anti-cathepsin B (CathB), CathD, CathL, LAMP1, LAMP2, PGRN and GAPDH antibodies. (B) Quantifications of lysosome proteins levels for experiment in (A). Mean \pm SEM; $n=3$, one-way ANOVA, *, p <0.05, **, p $<0.01$. 

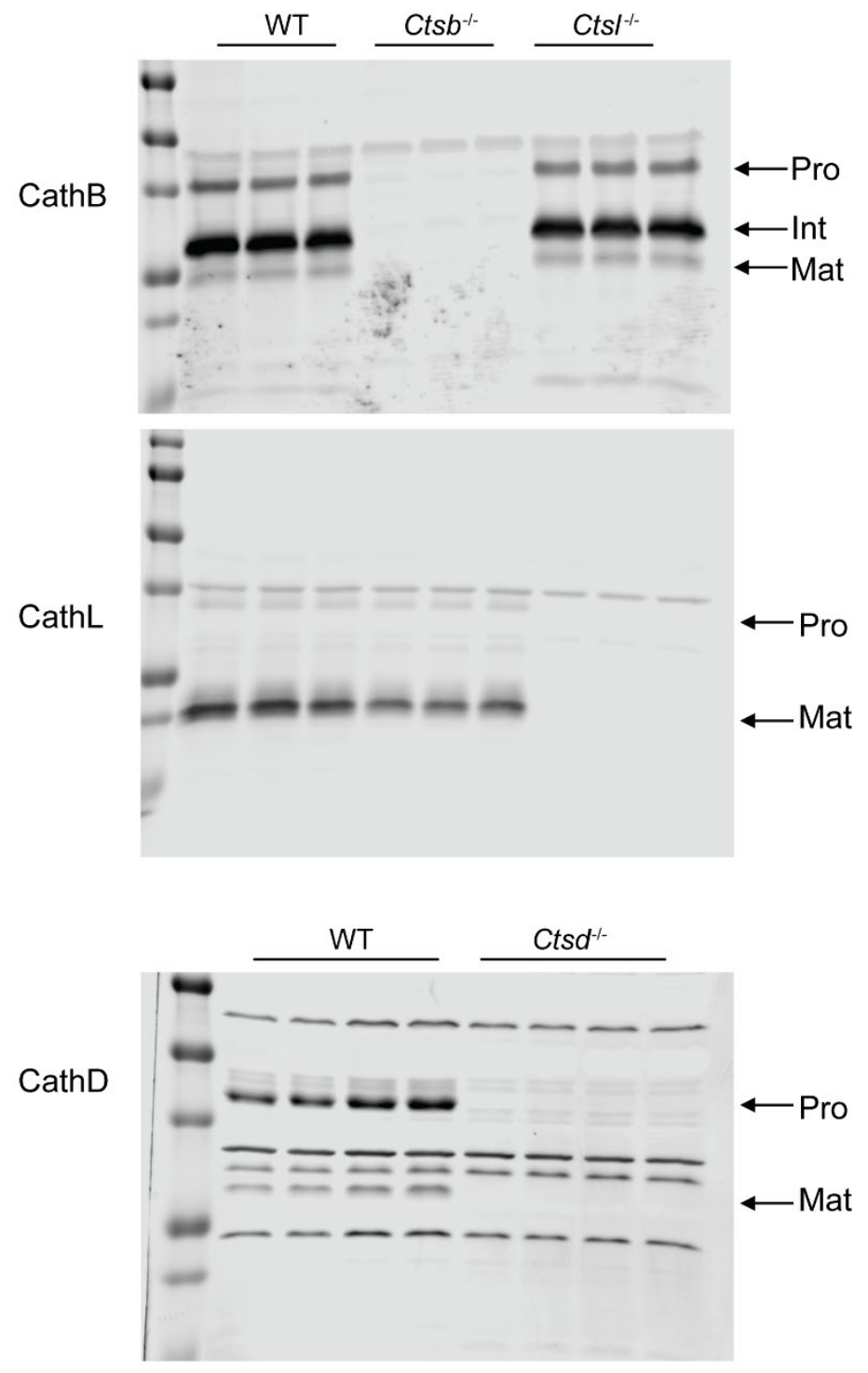

Figure S7: Western blot to confirm the specificity of cathepsin antibodies used in the study. Cortical lysates from mice of indicated genotypes were blotted with indicated antibodies. 